\title{
Clinical Pharmacists in Chronic Care [Part 2]
}

\author{
Abdul Kader Mohiuddin* \\ Department of Medicine, Nasirullah Memorial Trust, Bangladesh
}

*Corresponding author: Abdul Kader Mohiuddin, Department of Medicine, Nasirullah Memorial Trust, Tejgaon, Dhaka, Bangladesh.

Received Date: November 12, 2019

Published Date: January 03, 2020

\begin{abstract}
Pharmacy practice has changed significantly lately. The professionals have the chance to contribute straightforwardly to patient consideration so as to lessen morbimortality identified with medication use, promoting wellbeing and preventing diseases. Healthcare organizations worldwide are under substantial pressure from increasing patient demand. Unfortunately, a cure is not always possible particularly in this era of chronic complications, and the role of physicians has become limited to controlling and palliating symptoms. The increasing population of patients with long-term conditions are associated with high levels of morbidity, healthcare costs and GP workloads. Clinical pharmacy took over an aspect of medical care that had been partially abandoned by physicians. Overburdened by patient loads and the explosion of new drugs, physicians turned to pharmacists more and more for drug information, especially within institutional settings. Once relegated to counting and pouring, pharmacists headed institutional reviews of drug utilization and served as consultants to all types of health-care facilities. In addition, when clinical pharmacists are active members of the care team, they enhance proficiency by: Providing critical input on medicine use and dosing. Working with patients to solve problems with their medications and improve compliance.
\end{abstract}

Keywords: Chronic care; Pharmacy intervention; Diabetes care; CVD prevention; Inflammatory bowel disease

Abbreviations: AACP: American Association of Colleges of Pharmacy; ACPE: Accreditation Council for Pharmacy Education; IDF: International Diabetes Federation; HbA1c: Hemoglobin A1c; IHD: Ischemic Heart Disease; MI: Myocardial Infarction; CHD: Coronary Heart Disease; DALY: DisabilityAdjusted Life Year; QoL: Quality of Life; DRPs: Drug Related Problems; IBD: Inflammatory bowel disease; HRT: Hormone replacement therapy; BMD: Bone-Mineral Density; COPD: Chronic Obstructive Pulmonary Disease; LDL-C: LDL cholesterol; GERD: Gastroesophageal Reflux Disease; OSA: Obstructive Sleep Apnea; SCH: Subclinical Hypothyroidism; NAMI: National Alliance on Mental Illness; MDD: Major Depressive Disorder; NMHS: National Mental Health Survey; ABS: Australian Bureau of Statistics; NSMHWB: National Survey of Mental Health and Wellbeing; CHD: Coronary Heart Disease; MH: Mental Health; ADT: Antidepressant Drug Treatment; CANMAT: Canadian Network for Mood and Anxiety Treatments; PES: Psychiatric Emergency Services; DALY: Disability-Adjusted Life Year; DRPs: Drug-Related Problems; VLW: Value of Lost Economic Welfare; ALS: Amyotrophic Lateral Sclerosis; SNRIs: Serotonin and Norepinephrine Reuptake Inhibitors; TCAs: Tricyclic Antidepressants; ASPs: Antimicrobial Stewardship Programs; ESRD: End-Stage Renal Disease; CKD: Chronic Kidney Disease; MSM: Men who have Sex with Men; NSCLC: Non-small-cell lung cancer; ELISA: Enzyme-Linked Immunosorbent Assay; LLS: Leukemia \& Lymphoma Society; ALL: Acute Lymphoblastic Leukemia; AML: Acute Myeloid Leukemia; CML: Chronic Myeloid Leukemia; NRT: Nicotine Replacement Therapy; ADT: Androgen Deprivation Therapy; PSA: Prostate Specific Antigen; DRE: Digital Rectal Examination; PSA: Prostate Specific Antigen; FOBT: Fecal Occult Blood Testing; GLOBOCAN: Global Cancer Incidence, Mortality and Prevalence

\section{Background}

Clinical pharmacology is a professional discipline that combines basic pharmacology and clinical medicine. A clinical pharmacist offers invaluable support in the development of a final prescription with better patient management and enhanced safety [1]. Its development began in the early 1950s, primarily as a result of the efforts of Harry Gold. Pharmacist rounding with inpatient hospital services has been traced to the University of Kentucky in 1957 [1,2]. Drug therapy was becoming much more complex. Graham Calder pioneered a new role for pharmacists on hospital wards in Aberdeen [3]. The role of clinical pharmacists underwent significant changes from the 1960s through 1990s as their participation in direct patient care enhanced. In the early 1970s, federal funding assisted with greatly expanding clinical pharmacy faculty in Colleges of Pharmacy [4]. Pharmacy education debated where clinical pharmacy fit within pharmacy training. The AACP spearheaded an effort to examine this issue. Till then, two full generations of pharmacists have been educated and trained after the general adoption of the aims of clinical pharmacy 
[4,5]. ACPE has revised the standards for colleges and schools of pharmacy several times since 2000. ACPE Standards 2016 go into effect July 1, 2016. To some extent, pharmacy took over an aspect of medical care that had been partially abandoned by physicians [6]. Overburdened by patient loads and the explosion of new drugs, physicians turned to pharmacists more and more for drug information, especially within institutional settings. A clinical pharmacist often has a somewhat different approach to the use of drugs and may give valuable supplementary information about for example interactions, during the physician's decision-making process concerning potential changes of and the follow-up of the medication $[7,8]$. The concept of pharmaceutical care accentuates the pharmacists' responsibility to pursue the best possible patient outcomes of therapeutic regimen [9]. They possess in-depth knowledge of medications that is integrated with a foundational understanding of the biomedical, pharmaceutical, socio-behavioral, and clinical sciences [10]. To achieve desired therapeutic goals, the clinical pharmacists follow evidence-based therapeutic guidelines, evolving sciences, emerging technologies, and relevant legal, ethical, social, cultural, economic, and professional precept [1113]. In accordance, clinical pharmacists assume responsibility and accountability for managing medication therapy in direct patient care settings, whether practicing independently or in consultation or collaboration with other health care professionals $[14,15]$. Their functions encompass comprehensive medication management (ie, prescribing, monitoring, and adjustment of medications), nonpharmacologic guidance, and coordination of care. Interdisciplinary collaboration allows pharmacists opportunities to provide direct patient care or consultations by telecommunication in many different clinical environments, including disease management, primary care, or specialty care [16-19]. Pharmacists may manage chronic or acute illnesses associated with endocrine, cardiovascular, respiratory, gastrointestinal, or other systems [20]. Clinical pharmacist researchers generate, disseminate, and apply new knowledge that contributes to improved HRQoL [21-24]. Within the system of health care, clinical pharmacists are experts in the therapeutic use of medications. They consistently provide medication therapy evaluations and endorsements to patients and allied health professionals (AHPs) $[25,26]$. Clinical pharmacists are a primary source of scientifically accurate/logical information and advice regarding the safe, appropriate, and cost-effective use of medications $[27,28]$. They obtain medical and medication history, check medication errors including prescription, dispensing and administration errors, identify drug interactions, monitor ADR, suggest individualization of dosage regimen, provide patient counseling, etc. [29-35]. They also provide information about the use of drugs and medical devices like inhaler, insulin pen, eye drops, nasal sprays, etc. [36]. Participation of a clinical pharmacist in ward/ICU rounds and clinical discussions helps to identify, prevent or reduce drug interaction and ADR [29], [37-39] (Figure 1).

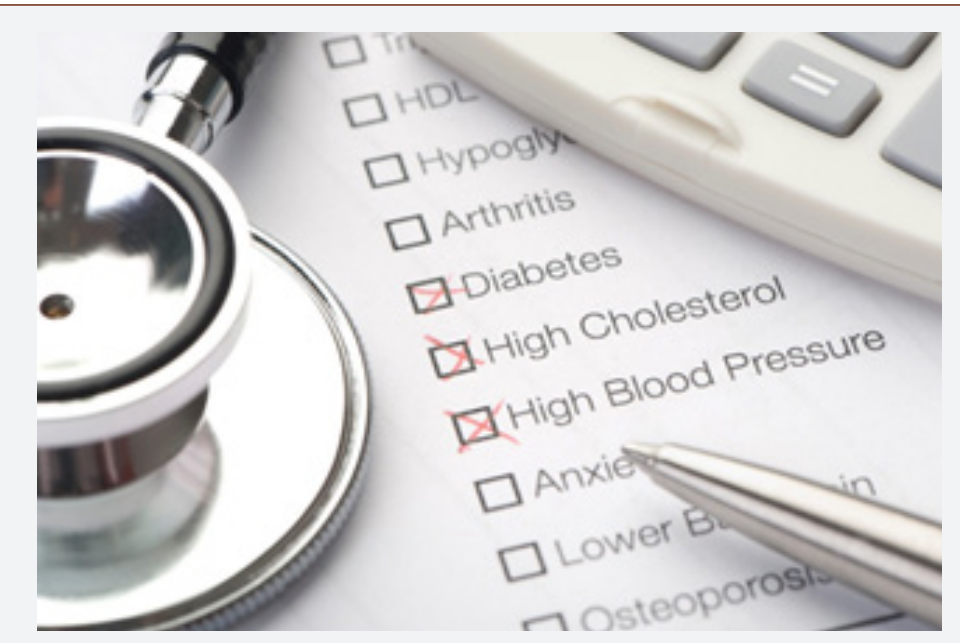

Figure 1: Clinical pharmacy offers chronic care services like asthma, diabetes, nutritional supplement counseling, smoking cessation, weight reduction, geriatric care, hyperlipidaemia, hypertension, naturopathy and wound care. The integration of clinical pharmacists into primary care clinics could have positive effects on the clinical outcomes of patients in glycemic control, blood pressure, lipid profile, in accordance with current guidelines.

\section{Introduction}

Population aging has increased the burden of chronic diseases globally. There are both ethical and practical imperatives to address health inequity issues related to chronic disease management for persons with social complexity, existing programs often do not appropriately address the needs of these individuals. This leads to low levels of participation in programs, suboptimal chronic disease management, and higher health-care utilization [40]. Unlike acute conditions, chronic diseases require consistent care and management outside of the healthcare setting, in the community or primary care setting, in terms of medication, lifestyle management, and health behavior modification [41-45]. It is typically a multi-component intervention that includes medication therapy review, patient medication education, medication monitoring, immunizations, disease self-care and support, and/or prescribing authority. Patients who take voluminous medications due to chronic disease have a high risk of drug duplication, interaction, or ADRS, which could result in extended hospital stays and higher costs [46]. To increase the safety and effectiveness of therapeutics, these patients must have specific needs met, with 
regards to appropriate medication use [47]. Studies have shown that integrating pharmacists into ambulatory clinics can improve chronic disease management and optimal use of medications [48]. Furthermore, pharmacist involvement in patient care may help to curtail inappropriate drug use, specifically in the elderly. A study in Canada saw the proportion of patients receiving an inappropriate medication drop significantly after medication review and optimization by a team that included a pharmacist [49]. Compared to usual care, pharmacist-led care was associated with similar incidences or rates of office, urgent care or ED visits, and hospitalizations and medication adherence, increased the number or dose of medications received and improved study-selected glycemic, blood pressure, and lipid goal attainment [50]. Another recent study shows telehealth-based chronic disease management program including clinical pharmacy specialists imparted statistically significant improvements in diabetes and hypertension outcomes along with clinically significant improvements in the areas of lipid management and tobacco cessation [51].

\section{Diabetes Care}

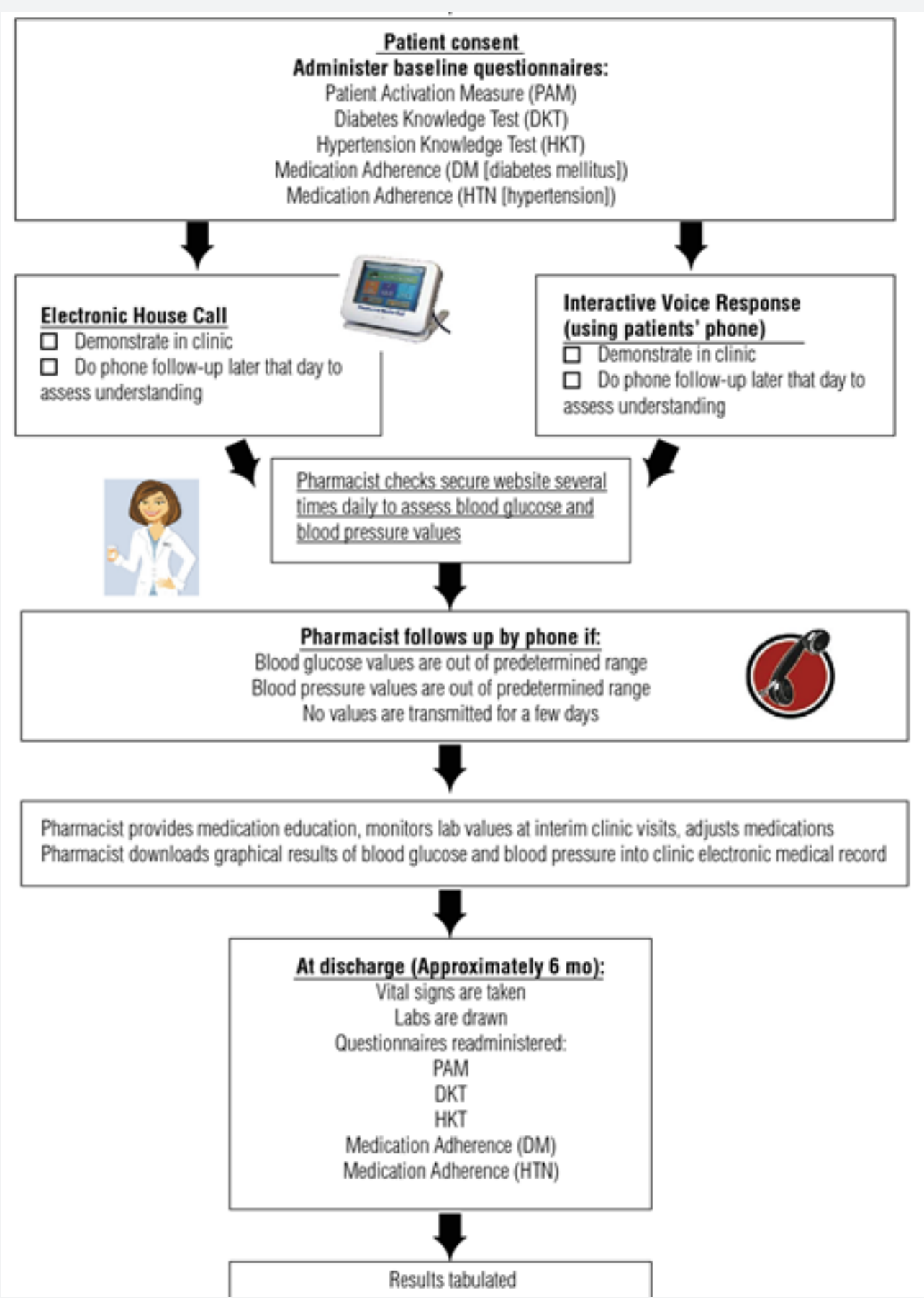

Figure 2: Clinical pharmacy offers chronic care services like asthma, diabetes, nutritional supplement counseling, smoking cessation, weight reduction, geriatric care, hyperlipidaemia, hypertension, naturopathy and wound care. The integration of clinical pharmacists into primary care clinics could have positive effects on the clinical outcomes of patients in glycemic control, blood pressure, lipid profile, in accordance with current guidelines. 
As the seventh-leading cause of death in the US, diabetes can lead to various health complications such as blindness, kidney disease, amputations, and heart disease. The worldwide existing prevalence of DM is about 425 million people, of whom 279 million are in urban areas and 146 million are in rural zones [52]. The IDF estimates that by 2040, one in 10 adults (642 million) will have diabetes. Around 50\% (212.4 million) of patients are unaware of their diabetes. More than $12 \%$ of total global health expenditure goes to diabetes, according to IDF [53]. Annual worldwide economic cost of diabetic care was calculated at $\$ 727$ billion in year 2017 which is predicted to be $\$ 776$ billion for year 2045 respectively [54]. Currently, more than 230 million Asian individuals are living with diabetes, accounting for approximately 55\% of the world's diabetic population. China and India collectively are home of nearly 110 million diabetic patients [55]. It is a risk factor for CVD and has been associated with 2- to 4-fold higher mortality [56] and another study says that half of all diabetic death was due to CVD [57]. The number of deaths caused by diabetes in the age range of 60-99 years in 2017 was 3,200,000 [58]. About half of diabetesrelated mortality (48\%) occurs in people younger than 60 years and it continues to reduce life expectancy by 6-8 years in people diagnosed at the age of 50 years [59]. More than $35 \%$ patients did not receive any diabetes education, while 30\% diabetic patients were compliant with drug regimens and the non-compliance was higher among the lower socioeconomic groups [60]. Pharmacist may provide a face-to-face counseling regarding knowledge on diabetes, self-monitoring of blood glucose, regular checkup of systolic blood pressure, body weight, and serum cholesterol levels. The pharmacist may also counsel regarding non-pharmacological management strategies such as diet control, exercise therapy, and early identification of symptoms of hypoglycemia (blurred vision, rapid heartbeat, sweating, fatigue, headache, dizziness, trouble thinking, seizures, and coma) and its management. In a satisfaction survey of 24 providers or clinical pharmacists, nearly $90 \%$ had favorable responses toward the protocol and its effect on access to and quality of care [61]. Management of DM remains a significant challenge in the US, as estimates indicate that greater than $40 \%$ of diabetes patients are uncontrolled with a HbA1c. Diabetic patients who received care from the collaborative team, including a clinical pharmacist, had improvement in most key indicators of diabetes like HbA1c, in both high- and low- income countries and in both urban and rural areas [62-71]. Emphasizing medication adherence, particularly for patients with longer duration of diabetes and those with multiple comorbid diseases should be strongly considered in future diabetes management programs implemented to improve glycemic control in patients with type 2 diabetes [72]. A mobile phone text message can serve as a simple and cost-effective option in improving medication adherence and clinical outcomes by providing information between clinic visits has been reported $[73,74]$. A report from the National Diabetes Commission suggested that an inappropriate attitude of health care professionals toward diabetes could lead to poor patient outcomes [75]. In educational program, a clinical or community pharmacist can improve adherence by providing medication consultation service, creating an individualized patient schedule on administration times and dosage of each medication, educating the patient on the importance of medication adherence, dietary adherence and exercise on better glycemic control, giving advice on how to reduce adverse effects of medications, and also by teaching how to take medications in the holy month of Ramadan or other religious fasting, and how to use pill boxes and diary logs to reduce forgetfulness. Literature indicates a number of interventional studies involving pharmacistbased educational interventions, showing clinically significant improvements in the clinical outcomes of the diabetes patients [76] (Figure 2).

\section{CVD Prevention}

Hypertension affects $26.4 \%$ of the global adult population and a key driver of global disease burden [77]. It is a major risk factor for CHD, stroke, retinopathies, and renal dysfunction. 18 million people die each year from CVDs, an estimated $31 \%$ of all deaths worldwide [78]. Of these deaths, $85 \%$ are due to MI and stroke [79]. CVD is currently the leading cause of morbidity and mortality and over $80 \%$ occur in LMICs [80]. Nearly $50 \%$ patients with chest pain related to exercise have obstructive coronary artery disease [81]. Coronary artery spasm plays an important role in the pathogenesis of IHD, including angina pectoris, MI, and sudden death, occurring most often from midnight to early morning [82]. A study of 1,015 patients with stable coronary artery disease (CAD) showed a 4.4fold escalation in the risk of stroke and a 3.8-fold escalation in the risk of death among patients who self-reported as non-compliant [83]. IHD has topped the list of causes of years of life lost for more than a decade, highlighting the shift in the global burden of disease from communicable to chronic disease. Risk factors for CVD, including raised blood pressure, hypercholesterolaemia and high BMI, are among the most important contributors to DALYs [84]. CVD claimed death of some 900,000 death in US in 2016 [85]. BP is still uncontrolled in $50 \%$ of the US population with hypertension. Additionally, BP can remain poorly controlled despite up to six physician visits per year [86]. Across South Asia, overall hypertension prevalence is estimated to be $27 \%$. Prospective Urban Rural Epidemiology study has shown more than $50 \%$ are unaware of it and up to $80 \%$ of hypertensive patients have low adherence to medication. Uncontrolled BP was found more than $50 \%$ in Bangladesh, 70\% in Pakistan and almost 60\% in Sri Lanka [87]. The goals of treatment of hypertension are to limit target organ damage, thereby reducing the morbidity and mortality associated with the disease [88]. Many factors including socioeconomic status, belief about medications, comorbidity, availability of medications, access to healthcare, level of health literacy, number of medications, duration of therapy, age, gender, culture, educational status, and knowledge of the disease and treatment have been associated with the rate of adherence. Lack of medication availability, low level of awareness about the disease and treatment, inability to afford medicines, mistrust in western medicine, and more trust on traditional and spiritual healers are very common in the rural population [89]. Non-drug therapies have been shown to lower BP, enhance antihypertensive drug efficacy, and decrease 
cardiovascular risk. All patients with hypertension and those in the prehypertensive category should be advised to make life-style modifications in addition to any pharmacologic treatment that they receive [90]. Surprisingly, $60 \%-80 \%$ of the population around the world (according to WHO) are partially or fully dependent upon herbal drugs for primary healthcare [91]. Interactions of some ingredients in supplements with other anti-hypertensive and cardiovascular preparations are well-documented [92]. Green tea showed $85 \%$ decrease in plasma concentration of nadolol, for example [93]. The pharmacist may play a relevant role in primary and secondary prevention of CVDs, mainly through patient education and advocacy, drug safety management, medication review (review of both drug-food and drug-drug interaction), monitoring and reconciliation, detection and control of specific cardiovascular risk factors (e.g., blood pressure, blood glucose, serum lipids) and clinical events [94].

Pharmacist intervention can increase patients' knowledge about their condition in a way that positively modifies their beliefs about medicines, increased medication intensification without significant change in medication adherence, modify factors affecting adherence, improve adherence and patient QoL by reducing BP levels in patients treated with antihypertensive agents, increased referral acceptance [86], [95-99]. Interventions that were most effective included combinations of more convenient care, information, reminders, self-monitoring, reinforcement, advocacy, family therapy, psychotherapy, crisis intercession, regular telephone follow-up, and supportive care [83]. Weight loss has been noted to modify risk factors via improving insulin sensitivity, reducing inflammation, decreasing $\mathrm{BP}$ and modifying the lipid profile [100]. It is astonishing that $7-28 \%$ of patients with coronary heart disease still smoke, but around half of smokers are planning to quit [101]. The World Bank suggests that around 180 million tobacco related deaths could be prevented between now and 2050 if adult tobacco consumption abate by $50 \%$ by 2020 [102]. A clinical pharmacist trained for smoking cessation counselling can play a key role in providing such intercessions, including the assessment of pharmacotherapy interactions with tobacco use [103]. Prescription smoking cessation medications include bupropion and varenicline [104]. A recent Canadian survey shows that pharmacist-led intervention resulted in more than $70 \%$ of patients using nicotine replacement therapy for smoking cessation [105] (Figure 3).

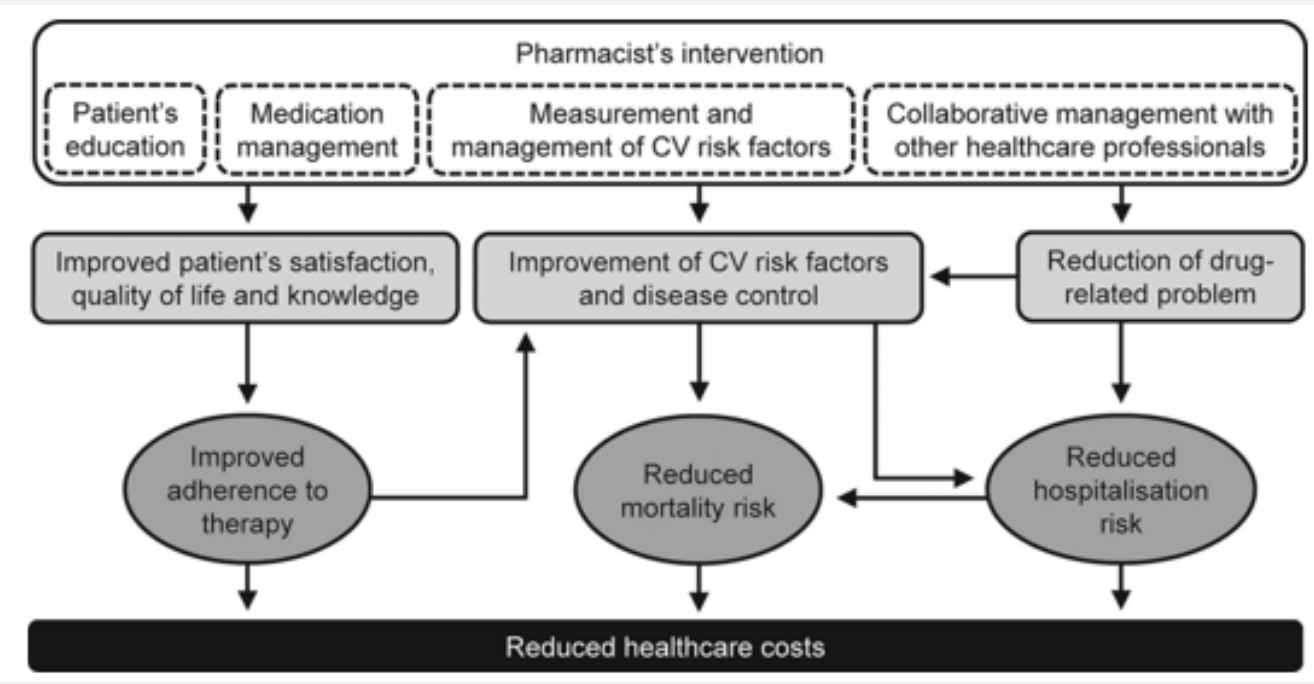

Figure 3: Effects of pharmacist's intervention on humanistic, clinical and economic outcomes in patients with CVD [94].

\section{Obesity Management}

In every single country in the world, the incidence of obesity is rising continuously with coronary artery disease, hypertension, type 2 diabetes mellitus, respiratory disorders and dyslipidemia [106]. The WHO estimated that in 2016 more than 1.9 billion adults were overweight (nearly $40 \%$ of the population) and over 650 million (13\% of the population) were people with obesity [107]. Globally, the annual cost of obesity-related diseases has reached $\$ 2$ trillion according to a recent report by McKinsey Global Institute [108]. Obesity increases cardiovascular risk through risk factors such as increased fasting plasma triglycerides, high LDL cholesterol, low HDL cholesterol, elevated blood glucose and insulin levels and high blood pressure [109,110]. Also, obesity causes cerebral vasculopathy, gallbladder lithiasis, arthropathy, ovarian polycytosis, sleep apnea syndrome, and some neoplasms [111]. Successful obesity treatment plans incorporate diet, exercise, behavior modification (with or without drug treatment), and/or surgical intervention [112]. Prior to recommending any treatment, the clinician must evaluate the patient for the presence of secondary causes of obesity, such as thyroid dysfunction $[113,114]$. If secondary causes are suspected, then a more complete diagnostic workup and appropriate therapy is important. The clinician should then evaluate the patient for the presence and severity of other obesityrelated diseases, evaluating appropriate lab tests as indicated. Based on the outcome of this medical evaluation, the patient should be counseled on the risks and benefits of available treatment options (along with obesity-related comorbidities, including T2D prevention, and improvements in dyslipidemia, hyperglycemia, osteoarthritis, stress incontinence, GERD, hypertension, and PCOS 
$[115,116]$. If obesity is present without other comorbid conditions, then the goal would be absolute weight loss. In the presence of comorbid conditions, relatively small reductions in total body weight can have significant effects on comorbidity [117] (Figure 4).

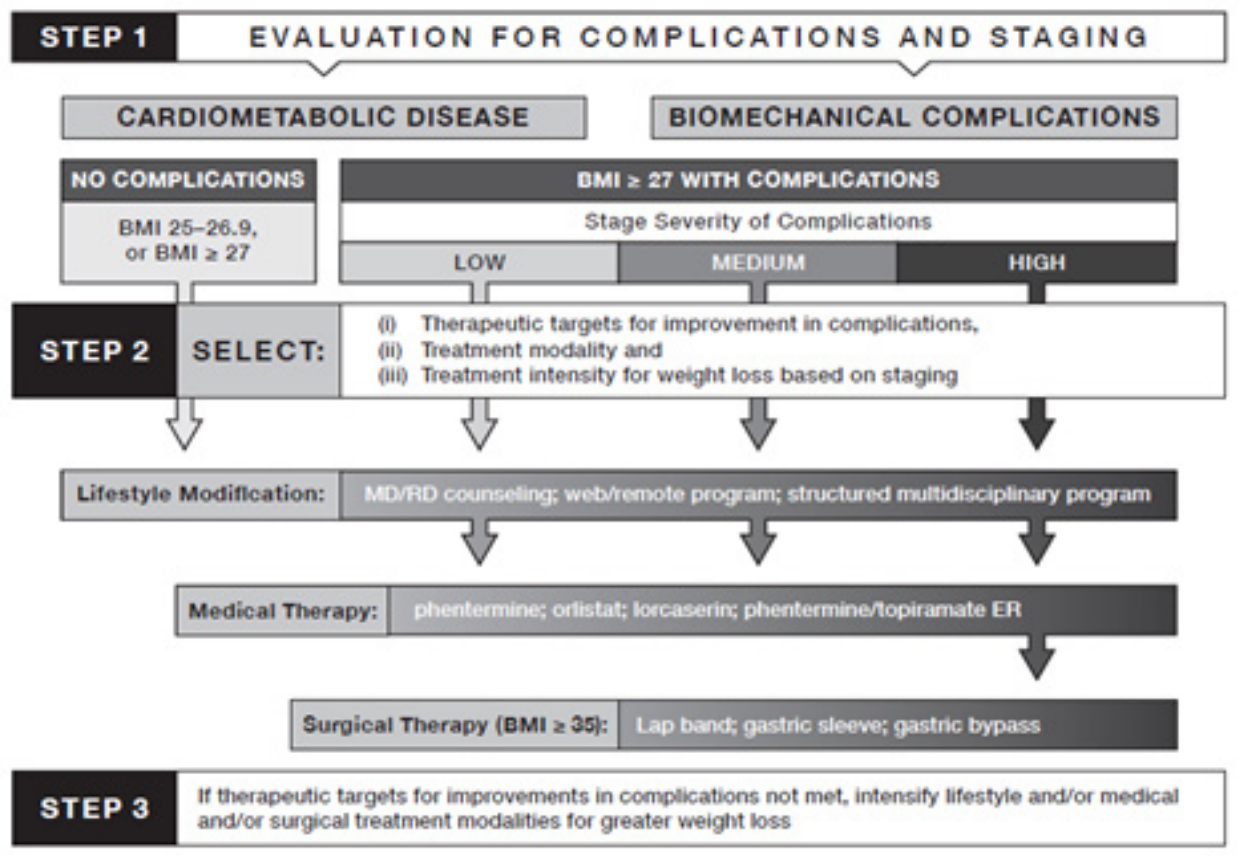

Figure 4: 2013 AACE Obesity Treatment Algorithm [118].

Pharmacists, commonly considered one of the most trustworthy and accessible health care professionals, are ideally situated to provide counseling for weight and lifestyle management. Well trained pharmacists to perform basic physical assessments such as weight, waist circumference, blood glucose monitoring, and pharmacotherapy counseling, while additional training could be easily obtained for services that would encompass dietary counseling, guidance on physical activity, and behavioral counseling [108], [119,120]. As pharmacists currently do not have a wellidentified role in obesity management, but study results display that pharmacist intervention was beneficial [121]. According to Canadian Pharmacists Journal, 2016 pharmacist prescribing resulted in $>3$ fold more patients achieving target LDL-c levels [122]. Pharmacists who identify and treat patients with dyslipidemia, including those with inadequately controlled LDL cholesterol levels, are better than physicians at attaining therapeutic goals [123]. Studies have demonstrated that pharmacist-led interventions, including lipid clinics, can help patients achieve these more aggressive goals $[124,125]$.

\section{Asthma \& COPD Management}

Asthma and COPD are common chronic conditions that comprise nearly $80 \%$ of direct health care costs associated with respiratory diseases in the EU [126]. In the UK alone, 5.4 million patients are currently receiving therapeutics for asthma; of these, 1.1 million are minor. Over three million people expire due to COPD worldwide every year, an estimated $6 \%$ of all demises worldwide [127]. It is the second most common reason for emergency hospital admission. According to WHO, COPD has become the fourth leading cause of mortality in the US. It is estimated to become the fifth leading cause of disease burden in 2020 [128]. In 2015 alone, the death toll due to asthma was 383,000 globally [129]. One in five individuals with a diagnosis of COPD, asthma, or both asthma and COPD in primary care settings have asthma-COPD overlap [130]. In COPD, the outpatient therapeutic and management goals are to reduce symptoms and risks from exacerbations, and to maintain drug therapy. In contrast with asthma, COPD is a disease caused by chronic and often daily exposure to noxious particles or gases. The small airways in COPD are gradually destroyed leading to chronic bronchitis and emphysema [131]. Optimal pharmacological treatment including rapid treatment of exacerbations, can improve symptoms, reduce exacerbation frequency, and improve exercise tolerance, while poor medication adherence and suboptimal inhaler technique negatively impact outcomes [132]. Adherence to inhaled medication is poor in the real world and shows great variability, ranging from as low as $20 \%$ to over $60 \%$ [133]. To improve adherence, the therapeutic decisions should be discussed with the patient and should take into consideration their lifestyle factors, demographic characteristics (age, co-morbidities, physical limitations, psychological and cognitive status), and pharmacological factors (polypharmacy regimens) to choose the best inhaler device for that patient [134]. Pharmacist-led comprehensive therapeutic interchange program of COPD inhalers may provide $30 \%$ pharmacy cost savings, improved medication adherence, knowledge of disease, decrease the number of prescriptions for exacerbations for these patients. and reduces 30 day readmission rate [135-138]. A pharmacist-driven spirometry service was associated with quality testing results, identified respiratory disease abnormalities, and helped modifications of pulmonary drug regimens based on evidence-based guidelines [137]. Despite advances in inhaler device technology, estimates of 
those making inhaler errors range up to $90 \%$ of patients irrespective of the device type used. Poor inhaler technique accounted for over $€ 750$ million in direct and indirect costs in 2015 in the UK, Spain and Sweden [139]. By providing pharmaceutical care to patients with asthma, the pharmacist can help them to achieve treatment goals, e.g. improvement of disease control and reduction of asthma symptoms, exacerbations and medication-related side effects [140]. Step up of therapy comprised increasing or starting corticosteroid/long-acting beta agonist combination inhaler; corticosteroid inhaler; short-acting muscarinic antagonist inhaler; oral corticosteroid; oral montelukast; or long-acting muscarinic antagonist inhaler. Step down of therapy comprised reducing or stopping corticosteroid/long-acting beta agonist combination inhaler; corticosteroid inhaler; or long-acting muscarinic antagonist inhaler. The pharmacist conducted activities such as issuing asthma action plans, educating patients, recommending stepping up/down therapy, reviewing inhaler technique and making other relevant recommendations such as device changes (e.g., dry-powder to metered-dose inhaler) [141]. Polypharmacy is burdensome and associated with patients hospitalized with acute exacerbations. It is plausible that repeated pharmacist intervention to ensure optimal pharmacotherapy and minimize adverse effects, with a direct link to a consultant respiratory physician, and the patient's GP, may lead to improved outcomes [142]. The interventions identified focused on key areas of asthma and COPD management and support including assessment of current symptoms; assessment and rectification of inhaler technique; identification of medication-related problems; medication adherence; provision of written and oral education materials; smoking cessation [143] (Figure 5).

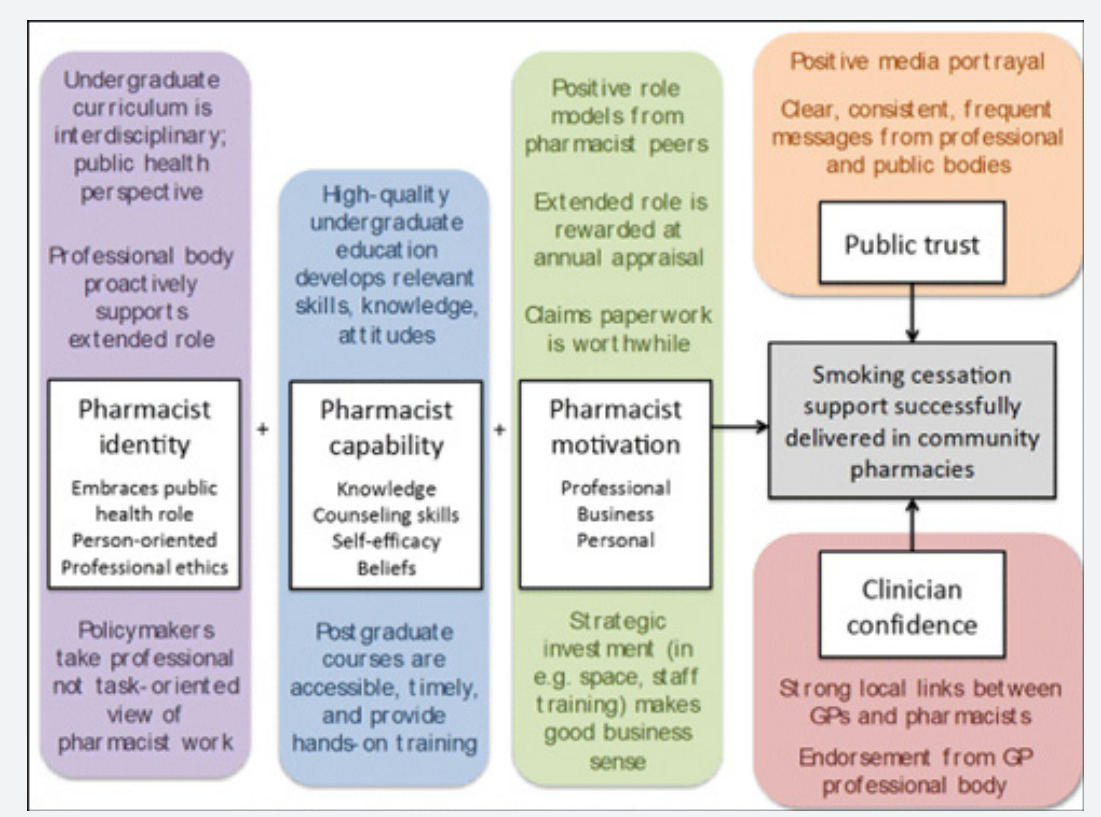

Figure 5: Unifying model showing key influences on successful delivery of smoking cessation support by pharmacists [144].

\section{Osteoporosis}

Worldwide, it is estimated that 1 in 3 women above the age of 50 will experience osteoporotic fractures, as well as 1 in 5 men [145]. The pervasiveness of osteoporosis is expected to rise in the US from approximately 10 million people to more than 14 million people by 2020 [146]. In 2015, direct medical costs totaled $\$ 637.5$ million for fatal fall injuries and $\$ 31.3$ billion for nonfatal fall injuries. During the same year, hospitalizations cost an average of $\$ 30,550$ per fall admission, totaling $\$ 17.8$ billion. By 2025 , the cost of fractures in the US is expected to exceed $\$ 25$ billion each year to treat more than three million predicted fractures [147]. Similar to other chronic diseases, osteoporosis has struggled with suboptimal medication adherence, resulting in an increased risk of fractures and all-cause mortality. Two gaps in osteoporosis management are well documented: (a) most patients at high risk for fracture are not identified for treatment, and (b) adherence to osteoporosis pharmacotherapy is suboptimal [148]. Nearly $50 \%$ osteoporosis patients are non-adherent to medications.
Furthermore, approximately $50-70 \%$ of the patients discontinue their osteoporosis medications within the first year of initiation, which results in increased morbidity and mortality [149]. In October 2010, the US FDA issued a safety communication regarding the risks of atypical fractures of the femur, with bisphosphonates drugs, the safety communication appeared to have influenced osteoporosis utilization in Medicaid recipients [150] (Figure 6).

High patient cost and safety concerns are barriers for nearly $60 \%$ patients [152]. Improved osteoporosis medication adherence can reduce osteoporosis-related health care costs by preventing fractures. Persistent pharmacotherapy for osteoporosis is necessary to prevent osteoporotic fractures and to reduce osteoporosis-related health care costs [153]. Treatment strategies of osteoporosis include non- pharmacological treatment - diet rich of calcium and vitamin D, healthy lifestyle, proper exercise plan, and pharmacological therapy [154]. BMD monitoring after initiating anti-osteoporosis therapy in the routine clinical practice setting [155]. 


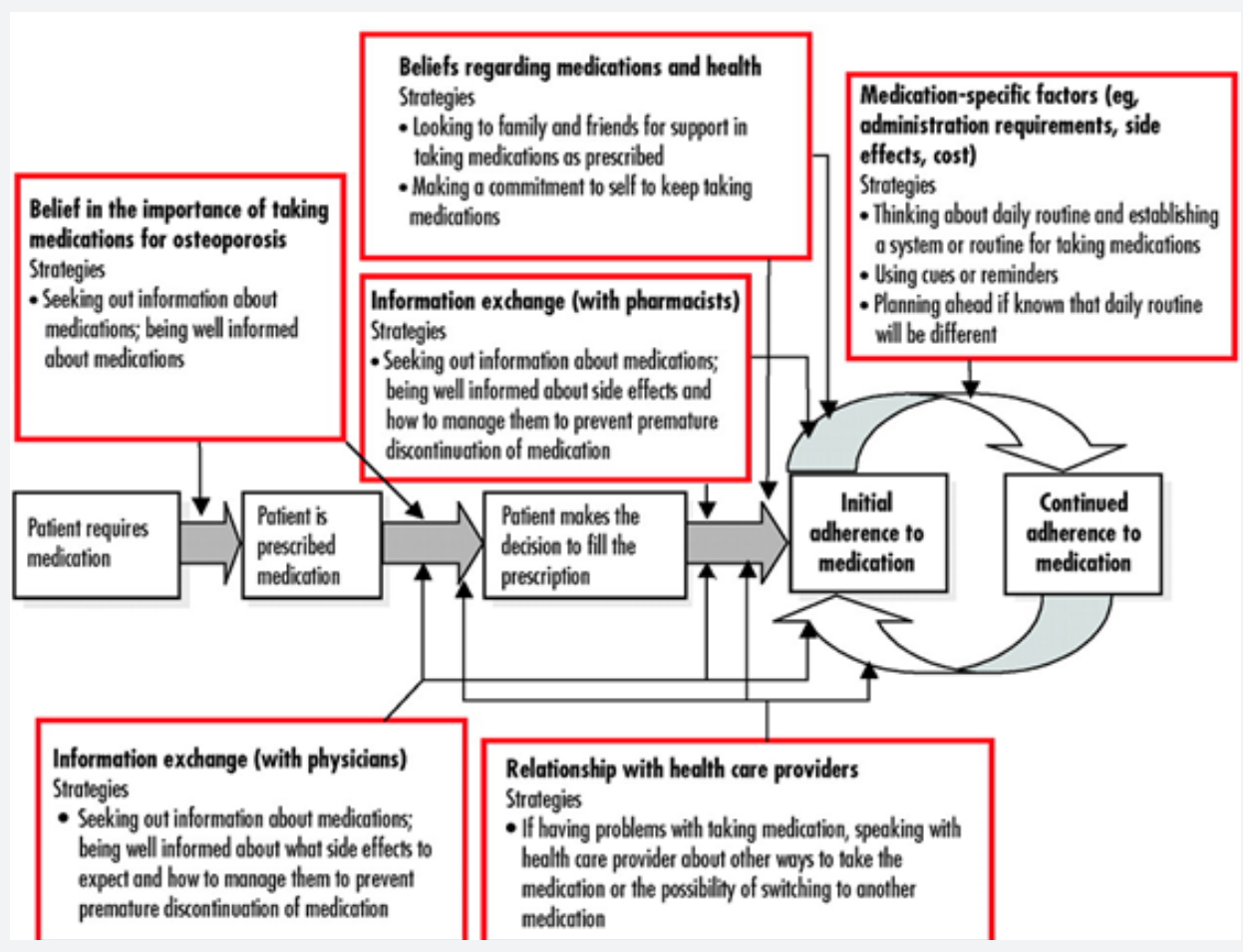

Figure 6: Mapping the factors influencing adherence and adherence strategies onto the medication-taking process in patients with osteoporosis [151].

Hypercalciuria, calcium malabsorption, hyperparathyroidism, hyperthyroidism, vitamin D lack, Cushing's syndrome, and hypocalciuric hypercalcemia attributed to secondary causes to more than $30 \%$ women. Disorders of calcium metabolism and hyperparathyroidism contributed to nearly $80 \%$ of the secondary causes [156]. Hormone replacement therapy (HRT) is not firstline therapy position for osteoporosis but is best for prevention of osteoporosis [157]. However, different types of estrogen or progestogen, as well as different formulations, doses, timing of initiation, durations of therapy, and patient characteristics, may play different roles in the effects of HRT [158]. Pharmacistphysician collaboration is associated with higher treatment rates of osteoporosis [159]. Physicians and pharmacist should invest time to educate patients about the potential side effects and box warnings of estrogen use. Routine women wellness exams should also be focused on the development of any malignancies or adverse effects of hormone replacement therapy given a positive history. The pharmacist can play an important role at multiple levels: supporting patients in treatment, by providing information on the disease, its treatment, proper use of medication, adherence and persistence, as well as raising awareness for the prevention of osteoporosis and identifying patients at risk [160]. The counseling should include educating and assessing the patient for proper use of estrogen medication therapies as they may be prescribed in many various preparations of oral, transdermal, vaginal insert, and topic vaginal creams for positive patient compliance and adherence to therapy [147].

\section{Inflammatory Bowel Disease (IBD)}

Inflammatory bowel disease (IBD) is a group of inflammatory conditions of the colon and small intestine. The two most common diseases are ulcerative colitis and Crohn's disease (CD). Crohn's disease can cause inflammation in any part of the GIT. Ulcerative colitis (UC) is an idiopathic inflammatory condition of the colon which results in diffuse friability and superficial erosions on the colonic wall associated with bleeding [161]. Although these diseases have undetermined etiology, research advances have outlined some of the pathways by which they occur: a) genetic predisposition associated with the environment induces a disruption of the intestinal microbial flora, b) the epithelial cells and the immune system of the intestine itself determine the risk of developing the disease [162]. Treatment of both, IBD and IBD related pain is challenging. The upholder of IBD therapy includes systemic immunosuppressive drugs, such as corticosteroids, anti-tumor TNF antibodies or immunomodulators. Furthermore, the management of an acute flare differs from the strategies for maintenance of remission [163]. A total of about 66,000 US residents with a new IBD diagnosis each year, since 2015 [164]. Direct costs (including consultations, drugs, hospitalization and surgery) of UC amount to $\$ 3.4$ to $\$ 8.6$ billion in the US and $€ 5.4$ to $€ 12.6$ billion in EU [165]. The prevalent populations of patients with CD or UC in the UC in 2016 are expected to incur lifetime total costs of $\$ 498$ billion and $\$ 377$ billion, respectively [166]. IBD is a relapsing-remitting condition that causes inflammation and ulceration in the bowels, affecting approximately 500,000 people in the UK [167] (Figure 7).

The increasing incidence of IBD in developing countries parallels the westernization of diet, which includes higher calorie intake, especially from sugar, refined carbohydrates, animal proteins and ultra-processed foods and a lesserintake offiber and fruits [168,169]. Incidence rate of IBD is stabilizing in some developed countries; however, the incidence rate is increasing in developing countries 
such as Asia and Eastern Europe [170]. Anxiety and depression are the most common psychological disorders in patients with IBD [171]. IBD is associated with significantly increased MI compared with non-IBD patients [172]. Patients with IBD are also at risk for asthma or COPD and bronchiectasis [173,174]. Sacroiliitis, an inflammatory arthropathy associated with ankylosing spondylitis, is found in patients with IBD but may go undiagnosed [175]. IBD patients showed increased risk for lymphoma and biliary cancer [176]. The general goals of treatment are to induce and maintain remission, minimize complications and disease manifestations, and improve overall QoL. Personalized IBD pharmacist adherence counselling, based on the Health Beliefs Model of medication perception, may increase medication adherence. Education using pamphlets and ad hoc physician education improved knowledge but not adherence [177]. IBD patients, mainly those having UC, need medications throughout their life with periodic dosing and occasionally, enemas and infusions may also be required. Treatment without adherence is highly regarded as the significant factor for relapse occurrence [178]. Medication nonadherence in IBD can be improved through a single personalized counseling session by IBD pharmacist adherence counselling (IPAC) intervention, and the benefit was durable for 2 years [179]. In addition to the disease, these patients are also managed with potent medications like steroids and biological agents, which have a host of adverse effects. Thus, the importance of the pharmacist who should be alert for any adverse reaction [180]. Pharmacistled drug monitoring clinics measure thioguanine nucleotides and thiopurine methyltransferase levels four weeks after treatment with thiopurines is started to optimize outcomes [181]. In the event that insurance coverage cannot be obtained for the selected biologic response modifiers, the pharmacist identifies and discusses alternative options with the GI team; some of these options may include switching to another formulary agent or enrolling patients in medication assistance programs. Once insurance coverage of the medication is secured, the pharmacist educates the patient on selfadministration, stability and storage requirements, and potential adverse effects. Additionally, the pharmacist highlights the significance of compliance with laboratory monitoring and reviews the importance of communicating with the GI team in the event of potential infection, worsening disease control, or issues obtaining or using the medication. The IBD pharmacist has a key role in the management of IBD patients contributing not only to medication monitoring, prescribing, and safety but also allowing greater capacity in the physician's, often highly stretched IBD clinics [182]. Beyond medication therapy coordination from beginning to end, the pharmacist plays an active role in assisting with medication reconciliation and ensuring patients are current on necessary immunizations [183]. $40 \%$ of patients with CD do not respond to treatment with biologics, $30 \%$ to $50 \%$ achieve complete remission after six months and $30 \%$ of patients maintain the response for 12 months with continual treatment. Current strategies to overcome loss of response involve increasing the dose, decreasing the interval between administrations or switching to an alternative agent [181].

\section{THE IBD SERVICE \\ The IBD multidisciplinary team Patient engagement Service development Electronic management and data/registry \\ Provision of information Investigations and treatment Training, education, and research}

FLARE
MANAGEMENT
Pathways and protocols
Information to patients
Rapid access to
specialist advice and
treatment
Steroid management
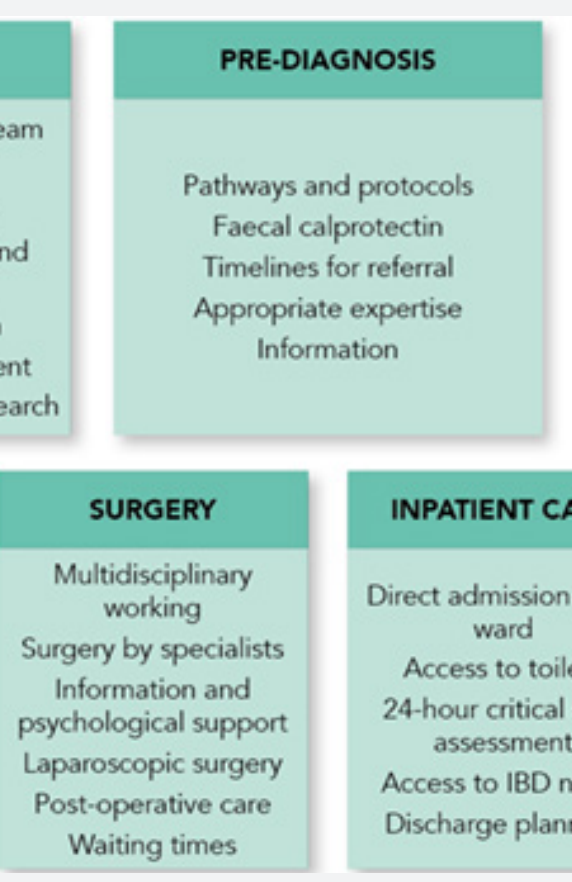

NEWLY DIAGNOSED

Shared decision-making Specialist assessment Care plan and treatment Information and support

Figure 7: The seven sections of the 2019 IBD Standards [167].

\begin{tabular}{|c|c|}
\hline INPATIENT CARE & $\begin{array}{c}\text { ONGOING CARE AND } \\
\text { MONITORING }\end{array}$ \\
\hline $\begin{array}{c}\text { Direct admission to GI } \\
\text { ward }\end{array}$ & $\begin{array}{c}\text { Access to IBD team } \\
\text { Personalised care plan }\end{array}$ \\
\hline $\begin{array}{c}\text { Access to toilets } \\
\text { 24-hour critical care }\end{array}$ & $\begin{array}{c}\text { Education/self- } \\
\text { massessment }\end{array}$ \\
$\begin{array}{c}\text { Access to IBD nurse } \\
\text { Discharge planning }\end{array}$ & $\begin{array}{c}\text { Pain and fatigue } \\
\text { Shared care }\end{array}$ \\
\hline
\end{tabular}

\section{Thyroid Disorders}

Primary hypothyroidism (due to thyroid gland dysfunction) is the most common, with typical causes being Hashimoto's disease, or iatrogenic (due to exposure to radiation or thyroid surgery). Secondary hypothyroidism occurs as a result of diseases of the pituitary or hypothalamus. Common symptoms in hypothyroidism include fatigue, weight gain, cold intolerance, bradycardia, constipation, depression, and skin and hair dryness [184]. Hyperthyroidism, on the other hand, presents with symptoms nearly opposite, including weight loss, heat intolerance, 
tachycardias or palpitations, hyper-defecation, nervousness, and hyper-hydrosis [185]. Iodine nutrition is a key determinant of thyroid disease risk; however, other factors, such as ageing, smoking status, genetic susceptibility, ethnicity, endocrine disruptors and the advent of novel therapeutics, including immune checkpoint inhibitors, also influence thyroid disease epidemiology [186]. The global prevalence of hypothyroidism is $4.6 \%$, with prevalence being more common in women and in older individuals $[187,188]$. In UK, the prevalence is around $3.5-5 \%$ and in USA, $0.2-3.7 \%$ [187]. The prevalence of thyrotoxicosis is 10-fold higher in women. Elevated diastolic blood pressure is present in $\sim 30 \%$ of patients with overt hypothyroidism and heart failure develops in $6-16 \%$ of patients with hyperthyroidism [77]. There is a high ( $>20 \%)$ prevalence of hypothyroidism in patients with T2DM, hypertension, and patients having both [189]. Hypothyroidism can directly cause obstructive sleep apnea (OSA) [190,191], Bruyneel et.al, 2019 reported 16\% of OSA patients had a thyroid problem and $8 \%$ of these were newly diagnosed with subclinical hypothyroidism (SCH) [192], over $50 \%$ of the patients studied did not receive any treatment, found in a recent
Egyptian study [193]. Both hypothyroidism and hyperthyroidism were strongly associated with erectile and ejaculatory dysfunction: hypothyroidism with delayed ejaculation, hyperthyroidism with pre-mature ejaculation [194]. Yuan et.al, 2019 reported highest prevalence of vitiligo in subclinical hypothyroidism, among 6 types of thyroid disorders [195]. Subclinical hypothyroidism is most often caused by autoimmune (Hashimoto) thyroiditis [196], who are at higher risk of developing audiological abnormalities as compared to the healthy individuals [197]. Hypothyroidism may also cause alveolar hypoventilation, decreased lung volumes, upper airway obstruction, depression in respiratory stimulus, and respiratory failure [198]. Thyroid dysfunction is a common extrapulmonary manifestation in COPD patients [199]. The American College of Physicians and the American Society of Internal Medicine (ASIM) recommend screening women older than 50 years of age for unsuspected but symptomatic thyroid disease [200]. However, the American Thyroid Association recommends that adults begin screening at the age of 35 years, and repeat screening every 5 years thereafter [201] (Figure 8).

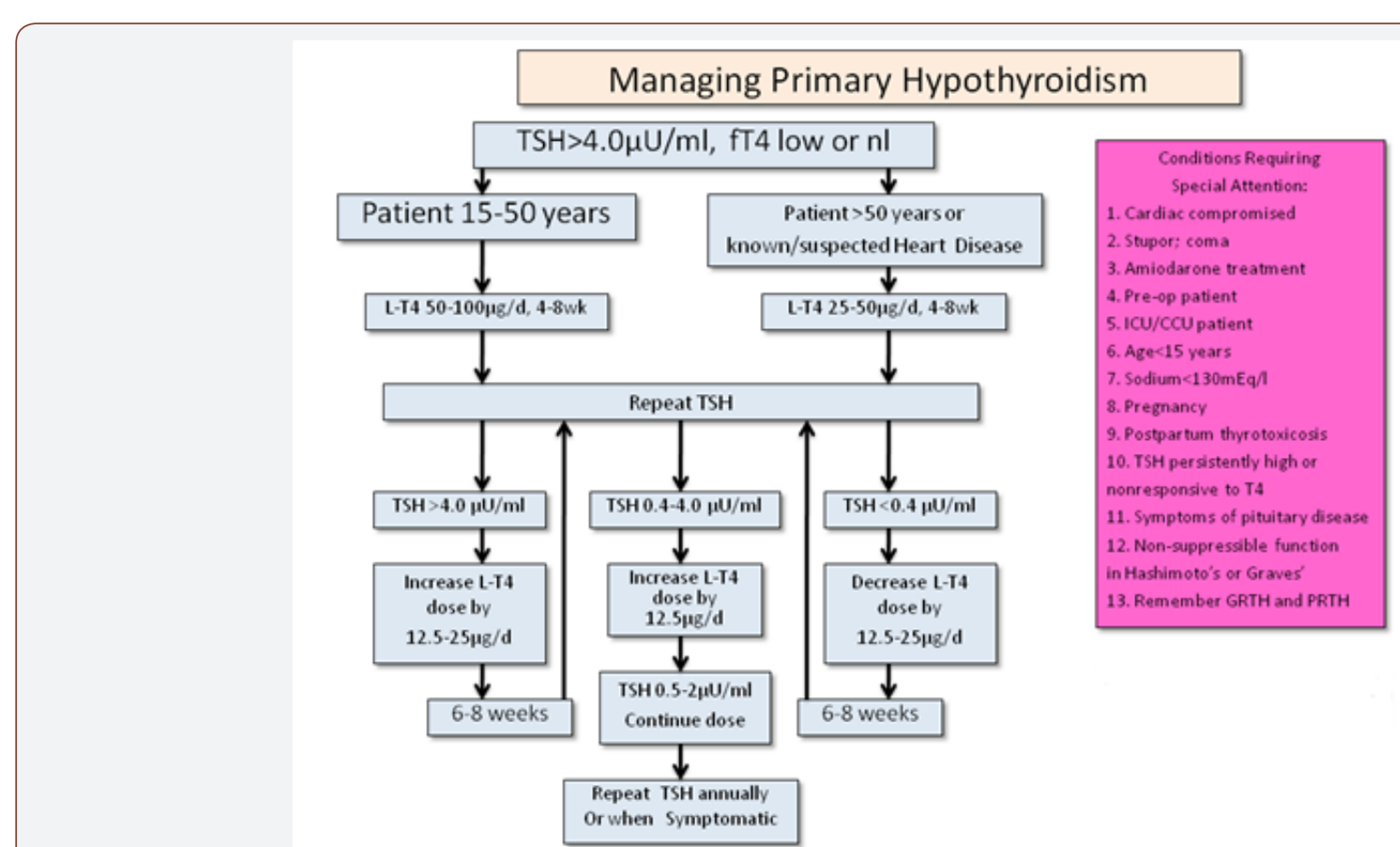

Figure 8: Managing Primary Hypothyroidism (Adapted from DeGroot LJ, 2016) [202]

Clinical pharmacist improves treatment outcome in term of knowledge, attitude and practice scores of the patients after advocacy [203]. Thyroid medications demand careful, patientspecific dosing. Once a physician has changed the dosage of medication to achieve the desired levels of thyroid hormone in a patient, it is decisive to maintain that particular dose and medication until otherwise directed. This is an important counseling point and one that many patients may not be aware of the degree of significance. While there are only a few medicines currently used to treat thyroid disorders, pharmacists can provide education on new or existing medications. Patients should have their thyroid function monitored annually once their treatment is established. It should be noted that pregnant women and patients with nephrotic syndrome or with diseases causing chronic malabsorption may require higher doses of levothyroxine. Pharmacists play an important role in ensuring patients with hypothyroidism are managed appropriately. This can include:

- Counselling patients about the timing of levothyroxine dosing and administration with other medicines;

- Discussing with patients the appropriateness of combined T4/T3 therapies in light of the large amount of debate on patient forums;

- $\quad$ Ensuring thyroid function tests are monitored adequately - tests should be assessed four to six weeks after a dose change and at least annually when replacement therapy is stabilized; 
thyroid stimulating hormone values change slowly, so frequent testing is unnecessary;

- $\quad$ Ensuring adequate titration of levothyroxine dose after test results are known [204].

Whether stopping by in person or picking up the phone to call, patients should be inspirited to reach out to their pharmaciststhe most accessible healthcare provider-the next time a question arises about any medication, as it is both the duty and the joy of a pharmacist to provide this service.

\section{Psychiatric Disorders}

Almost 1 in 5 adults (44 million) in the US exposed to psychiatric illness and distress in a given year, according to the NAMI. A nearly 10 million people suffer a debilitating mental illness that substantially hampers with their QoL $[205,206]$. Mental and addictive disorders afflicted more than 1 billion people round the globe in 2016. They caused 7\% of all global burden of disorder as measured in DALYs and 19\% of all years lived with disability [207]. Depression was the dominant cause of disability in the world, and suicide was the 10th leading cause of death in 2015 [206]. Major depressive disorder (MDD) is the fourth cause of infirmity around the world and is estimated to be the second dominant cause of infirmity by 2020 [208]. In EU, factors that had the strongest alliance with depression were chronic diseases, pain, circumspection in daily living, grip strength and cognitive deterioration. The gap in MH service use was nearly $80 \%$ [209]. The therapeutic gap in developing countries was 76\%-85\%, according to WHO. According NMHS, it is $83 \%$ in India for mental disorder and $86 \%$ for alcohol use disorders [210]. Swaminath et.al, 2019 revealed that mental morbidity above the age of 18 years is $10.6 \%$ with a lifetime preponderance of $13.7 \%$. This means that 150 million Indians need active therapeutic intervention [211]. Canadian Mental Health Association estimated that 500,000 Canadians miss work every week due to MH issues, costing the Canadian economy around \$51 billion per year, as depicted by Hayes et.al, 2019 [212]. According to Australian Bureau of Statistics (ABS) National Survey of Mental Health and Wellbeing (NSMHWB) 45\% of Australians exposed to a mental disorder in their lifetime, with $20 \%$ experiencing a mental disorder in the past [213]. Shpigelman et.al, 2019 reported that individuals with silent psychiatric disabilities have lower levels of self-esteem and body image compared to individuals with visible physical disabilities. Gender, family status and the acerbity level of the infirmity were found to be correlated with self-esteem and body image [214]. Mental disorders and suicide resulting from workload or work-related stress have become major occupational health issues worldwide, particularly in Asian countries [215]. Depression and anxiety in more common chronic physical circumstances such as CHD or diabetes can be correlated with increased mortality, as reported by Uhlenbusch et.al, 2019. Also, depression is associated with an escalation of about $50 \%$ in costs of chronic medical ailment [216]. Rokach et.al, 2019 revealed that anxiety and depression lead to sexual dysfunction is between $30 \%$ and $70 \%$ in sexually active men and women in high-income countries [217]. Despite psychiatry's present status as the sixth largest medical specialty, the availability of clinicians has not kept up with demand [218]. For over 40 years, clinical pharmacists have handout to these care models in capacities ranging from educator to consultant to provider. Medicines are a major treatment modality of management for many mental illnesses and pharmacists are therefore well positioned to reinforce MH services with the potential to reduce the associated burden of mental disorders [219] (Figure 9).

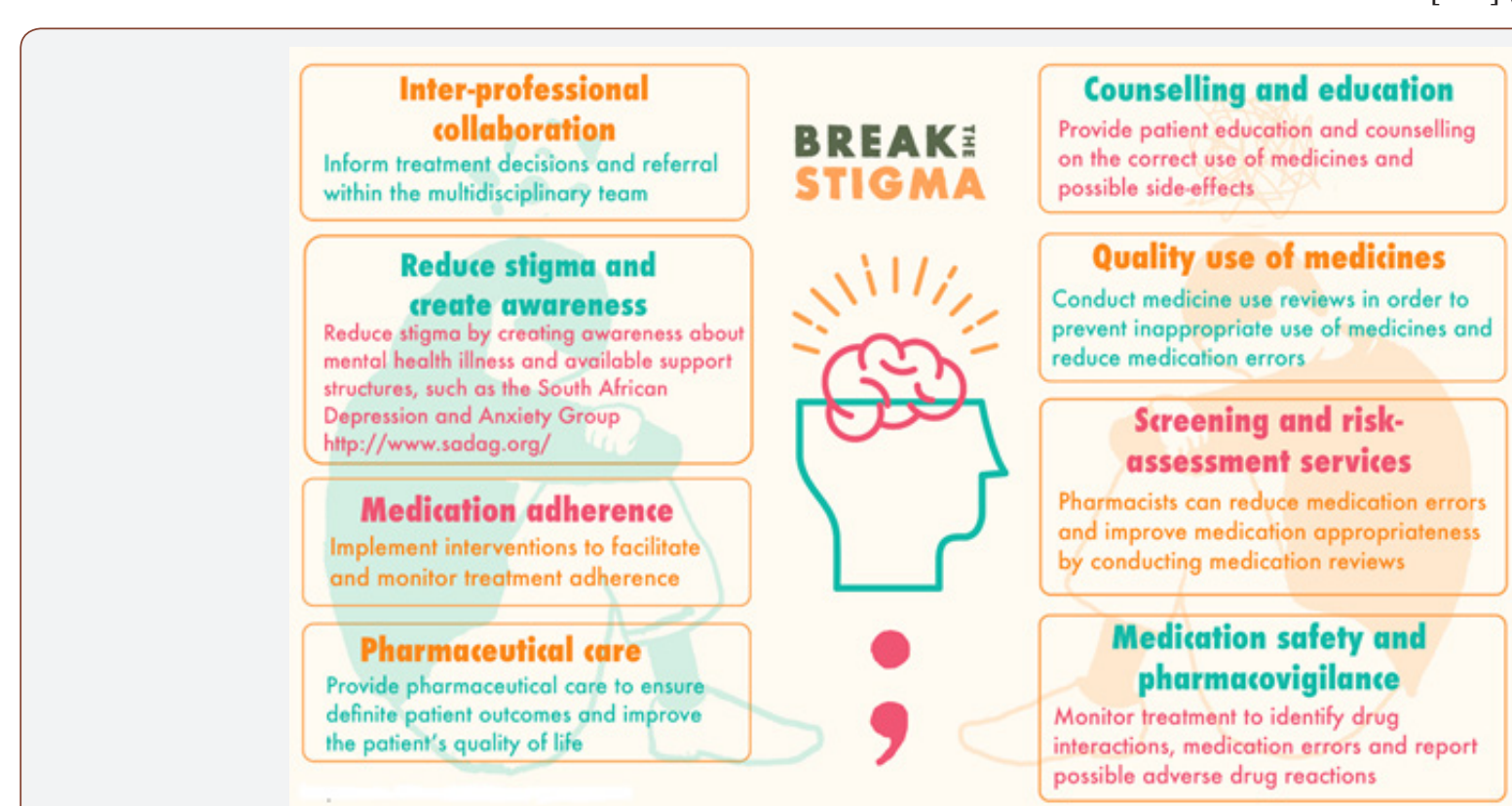

Figure 9: Role of Pharmacists in Mental health Disorders [220].

Antidepressant drug treatment (ADT), alone or in association with psychotherapy, is endorsed by the CANMAT for a minimum duration of 8 months. However, a large proportion of individuals show suboptimal attachment to ADT. In previous studies, more than
$35 \%$ to $70 \%$ ceased treatment within 6 months, with up to $25 \%$ to $40 \%$ of patients having ceased their therapy within the first month [221,222]. Also, Holvast et.al, 2019 depicted non-compliance to antidepressants is high among older patients with depression in 
primary care settings [223]. Transitions in care have the aptitude to be destabilizing periods for many patients and is an area where pharmacist-guided medication therapy management (MTM) has been found to be propitious [224]. The pharmacist interim prescriber clinic was associated with a compelling decrease in mean number of patients seen per month in PES [218]. The clinical pharmacist can make an impact by bettering mild-to-moderate MH conditions, promoting interdisciplinary collaboration, and increasing documentation and backlash that align with published treatment guidelines [206]. Chavez et.al, 2019 reported that pharmacists improved rate of patient interest in behavioral health counseling during the consult and recommending counseling directly to the patient or even initiating the referral themselves [225]. Bingham et.al, 2018 highlighted the value of the pharmacist's involvement, suggesting the potential for improved nutrition, physical activity, and sleep for patients with MH conditions, at least in the short term [226]. Throughout the US, pharmacists have crafted intercessions designed to prevent, identify, and manage opioid misuse and abuse [227]. Also, Eltorki et.al, 2019 reported that physicians and nurses have mostly positive perceptions and confidence from clinical pharmacists at the psychiatric hospital [228]. In Australia, The Pharmaceutical Society's Mental Healthcare Framework admits pharmacists as primary health care professionals who have a significant role to play within MH care. Globally, the International Pharmaceutical Federation has urged members to include pharmacists as part of their "human resource development policy" so that "an increase by $20 \%$ of service coverage for severe mental disorders can be achieved" [229].

\section{Neurological Disorders}

Chronic neurological diseases like Alzheimer's disease (AD), Parkinson's disease (PD), dystonia, Amyotrophic lateral sclerosis (ALS, Lou Gehrig's disease), Huntington's disease, neuromuscular disease, multiple sclerosis (MS) and epilepsy, to mention only a few - afflict millions of people worldwide and account for tremendous morbidity and mortality [230]. Contributing $11.6 \%$ of global DALYs and $16.5 \%$ of deaths from all causes, neurological disorders remain the leading group cause of DALYs and the second leading group cause of deaths in the world [231]. Direct and indirect costs for healthcare related to AD are estimated at nearly $\$ 500$ billion annually [232]. PD is the second most prevalent neurodegenerative disease after $\mathrm{AD}$, affecting approximately 4-10 million people worldwide, and is expected to double in prevalence by 2030 as the population ages [233]. The incurred medical expenses were approximately $\$ 14$ billion in 2010 [234], which is $\$ 52$ billion now, in US only $[235,236]$. Approximately 350,000 individuals in the United States and 2.5 million individuals worldwide have multiple sclerosis. Almost $10 \%$ of the cases present before the age of 18 [237, 238]. The global MS drug market was valued at US $\$ 16.3$ billion in 2016, expecting to reach US $\$ 27.8$ billion by 2025 [239]. Epilepsy is another most common serious brain conditions, affecting over 70 million people worldwide [240], with an estimated cumulative value of lost economic welfare (VLW) \$647.37 billion in 2016 [241]. Clinical pharmacist's activity can enhance drug therapy's effectiveness and safety through pharmacotherapy interventions (PIs), thus minimizing DRPs and optimizing the allocation of financial resources associated with health care.

\section{Alzheimer's disease}

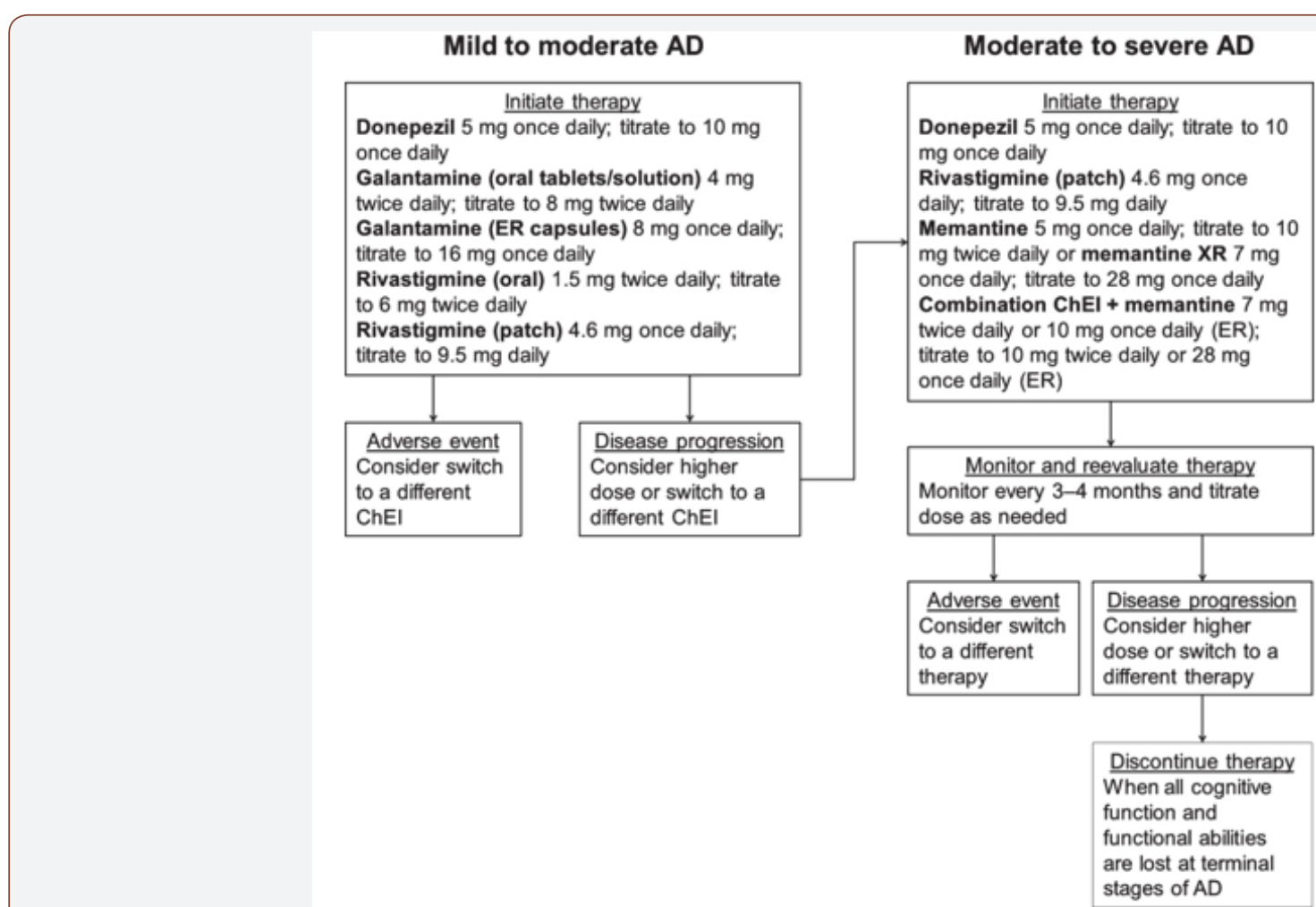

Figure 10: Treatment algorithm for Alzheimer's disease based on severity of symptoms [242]. Abbreviations: AD, Alzheimer's disease; ChEl, cholinesterase inhibitor; ER, extended release; XR, extended release. 
Patients with AD particularly susceptible to risk of anticholinergic side effects with certain medications and should be assisted by a pharmacist in selecting safe formulation such as OTC product. Pharmacists can also counsel patients and their caregivers on the safe use of alternative medicines that high majority of caregivers had requested relaxing plants and vitamins from the pharmacy for anxiety and insomnia [242]. As AD is a progressive condition, in its early stages, individuals may present with MCI and some $40 \%$ of individuals with MCI deteriorated to dementia (estimated out-of-pocket caregiver costs more than 10 billion in 2016 in Canada alone). It is estimated that patients with dementia cost the healthcare system over $300 \%$ more than their cognitively intact peers in the same age group [243]. Patient and caregivers' education, monitoring its progression, becoming familiar with screening tools that can be used in pharmacy practice to assess cognitive function and helping to manage medications for patients in different stages of dementia are essential contribution by the pharmacists [244]. In Germany, pharmacists adapt in identifying problems related to drug administration, adherence, and drug interaction among patients with dementia. Meanwhile, in the UK, a trial targeting peoples with dementia initiated on anti-psychotics demonstrated that pharmacist-led medication review successfully limited the prescribing of anti-psychotics to people with dementia because of the increased risk of ADRs. In Japan, study involving hospital pharmacists on donepezil deliberation for patients with $\mathrm{AD}$ and their caregivers has heightened medication adherence though this drug could cause insomnia and GI disturbance. In Malaysia, while medication reviews for patients with other chronic diseases have been invoked by hospital pharmacists via medication therapy adherence clinics, this has not been done for AD patients. It is crucial to ensure that the pharmacists are equipped with proficient knowledge on AD because poor management in AD can result in side effects, inappropriate dosing, and non-compliance to medications [245] (Figure 10).

\section{Parkinson's disease}

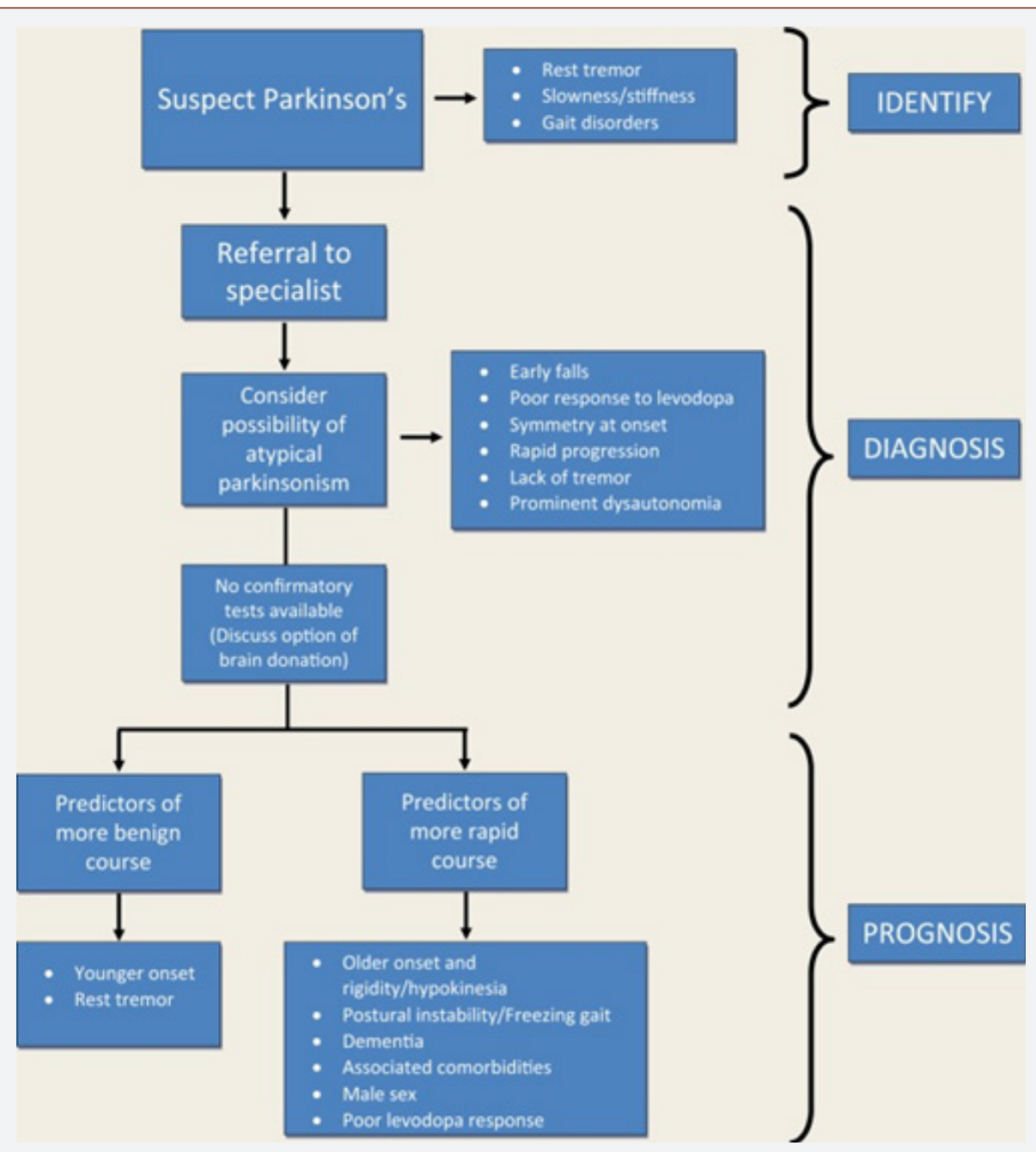

Figure 11: Summary of the identification, diagnosis and prognosis in Parkinson's disease [250].

PD is a progressive, debilitating neurodegenerative disease that often requires complex pharmacologic treatment regimens. Healthy ageing, primarily when a neurodegenerative disease is present, is possible by applying the correct pharmacological therapy, along with diet and food supplementation often are critical factors for PD management [246]. Parkinson's disease psychosis (PDP) may affect up to $60 \%$ of patients with PD over the course of their disease, and is associated with poor prognosis, including increased risks of mortality and nursing home placement [247]. Current management strategies aim to provide symptomatic relief and to 
slow down the disease progression. However, no pharmacological breakthrough has been made to protect dopaminergic neurons and associated motor circuitry components [248]. To carry out MTM with PD patients, the pharmacist's expertise needs to transcend the technical knowledge about the PD pharmacological treatment. It has been estimated that the PD patients' adherence to the treatment is nearly $40 \%$, compromising the benefits of the therapy. MTM aims at optimizing the pharmacological therapy results, so the pharmacist monitors the results of the treatment prescribed by the doctor and elaborates a healthcare plan to guarantee the treatment's effectiveness, safety, and convenience, and therefore improve the patients' QoL [249]. During this time, pharmacists can serve as invaluable partners in the care of people with PD by assisting with complex medication schedules, addressing side effects, assisting with different formulations of medications, obtaining approval for medications on emergency release, ensuring appropriate intake to maximize the absorption of medications, suggesting and monitoring diet and supplementation and guiding the choice of medication based on patient preference, other concurrent medications and medical conditions, and affordability [250].

Exhibit 1: Pharmacists' contribution to PD detection and management [251]

- Observe or examine patients who present with or complain of parkinsonian symptoms (tremor, rigidity, bradykinesia, postural hypotension).

- $\quad$ Review medications to determine possibility of druginduced PD.

- $\quad$ Refer patients who present with PD symptoms to their family physician for an accurate diagnosis and further referral to neurologist.

- $\quad$ Provide written and verbal education to both patients and caregivers on the advantages and disadvantages of various antiparkinsonian medications.

- Develop therapeutic goals with patients with PD, caregivers and other members of the patient's health care team.

- Actively assess anti-parkinsonian medications for appropriateness, effectiveness, tolerability, safety and affordability based on clinical and lifestyle characteristics of the patient.

- Assess patient's adherence to anti-parkinsonian medications.

- Assist patients, caregivers and other members of the health care team with adjusting doses of anti-parkinsonian medications.

- Assist patients with appropriate dosing, administration and timing of anti-parkinsonian medications.

- $\quad$ Recognize real and potential drug-related problems related to anti-parkinsonian medications and use full scope of practice available in your jurisdiction to facilitate resolution of drug-related problems in collaboration with patients, caregivers and other members of the health care team (Figure 11).

\section{Epilepsy}

Medication nonadherence directly contributes to poor seizure control. A lack of emphasis on correcting poor adherence and failures in patient adherence can result in unwarranted alterations to a patient's drug regimen [252]. Timely recognition and effective early therapy with first- and second-line antiepileptic drugs (AEDs) may avert unnecessary hospitalizations. Seizures should be recognized and addressed like any other symptom that causes discomfort or reduces QoL. Use of alternative AED administration routes (buccal, intranasal, or subcutaneous) may offer possibilities for effective and individualized AED therapy, even during the last days of life. In hospice or home care, however, also IV treatment is possible via vascular access devices for long-term use. Aggressive unlimited ICU treatment of refractory status epilepticus (SE) in palliative patients is mostly not indicated [253]. There are three types of non-compliance: (i) in medication; (ii) in dietary/exercise; and (iii) in an appointment. First, non-adherence in medication defined as a non-adherence which includes failure to have the prescription dispensed or renewed, the omission of doses, errors of dosage, incorrect administration, errors in the time or frequency of administration, and premature discontinuation of the drug regimen. Second, a non-adherence in dietary/exercise occurs if the patient fails to follow the diet and exercise recommendations. Last, a non-adherence in an appointment occurs if the patient fails to come at clinics for the scheduled check-up [254]. Routine assessment of adherence barriers is imperative from toddlerhood to young adulthood given that the prevalence of barriers and their relative influence on important health outcomes vary by developmental stage [255] (Figure 12).

Therapeutic drug monitoring for AEDs is commonly used to help guide and assist clinicians with optimal dosing in patients. Monitoring serum concentrations can allow clinicians to achieve seizure control while minimizing adverse effects. Established drug levels for various AEDs should be primarily viewed as reference ranges and not therapeutic levels. Pharmacists can play a significant role in optimizing therapy for patients with epilepsy. Patient counseling on the potential adverse effects of AEDs is important. Pharmacists involved in the review of prescriptions were able to prevent errors in dose and frequency of administration of AEDs. Patients and family members should be educated on expected CNS and cognitive side effects, potential skin reactions, and the risk for suicidal behavior. Patient education should also address the significance of medication adherence. Patient medication profiles should be investigated for possible drug interactions, and dosage adjustments or alternative agents should be endorsed if necessary. Additionally, pharmacists can advise clinicians on appropriate therapeutic drug monitoring. The development of instruments to guide the care of epileptic patients, such as algorithms and protocols, could assist with the exertion of relevant and effective methods of patient assessment and would also encourage the pharmacotherapeutic monitoring of epileptic patients through pharmaceutical care [257-261]. 


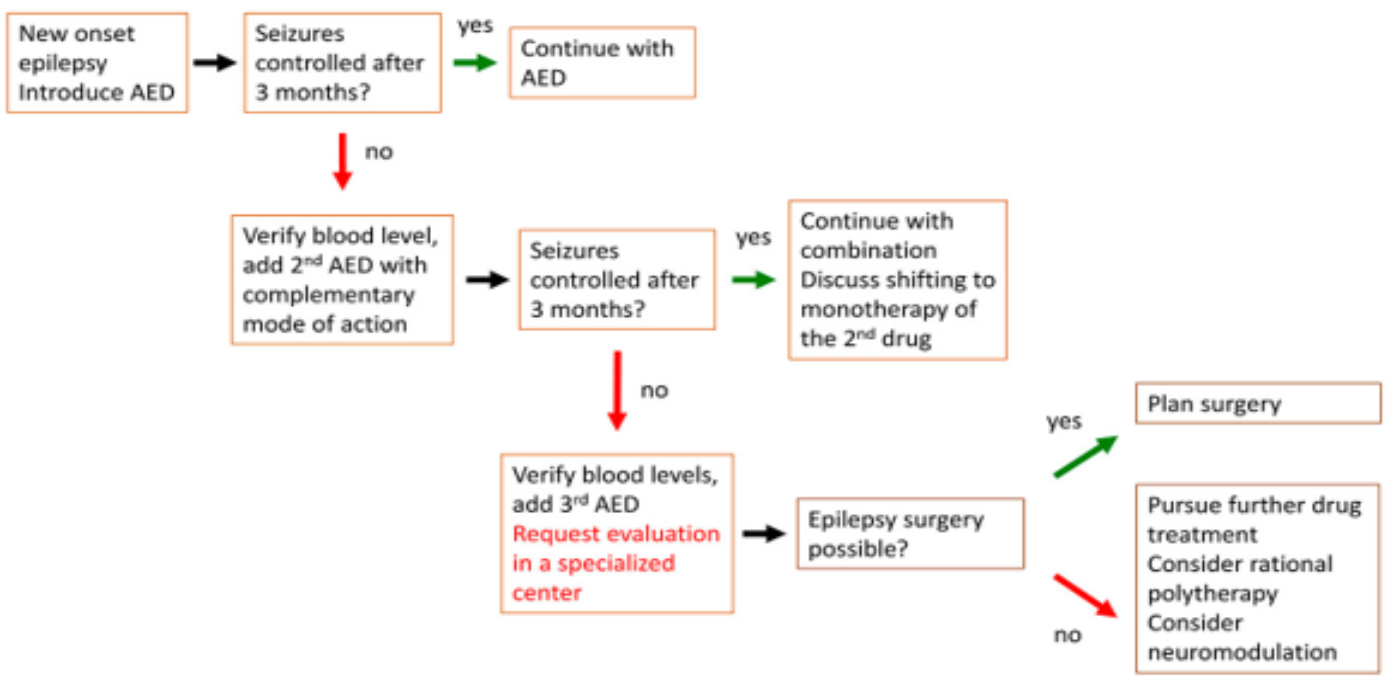

Figure 12: Practical approach to modern epilepsy care [256]. Risk of seizure recurrence can be significantly reduced by $30-40 \%$ when treatment is immediately introduced once epilepsy is diagnosed. The reduction is effective for the first 2 years. However, long-term outcome is not affected, and in the UK study around $75 \%$ were seizure-free at 2 years, no matter whether treatment was delayed until after the second or third seizure or not. Overall, if patients' relapse, $90 \%$ do so within the first 2 years.

\section{Fibromyalgia}

Fibromyalgia (FM) is an idiopathic chronic condition that causes comprehensive musculoskeletal pain, hyperalgesia and allodynia, afflicting $2.10 \%$ (a total of $4 \%$ female and $2-5 \%$ male) of the world's population, $2.3 \%$ of the European population, $2.4 \%$ of the Spanish population [262,263]. In France, work productivity loss accorded almost $90 \%$ of the total costs incurred by patients with FM, with an economic cost of 13000 million euros yearly which is around $\$ 100$ billion in US [262], [264,265]. Work disability was found to be $35 \%$ in US and Australia and 30\% reported in Canada due to FM [266]. FM is more common in female compared to male, with a ratio of $2: 1$ [267] or 3:1 [268], although other studies reveal 85\%-90\% FM patients are middle aged women [269,270]. 30-50\% of FM patients have anxiety and/or depression at the time of investigation [271], while patients have a lifetime history of depression (50-75\%) [272] and depressive disorders (13\%-63.8\%) [273]. Physical complications of FM are indicated in (Figure 13).

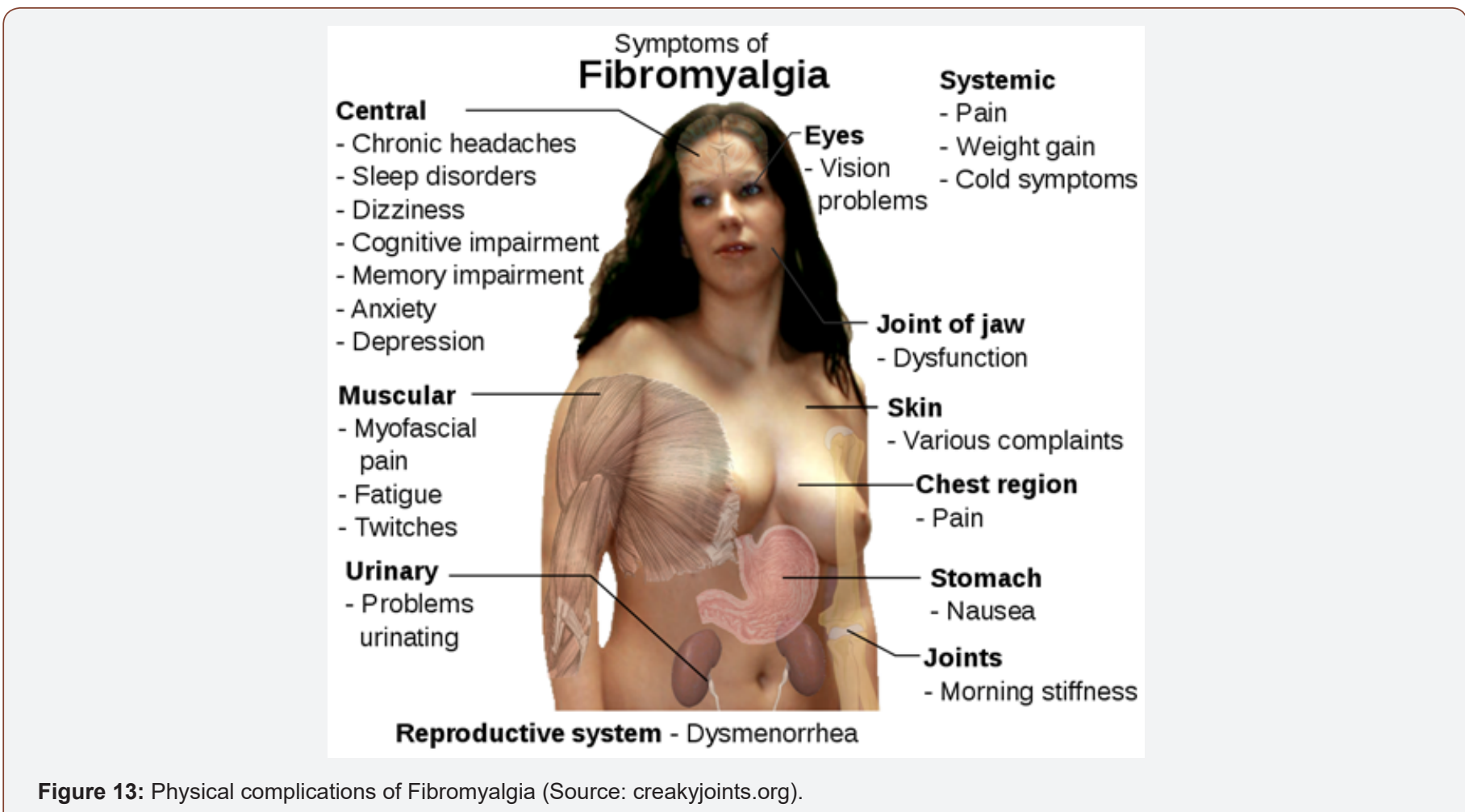

The APS guidelines cite strong evidence supporting the use of TCAs and moderate evidence for serotonin and norepinephrine reuptake inhibitors (SNRIs), fluoxetine, tramadol, and pregabalin [274]. A nearly 70\% German FM patients used thermal baths, 
$35.2 \%$ use alternative therapeutics such as homeopathy, dietary supplements, and $18.4 \%$ use introspective or meditation-based exercises such as yoga or Tai chi [275]. Low FODMAP was found be compelling in QOL, quality of sleep, anxiety and depression and inflammatory biomarkers in FM patients [276-281]. Cognitive behavioral therapy (CBT) interventions may slow or reverse cortical gray matter atrophy, diminishes circulating proinflammatory cytokines (IL-6, IL-8, and TNF- $\alpha$ level) of FM patients, pain symptoms and pain perceptions, helps FM patient having fear of pain, anxiety, depression and sleep disturbances [282-287]. Physiotherapy and acupuncture, both are compelling, not found to be more beneficial than each other, longer post-treatment follow-up may help arbitrate the superior treatment option [288]. Low to moderate intensity endurance and strength training are strongly suggested in FM patients. Strength training alleviates pain, fatigue, number of tender points, depression, and anxiety, with increased functional capacity and QoL. Exercise activates the endogenous opioid and adrenergic systems but does not consistently alleviate pain in FM patients [264], [275]. Pharmacists can participate in ongoing follow-up to monitor patients' responses to both pharmacologic and nonpharmacologic intercession. The assessment should consider both the impact on symptoms of FM and on the patient's function. If patients do not achieve a satisfactory treatment response or experience intolerable adverse events, pharmacists can collaborate with other members of the healthcare team to arbitrate whether a trial of another medication would be appropriate. Because emerging evidence indicates FM has many possible root causes, lack of treatment response to one medication does not affect whether another medication will be effective. Pharmacists can assess and triage patients who present to the pharmacy with a history of symptoms that are associated with FM $[289,290]$ (Figure 14).

\section{Management of Fibromyalgia}

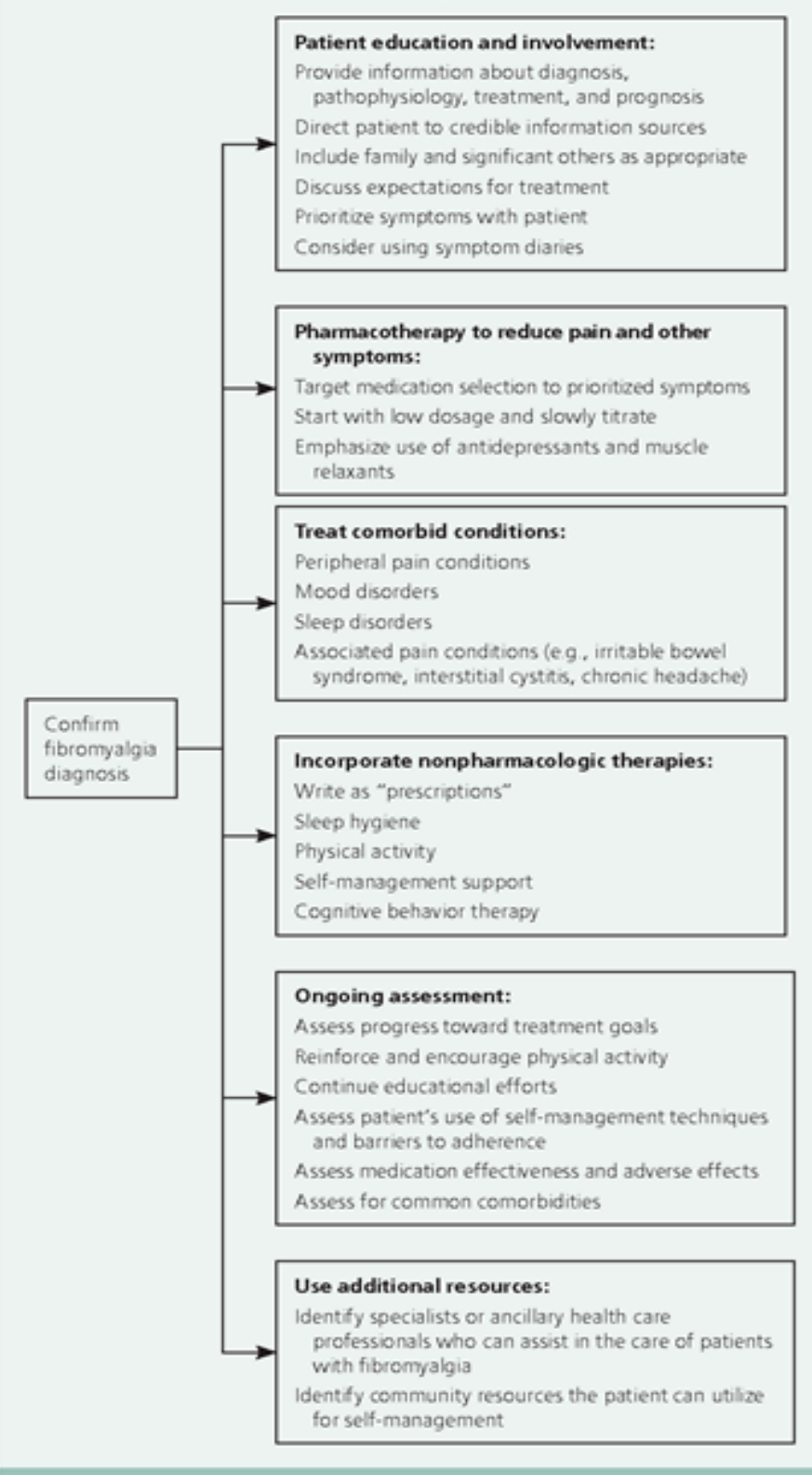

Figure 14: An integrated approach for FM management [291]. 


\section{Recurrent Urinary Tract Infections}

Between $50 \%$ and $60 \%$ of adult women will face at least one UTI event in their life, and close to $10 \%$ of postmenopausal women indicate that they had a UTI in the previous year, according to Medina et.al, 2019 [292]. Recurrent UTIs (RUTIs) are mainly precipitated by reinfection of the same pathogen mostly caused by frequent sexual intercourse, heterosexual anal intercourse (without circumcision and a condom), different sexual partners (Each sex partner shares his/her UGT microbiota with the other), utilization of spermicide and another sexual partner, sexual intercourse with addicted partners, sexual intercourse with sex workers, sexual intercourse with online dating friends, sexual intercourse with another sex partner for 2 months. [293-303]. Many other factors have been thought to predispose women to RUTIs, such as voiding patterns pre- and post-coitus, wiping technique, wearing tight undergarments, deferred voiding habits and vaginal douching; nevertheless, there has been no proven association [304]. Obesity was found to be associated with RUTIs in premenopausal women [305]. Several other risk factors are associated with cystitis, a prior UTI, vaginal infection, diabetes, and genetic susceptibility [306]. Pathogens responsible most commonly are Escherichia coli, Klebsiella pneumoniae, Proteus mirabilis, Enterococcus faecalis and Staphylococcus saprophyticus [293], [306-310]. The role of dietary pattern in RUTI is also not clear. Increasing fluid consumption is often recommended for patients with UTI [301], [307-314] but there has been no clear clinical evidence to support this recommendation [315]. After a first episode of a UTI, $27 \%$ of women have a confirmed recurrence within the next 6 months [292]. Although there have been few studies on the determent of
RUTIs without use of antibiotics within the past years, interest probiotics has increased over the years. Reviews by Akgül et.al, 2018 concluded that evidence of probiotic appliance in UTIs is not yet sufficient to recommend use of probiotics [316]. Different vaccines based on the whole cells (killed or live-attenuated vaccines) and antigens (subunits, toxins and conjugated vaccines) have been evaluated against UTIs pathogens, as reported by Asadi et.al, 2019 [317]. Substantial efforts have been expended in development of endogenous antimicrobial peptides (AMPs) as new therapeutic options suitable in the treatment of drug-resistant microbial infections. For example, Wnorowska et.al, 2019 reported that combination of natural peptide LL-37 with synthetic analogs might be a potential solution to treat UTIs caused by drug-resistant bacteria [318]. UTI is one of the most prevalent diseases with diverse etiological agents annually affecting 250 million and causes death of 150 million people overall. Financial burden of UTIs exceeds $\$ 3.5$ billion in US alone, while over half of the anti-infection agents prescribed for a suspected UTI in older adults being considered unnecessary. Surprisingly, nosocomial UTIs account for nearly $40 \%$ of all hospital acquired infections and around half of UTI in children are missed. Sexual intercourse $\geq 3$ times/week was associated with greater frequency of UTIs. Close proximity of the urethral meatus to the anus and shorter urethra, is a likely factor in women (Figure 15). Genital hygiene practices such as urination after and washing genitals after intercourse, male partner washing genitals before intercourse, taking baths, frequent replacing of underwear, controlled frequency of sexual intercourse, and washing genitals from front to back were associated with a reduced frequency of UTIs [319-322](Figure 15).

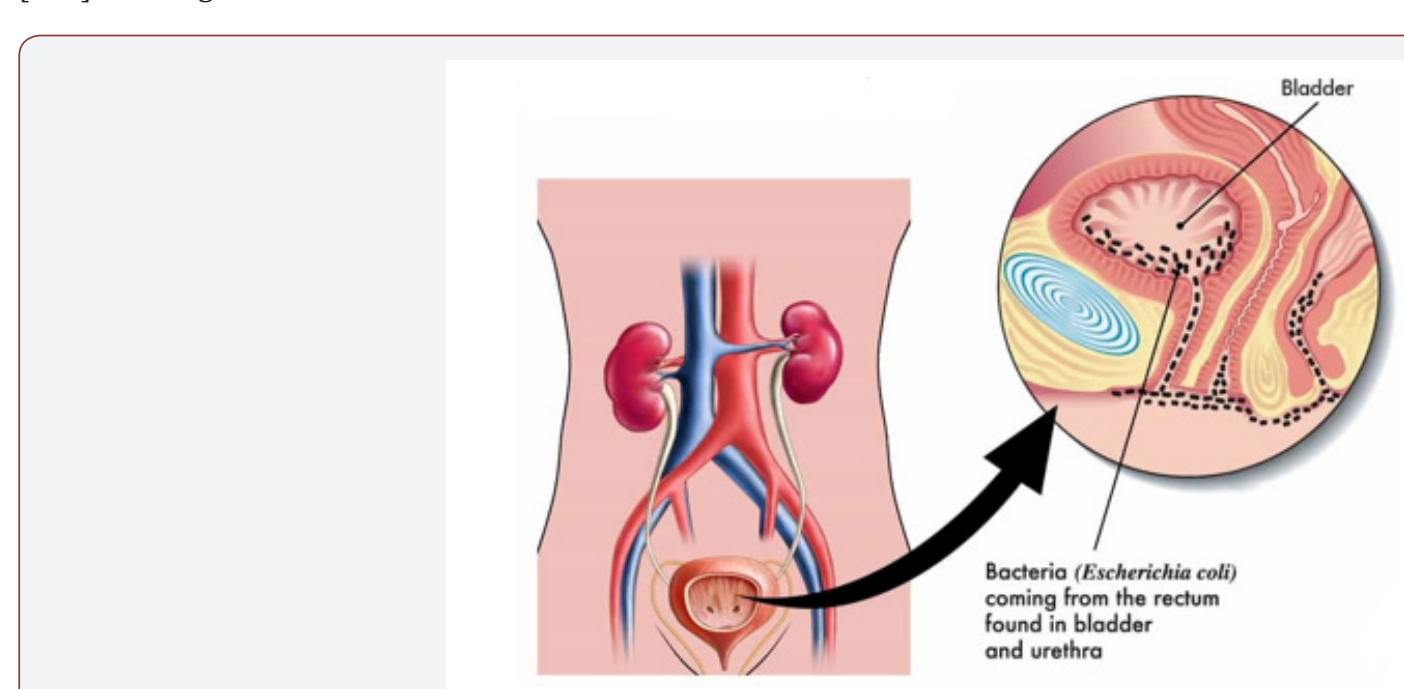

Figure 15: Bacterial spreads to the urinary bladder due to close proximity to anus, causing inflammation (Source: fabHow).

Pharmacist management of uncomplicated UTI is effective, safe, and patient satisfaction appears very high. In Quebec, pharmacists can prescribe for UTI in women if there has been an interpretation of UTI and a resulting prescription to treat it in the past year. In Saskatchewan, prescribing for UTI in women has been suggested, but is not yet approved. And in Alberta, pharmacists who have Additional Prescribing Authorization are able to prescribe for UTI if it is within their scope of practice and if, through their own estimate or collaboratively with another health professional, it is determined that treatment is appropriate. If a patient has been prescribed an antibiotic for a presumed UTI, the pharmacist should also apprise here to confirm the aptness of treatment. Patients should be asked about symptoms such as dysuria, frequency, urgency, suprapubic pain, flank pain or tenderness, fever, or hematuria in non-catheterized patients. In catheterized patients, symptoms suggestive of UTI include fever, rigors, flank pain or 
tenderness, acute hematuria, purulent discharge from catheter site and new or deteriorated mental status (in the presence of leukocytosis) with no attributable alternative cause. In cases of complicated UTI or pyelonephritis, a urine culture should always be sent. Pharmacists who are unable to order urine cultures should advocate for or make advises to have them done when they are pertinent and should discourage the sending of urine cultures when they are not indicated. Pharmacists should also familiarize themselves with the local antibiogram, as this will assist in the selection of empiric therapy. They should keep in mind, however, that resistance rates portrayed in hospital antibiograms may not be representative of the expected resistance patterns of uncomplicated infections, as these antibiograms are often heavily influenced by patients with complicated and nosocomial infections, which tend to be more resistant in nature. Medically underserved populations pose a unique challenge for providing effective patient education, compared with the general population. Patient adherence to provider recommendations is key to achieving therapeutic success. Also, as there are many modifiable risk factors for developing UTIs, it is important to effectively communicate these factors to patients to prevent recurrence and subsequent readmissions. As pharmacists already play a key role in medication counseling prior to hospital discharge, this presents an opportunity to incorporate patient education on infection management and prevention by pharmacists as part of ASPs [323-325] (Figure 16).

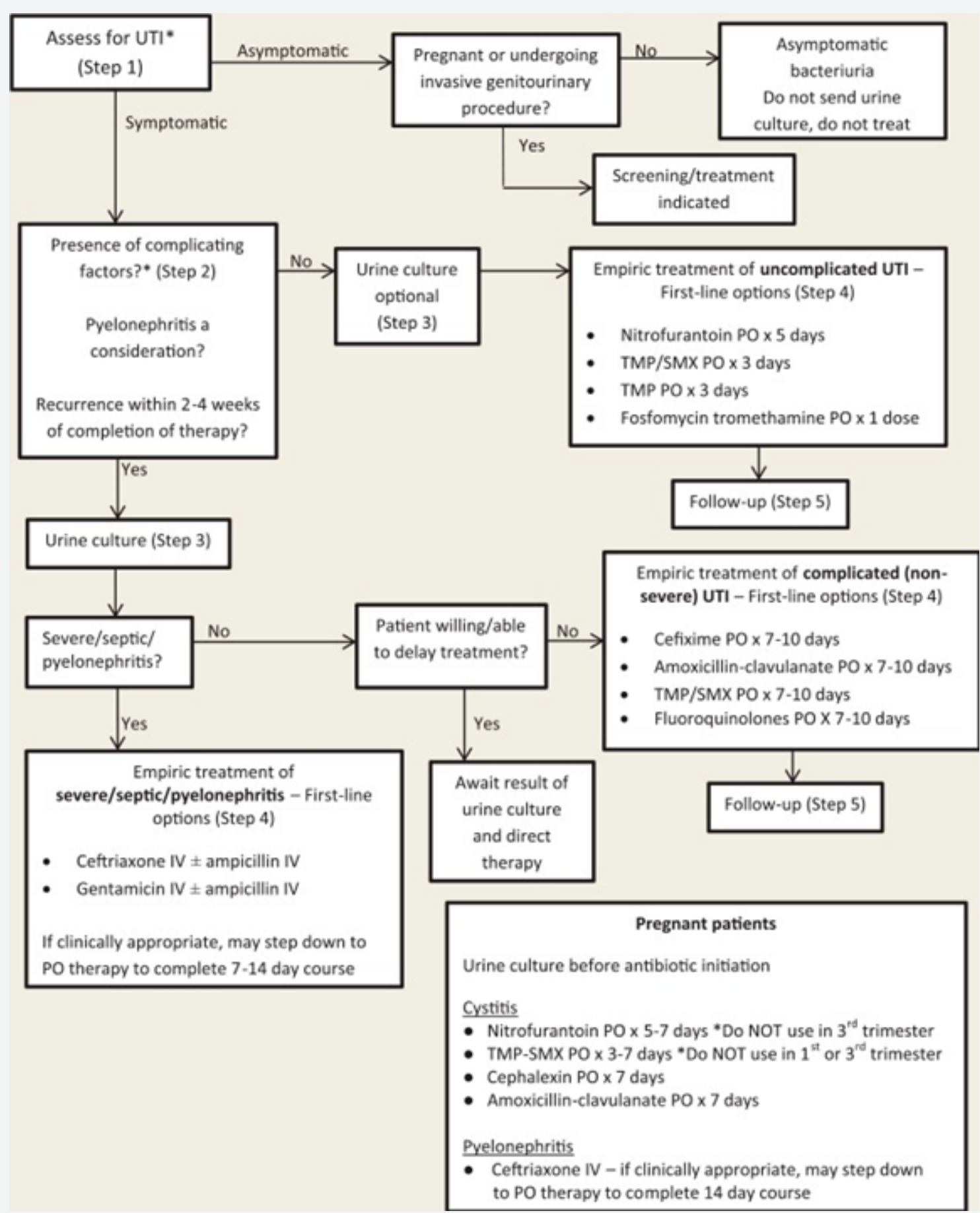

Figure 16: Proposed algorithm for assessment and management of urinary tract infection by Beahm et.al, 2017 [323]. 


\section{Renal Failure}

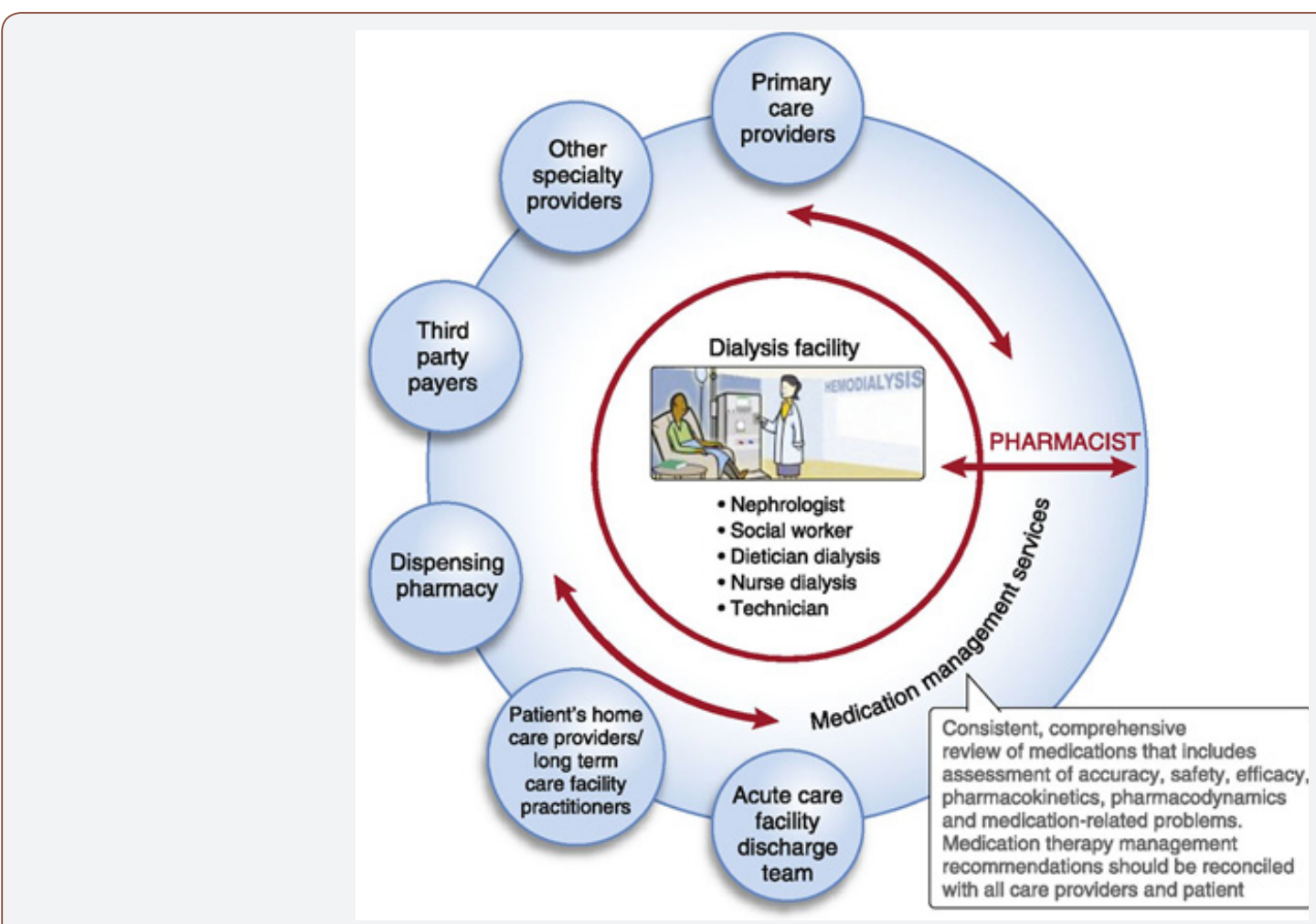

Figure 17: Dialysis facility-centered medication management services model [340]. In this model of care delivery, a pharmacist can provide crosscutting medication management services by communicating bidirectionally between the dialysis unit team and the patient's care providers, family, and payers, closing the loop of communication, improving medication list accuracy, and identifying and resolving MRPs. The pharmacist in this model could function like a consultant, providing medication management services to patients in several dialysis units.

Kidney disease is a global public health problem, affecting over 750 million persons worldwide [326]. Over 30 million American adults may have CKD [327] and 1.8 million in UK [328]. The global estimated prevalence of CKD is $13.4 \%$ (11.7-15.1\%), and patients with ESRD needing renal replacement therapy is estimated between 4.902 and 7.083 million [329]. In 1990, renal failure was considered as the 27 th mortality factor in the world and reached the 18th rank in 2010. According to the Centers for Disease Control and Prevention, in 2014, more than $20 \%$ of people with serious hypertension suffered from chronic kidney disease and were at risk for ESRD. On the other hand, hypertension is present in over $90 \%$ of individuals with advanced kidney disease [327], [330]. In all developed countries and in many developing countries, diabetes and hypertension are considered as the main cause of CKD. Dialysis remains the most commonly employed treatment option for patients with ESRD because not all patients are medically suitable for kidney transplantation, and the demand for kidneys far exceeds the supply. The total cost of dialysis is mostly composed of the costs of the treatment itself (including disposables, machines, accommodation, electricity, water and human resources) and the costs of medications, transportation, complications, additional hospital admissions and interventions [331]. Total annual cost of CKD far exceeds $\$ 5$ billion in Korea [332], \$114 billion in US [327] and Canada $\$ 40$ billion [333]. The prevalence of CKD and ESRD is projected to rise by up to $80 \%$ by 2020 due to ageing population and the rising prevalence of diabetes in Australia [334]. Multidisciplinary healthcare teams of physicians, nurses, dieticians, and clinical pharmacists share the goal of disease aversion progression and managing comorbid conditions in CKD and ESRD patients. At the initial appointment, the patient meets with all team members for a need estimate. The pharmacist obtains the patient's medication and allergy histories. The pharmacist also educates the patient about the importance of medication management in chronic kidney disease, adherence to drug regimens, and the potential risks of nephrotoxic medications. At subsequent visits, the patient is seen by specific team members, as appropriate to the person's laboratory results or as requested by the patient or other team members. As specialists in pharmacotherapy, clinical pharmacists are routinely involved in patient care and interact with other health care professionals, addressing multiple, often unmet needs for pharmacotherapy optimization. Ideally, this happens through a preventive, rather than a reactive, approach [335]. The pharmacist continually assesses drug therapy for efficacy and adverse effects, using laboratory results, the results of physical examinations performed during clinic visits, and information obtained during phone conversations with the patient. The main areas of focus for the CKD pharmacist are management of anemia, monitoring for hypertension, reduction of cardiovascular risk, adjustment of doses, and recommendations relating to medications that are eliminated renally. Drug coverage and supply issues involve communication with community pharmacists and the office of the provincial health plan. The CKD pharmacist deals with drug information requests from team members and other health care providers. Management of inventory and reporting (to the public 
health department) of vaccinations performed in the clinic are also the pharmacist's responsibility. Other members of the team participate in the patient education classes, which are offered throughout the year to provide patients with self-management information [336]. One large cross-sectional study observed associations between uncontrolled hypertension and CKD patients with greater medication nonadherence. An earlier study reveals that clinical pharmacists' interventions reduced DRPs, gaps between clinical interventions and hospital admissions, length of hospital stays, number of transplant rejections, improved outcome of renal function and incidence of ESRD or death [337-339] (Figure 17).

\section{HIV/AIDS}

There are nearly 40 million HIV-positive people in the world, while the developing countries contain $95 \%$ of them. It is estimated that 14 thousand individuals are being infected with the HIV each day worldwide and more than 30 million people have lost their lives because of the AIDS, since the first HIV positive patient was identified. Whilst AIDS-related deaths and total new infections have fallen by $34 \%$ and $18 \%$, respectively, since 2010 , worldwide new infections in 2016 and 2017 have remained constant at 1.8 million cases, $10 \%$ of whom were children. About 2.1 million new HIV-positive cases were diagnosed in 2015 only [341,342]. South and Southeast Asia placed the third rank of the highest HIV/AIDS incidence after the states of sub-Saharan Africa and North Africa in 2012, as 3.9 million people were living with HIV and 270,000 people becoming newly [343]. Interestingly, HIV prevalence among prisoners has been reported to vary between different countries from 0\%-2\% in Australia to 2\% in America, 11\% in Latin American countries, $10 \%$ in the Middle East, and 20\% in African countries [344]. In China, men who have sex with men (MSM) transmission has surpassed both injection drug use and blood donors and has become the major HIV transmission route, rose from $44.3 \%$ in 2008 to $63.5 \%$ in 2012 and to $71.3 \%$ in 2015 in Nanjing [345]. Another study revealed that married Indian women who experience physical and sexual violence from husbands face a significantly increased risk of HIV infection as compared with women who are not thus abused [346]. However, the HIV epidemic has cost the global economy over half a trillion dollars so far in the 21st century (between 2000 and 2015), according to a new scientific study [347] (Figure 18).

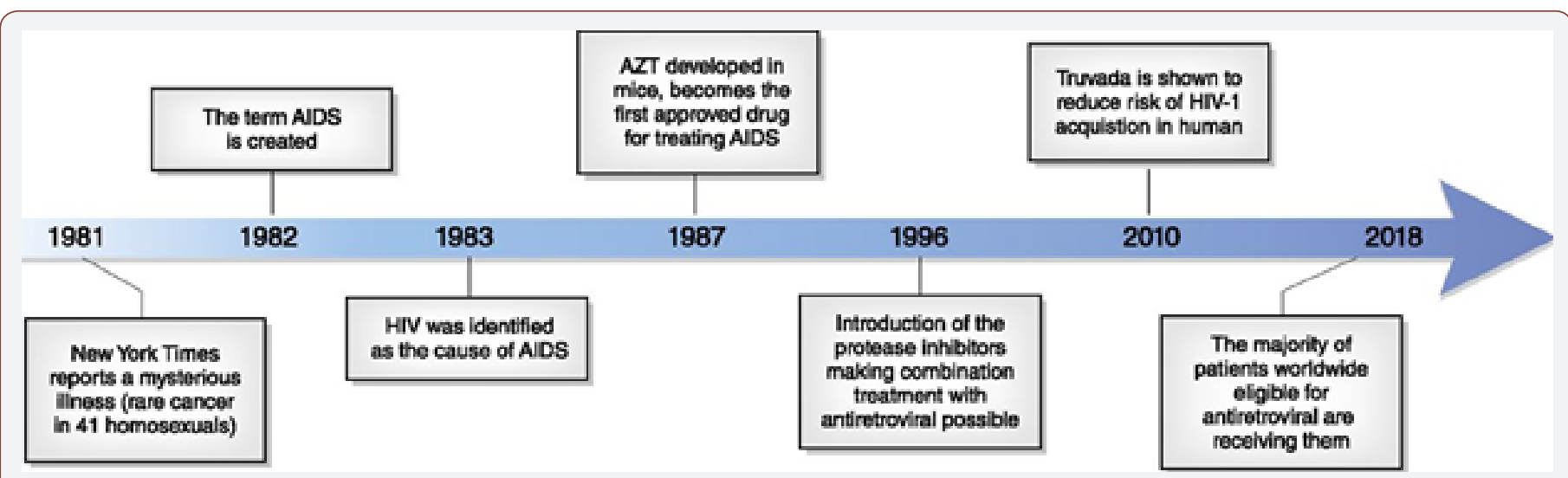

Figure 18: Diary of key sentinel timeline events from discovery to evolution of therapy of HIV-1. AZT, Zidovudine [348]. Ever since the first report by the New York Times on a mysterious illness in 1981 and the identification of HIV-1 as the cause of this illness in 1983, significant strides have been made in the treatment and management of HIV-1. Since the introduction of combination antiretroviral therapy in the mid1990s, there have been $>30$ agents approved for the treatment of HIV-1-positive individuals.

Exhibit 2: Guidelines for HIV Prevention \& Treatment [485]

HIV infection is diagnosed by tests for antibodies to HIV-1 and HIV-2. Antibody testing starts with a sensitive screening test such as enzyme-linked immunosorbent assay (ELISA). Reactive screening tests must be confirmed by a supplemental test, such as Western Blot, or by immunofluorescence assay. If confirmed by a supplemental test, a positive test indicates that a person is infected with HIV and is capable of transmitting the virus to others. HIV is detectable within 3 months after infection in at least $95 \%$ of patients. Although a negative antibody test result indicates that a patient is not infected, it cannot exclude the possibility of a recent infection. Patients with a new diagnosis should receive initial behavioral and psychosocial counseling on-site. Providers should be alert for medical or psychosocial conditions that might require immediate attention. Patients should be encouraged to notify their partners (including sex partners and needle sharing) and to refer them for counseling and testing. Needlestick injuries are fairly common occurrences in the health care field. Guidelines are available from the US Public Health Service for the management of occupational exposure to HIV, HBV, and HCV and recommendations for postexposure prophylaxis. These guidelines are updated regularly and include such topics as implementation of a bloodborne pathogen policy, treatment recommendations after needlestick injuries, monitoring for adverse effects, and laboratory testing to monitor for seroconversion. Health care providers should be knowledgeable about the symptoms and signs of acute retroviral syndrome, characterized by fever, malaise, lymphadenopathy, and skin rash, which occur within the first few weeks after HIV infection. This presentation occurs before the antibody test results become positive. Current guidelines suggest that patients with recently acquired HIV infection might benefit from antiretroviral drugs and may be candidates for clinical drug trials. Anyone with an acute 
HIV infection should be referred immediately to an appropriate HIV care provider. Once detection has been confirmed, this should prompt education efforts to reduce the spread of HIV to others. This includes counseling patients on high-risk behaviors (eg, sharing of intravenous needles, unprotected sexual behavior).

The core goals of management remain maximal suppression of viral replication and promotion of immune reconstitution through combination antiretroviral therapy (ART). In both the unadjusted and the adjusted analyses, patients with pharmacist-assisted ART management achieved more rapid viral suppression than patients managed without such assistance [349,350]. Secondary goals of therapy include promoting long-term adherence, avoiding drug interactions, minimizing toxic effects, simplifying treatment regimens, decreasing drug costs, managing comorbid conditions, and preventing transmission of HIV by achieving undetectable viral load. Pharmacists' involvement in the care of HIV-positive patients has been associated with improved patient outcomes, including enhanced, reduced pill burden and dosing frequency, greater increases in CD4 cell counts, higher rates of viral suppression, and decreases in medication errors [349]. Pharmacist involvement ensured identification, prevention, and solving of DRPs [351], increased CD4+ T-lymphocyte counts [352], reduced cost associated with medicine, doctor/hospital appointments, laboratory tests, and hospitalizations [353], reduced pill burden and dosing frequency
[354] and greater adherence to and persistence with ART adherence (early studies indicated $95 \%$ adherence was needed for viral suppression) [355]. In a US Department of Veterans Affairs Medical Center adherence study, the results demonstrated a $10 \%$ increase in adherence associated with a viral load decrease [356]. Pharmacist counseling of patients with HIV includes several key aspects: an evaluation to ensure appropriate dosage, patient administration counseling, ART adherence education, medication interactions, and possible adverse effect management. If lab data are available, monitoring of CD4+ cell counts, and HIV RNA viral load could also be reviewed [357]. One common reason patient cite for missing medication doses is forgetfulness. Reminder strategies such as pillboxes, calendars, or other medication planners can help improve adherence [358]. According to an analysis of the retrospective data, more than $50 \%$ of HIV-positive patients continued their regimens at home, and the remainder had provider support for not having a home regimen. A pharmacy resident or a student trained in medication reconciliation could be appointed with gathering patient information through insurance claims, outpatient pharmacies, and patient or caregiver interviews [359]. This visit gives pharmacists the opportunity to detect any problems in adherence and to suggest ways of managing adverse effects or other problems to patients before the drugs have to be discontinued (Figure 19).

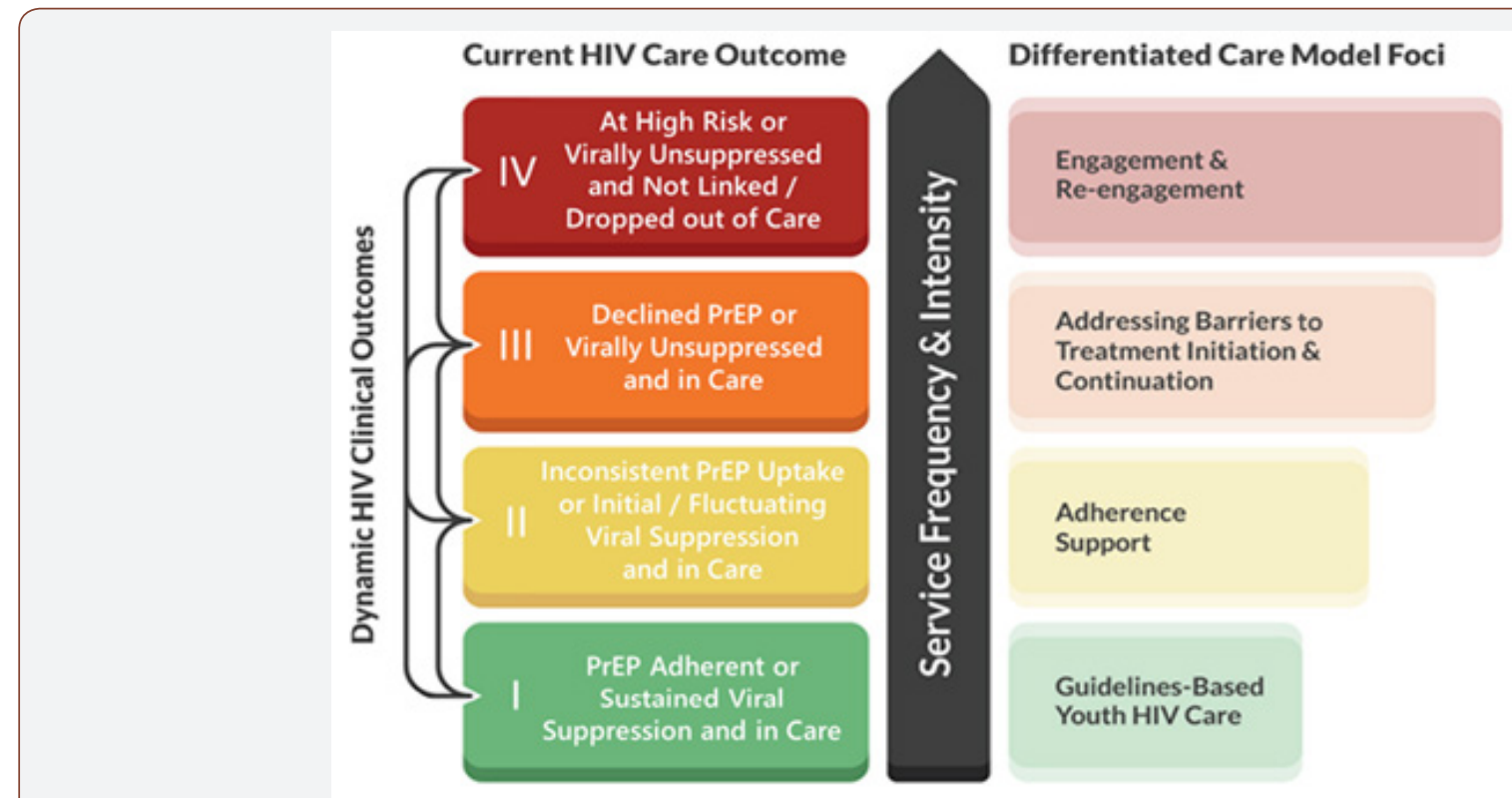

Figure 19: Integrated AYA-centered Framework for differentiated HIV prevention and Treatment Services [360]. Abbreviations: adolescents and young adults (AYA); Pre-Exposure Prophylaxis (PrEP).

\section{Cancer Care}

In 2019, 1,762,450 new cancer cases and 606,880 cancer deaths are projected to occur in the United States [361]. Globally, cancer is responsible for at least $20 \%$ of all mortality [362], 18.1 million new cancer, 9.5 million death in 2018 [363,364], the 5- year prevalence of 43.8 million [365], is predicted to rise by $61.4 \%$ to 27.5 million in 2040 [366]. Approximately $70 \%$ of deaths from cancer occur in LMICs [367]. Asia, Africa, and Latin America are collectively home to more than $50 \%$ of cancer patients; with more than half of global cancer-related mortalities occurring in Asia alone [368]. The 3 most prevalent cancers in 2019 are prostate, colorectal and skin melanoma among males, and breast, uterine corpus, and colorectal among females [369]. Overall cancer death rates declined faster in blacks than whites in US, although rates for cancers of the breast, uterine corpus, and pancreas are increasing in black people [370]. Also, black men have a 70\% higher prostate cancer and a more than 2-fold higher mortality rate compared with white men [371]. The 
cost of delivering cancer treatment is estimated to rise globally with a projected total spending of $\$ 458$ billion by 2030 [372]. However, the financial burden stems from employment loss, cost of care even when patients don't require chemotherapy, out of pocket costs' opportunity costs of informal care time and can continue long after the death of the patient [373,374]. Studies say 46 billion in productivity lost in major emerging economies due to cancer [375] and economic costs of tobacco-related cancers exceed USD 200 billion each year [376]. Also, cancer causes 2.6 times more likely to file for bankruptcy than the non-cancer people [377]. Cancer trends in young adults, reflect recent changes in carcinogenic exposures, which could foreshadow the future overall disease burden [378]. Cancer cachexia (anorexia, weight loss, loss of adipose tissue and skeletal muscle) is reported in $30 \%-80 \%$ cancer patients and causes $20 \%$ of all cancer deaths [379]. Worldwide, some $60 \%$ $80 \%$ people depend on alternative medicines [380-382], which is also true for nearly $40 \%$ to $70 \%$ European [383,384], 50\% Italian, $40 \%$ Korean, $30 \%$ British [385] and up to $87 \%$ of Australian cancer patients [386]. Use of unapproved/unlabeled/wrong herbal treatment is not uncommon $[387,388]$ and also drug interactions reported phyto-therapeutics in oncology [389]. So, proper and up-to-date knowledge is necessary in using alternative treatment options as patients who received alternative medicines had a 2.5 greater risk of dying compared to those who received conventional cancer treatment [390]. In oncology, a retrospective observational cohort study of a pharmacist-managed oral chemotherapy management clinic that provided services (including education on oral chemotherapy agents, concurrent medications, symptom management, and insurance assistance) to cancer patients for up to three months found that the program led to reductions in rates of adverse effects, non-adherence, drug interactions, and medication errors over time, as well as potential cost avoidance or cost savings [391]. Patients also appear to value pharmacist-led interventions in the oncology setting. Based on a survey of outpatients, $86 \%$ felt it important to discuss their initial treatment with a pharmacist, while $76 \%$ requested pharmacy follow-up at future visits; patients were interested in visiting a pharmacist regularly while receiving chemotherapy, and may be willing to pay for pharmacy counseling services [392]. However, inpatient clinical pharmacy services positively impact on patient care. An experienced cancer pharmacist possesses the specific knowledge about the medications used in the care of cancer patients and has been shown to obtain more accurate medication histories than doctors or nurses in the hospital setting [393]. In the UK, pharmacist independent prescribers can prescribe for any condition within their clinical competence including systemic anti-cancer therapy [394]. Greater training of pharmacists may lead to greater therapeutic interventions and interactions with patients regarding their treatment regimens. Pharmacist intervention aids completion of planned chemotherapy and management of treatment-related adverse events [395]. Ambulatory care clinical pharmacists are often responsible for managing comorbid conditions of patients with cancer. There are over 100 types of cancers, located in different organs and sub- tissues and originating from different cell types. Some cancer types (e.g., colon, breast, and non-Hodgkin's lymphoma) contain even more specific classifications based on their molecular subtypes. Despite this complexity and variability, most types of cancer are treated with the same generic therapies [396].

\section{Lung cancer}

American Cancer Society estimated that in 2018 lung and bronchus cancers would be responsible for 234,030 new cases which represent $14 \%$ of all new cancer cases and 1.5 million deaths [397]. Also, Global lung cancer deaths were estimated at 1.7 million in 2015 , contributing to approximately $20 \%$ of all cancer-related deaths. In 2004, lung cancer was associated with highest treatment cost at $\$ 4.2$ billion [398], which was $\$ 268$ billion in 2010 [399]. The overall economic impact of lung cancer in Europe is substantial, it was found more than €100 billion, when costs related to disability and premature mortality are considered as well [400]. Non-smallcell lung cancer (NSCLC) is the most common type of lung cancer, accounting for about $80 \%-85 \%$ of all cases [401,402]. More than half of the NSCLC cases are diagnosed at an advanced stage (stages III and IV) [403,404]. Smoking causes at least $80 \%$ of lung cancer deaths [405]. Lin et.al, 2019 concluded association between lung cancer incidence and increased reliance on coal for energy generation [406]. Other possible reasons are exposure to indoor and outdoor air pollution, exposure to radiation, and occupational exposure to agents such as asbestos, nickel, chromium, and arsenic [407]. India currently produces approximately 730 million $\mathrm{kg}$ of dry tobacco. Its use is associated with several types of cancers which are very common in LMICs contributing to $50 \%$ of all cancers in men and $20 \%$ in women. Globally, $90 \%$ of lung cancer deaths in men and $80 \%$ in women are attributable to smoking. By 2030, tobacco use is estimated to kill around 10 million people a year. The epicenter of this tobacco epidemic is LMICs with $70 \%$ of estimated deaths and $80 \%$ of the 1 billion smokers in the world coming from here [372] (Figure 20).

Chemotherapy remains the indispensable choice for the vast majority of patients with advanced NSCLC, including primary tumors and lung metastases. Use of the pulmonary route is a promising way to decrease the severe systemic toxicities associated with chemotherapy. Inhalation allows the administration of high drug doses directly to lung tumors without prior distribution in the organism [409]. Pharmacists are expected to assist patients with completion of adjuvant chemotherapy. A clinical trial directly comparing preoperative with postoperative chemotherapy for early-stage NSCLC demonstrated an attrition rate of $34 \%$ for postoperative chemotherapy within the protocol-defined window of 6 to 7 weeks owing to a wide range of complicating factors [410]. Pharmacist intervention aids completion of planned chemotherapy and management of treatment-related adverse events [395]. More than $80 \%$ lung cancer in UK are preventable. One-fifth of lung cancers occur in people who have never smoked. More than $90 \%$ of lung cancer cases are symptomatic at diagnosis, with a cough being most common. Pharmacists are ideally placed to detect 
early signs and symptoms of lung cancer, offer advice and refer people to a GP when appropriate. Pharmacists and pharmacy staff who have the opportunity to talk to patients about the signs and symptoms of lung cancer. With practical guidance, pharmacists can appropriately use immune checkpoint inhibitors for stage III NSCLC, educate patients and other clinicians about immunotherapy, and monitor and manage immune-mediated adverse events. Adding a specialist cancer pharmacist to the outpatient lung cancer team led to significant improvements in patient medication adherence. Both patients and GPs were highly satisfied with the service. Medication misadventure and clinic attendances were reduced [393], [411,412].

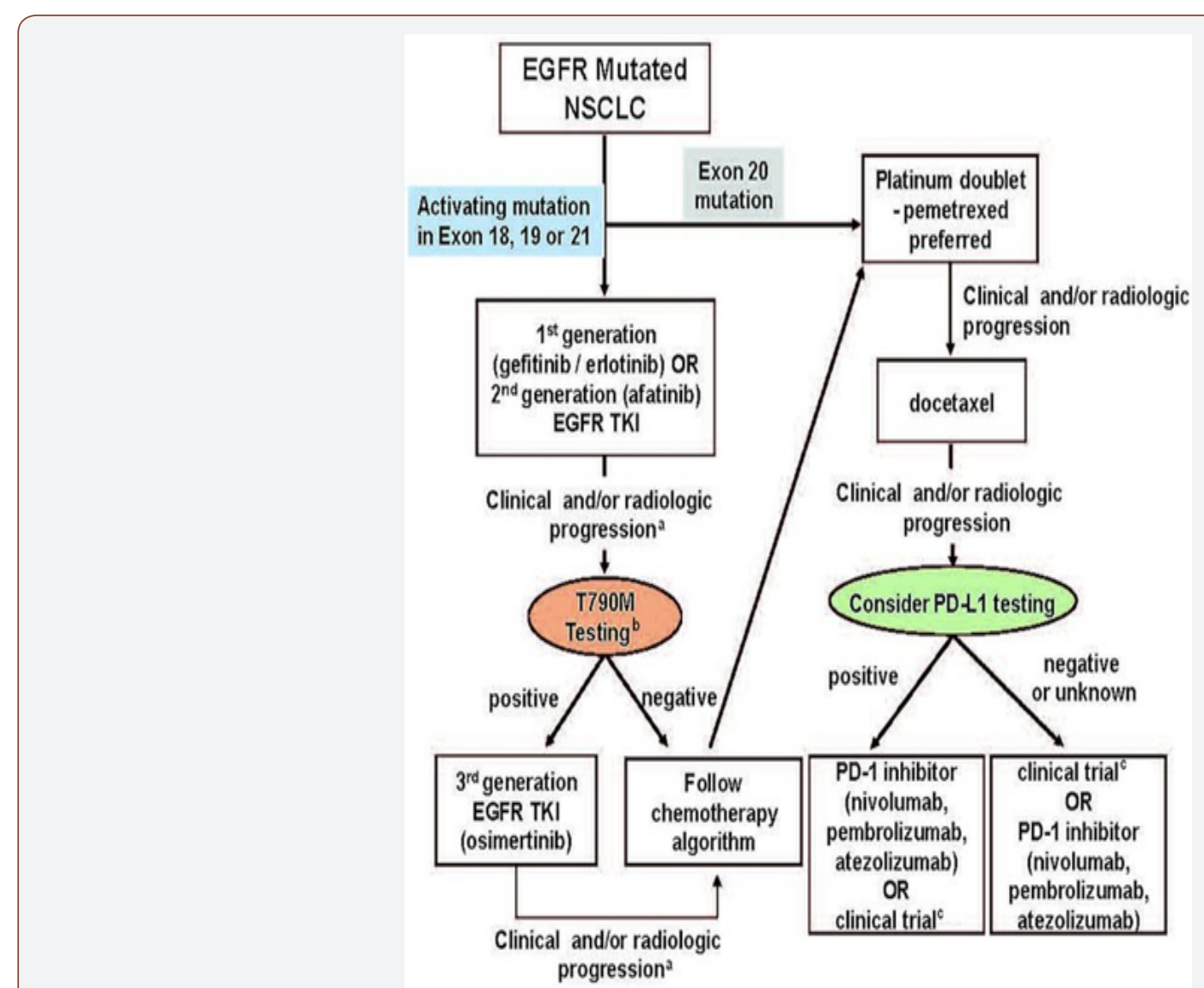

Figure 20: Algorithm for the management of EGFR-mutated NSCLC [408]. Molecular testing is recommended at multiple points along the treatment pathway for this patient population. Additional challenges arise because of the known benefits of treating oligometastatic disease, especially in the brain, and treating beyond classical radiologic progression. Clinical trials should be considered at all steps along the treatment path. (a) If oligo-progression (such as isolated brain metastasis) occurs, consider local therapy and continuation of tyrosine kinase inhibitor. (b) Re-biopsy currently required. Biopsy of growing lesion is recommended if possible. Testing can be performed on histology or cytology cell block. Consider testing plasma free DNA as an alternative if clinically available. (c) Clinical trials are preferred at all treatment steps, if available. EGFR = epidermal growth factor receptor; TKI = tyrosine kinase inhibitor.

\section{Leukemia}

Hematopoietic cancers constitute a diverse group of diseases including leukemias, lymphomas, plasma cell tumors, myelodysplastic syndromes, and mastocytosis. They arise primarily from two categories of immunological cell types, myeloid and lymphoid cells [413]. AML is the most common form of acute leukemia in adults, accounting for over $80 \%$ of all diagnosed acute leukemias [414,415]. Globally, between 1990 to 2018, the number of leukemia cases markedly increased from 297,000 to 437, 033 [416], accounting for close to 250,000 annual deaths due to AML worldwide [417]. Optimization of post-remission therapies to maintain complete remission and prevent relapse is a major challenge in treating patients with AML [418]. Children with Down syndrome have a 150 -fold increased risk of developing AML and 20 -fold increased risk of developing ALL [419]. The incidence of ALL is about 3.3 cases per 100,000 children [420]. Outcomes for patients with CML have substantially improved due to advances in drug development and rational treatment intervention strategies [421]. Allowed costs for leukemia patients averaged almost $\$ 157,000$ in the year after diagnosis, with costs for AML almost tripling that amount, according to a new report from the Leukemia \& Lymphoma Society (LLS) [422]. Malignant blood disorders cost $€ 12$ billion ( $\$ 13$ billion) in EU in 2012, with more than $60 \%$ of that amount spent on healthcare costs and nearly a third spent on drugs [423] (Figure 21).

The Leukemia/BMT Program's pharmacists have advanced specialty training in leukemia and bone marrow transplantation. They work directly with patients and the healthcare team, and are responsible for providing unbiased, patient-specific drug prescribing information and for identifying, preventing and resolving DRPs. They provide medication counseling when chemotherapy starts. While patients are on treatment, they check 
in periodically during a clinic visit (or hospitalization for inpatient chemotherapy) to answer any new medication-related questions or provide recommendations for symptom management. They can educate and counsel patients on chemotherapy and supportive-care medications both during their visit to the clinic or infusion center and after they head home. This entails reviewing home medications for potential drug-drug interactions, providing written materials detailing treatment regimens, and recommending options for nausea and pain management. Myeloma regimens, as an example of one condition for which multiple drugs are given on differing schedules, can be particularly complex. To ensure that patients are prepared to follow these regimens, pharmacists may work with nurses to create treatment calendars as visual aids [425]. The pharmacy team would ensure the NRT product is suitable for the patient based on their smoking status and lifestyle and continue to ensure the NRT product is suitable on dispensing. Research has indicated that non-adherence is a major contributing factor for treatment failure in patients with CML receiving imatinib, oncology pharmacists had a nearly $90 \%$ imatinib adherence rate compared to $65.8 \%$ in the usual care group [426].

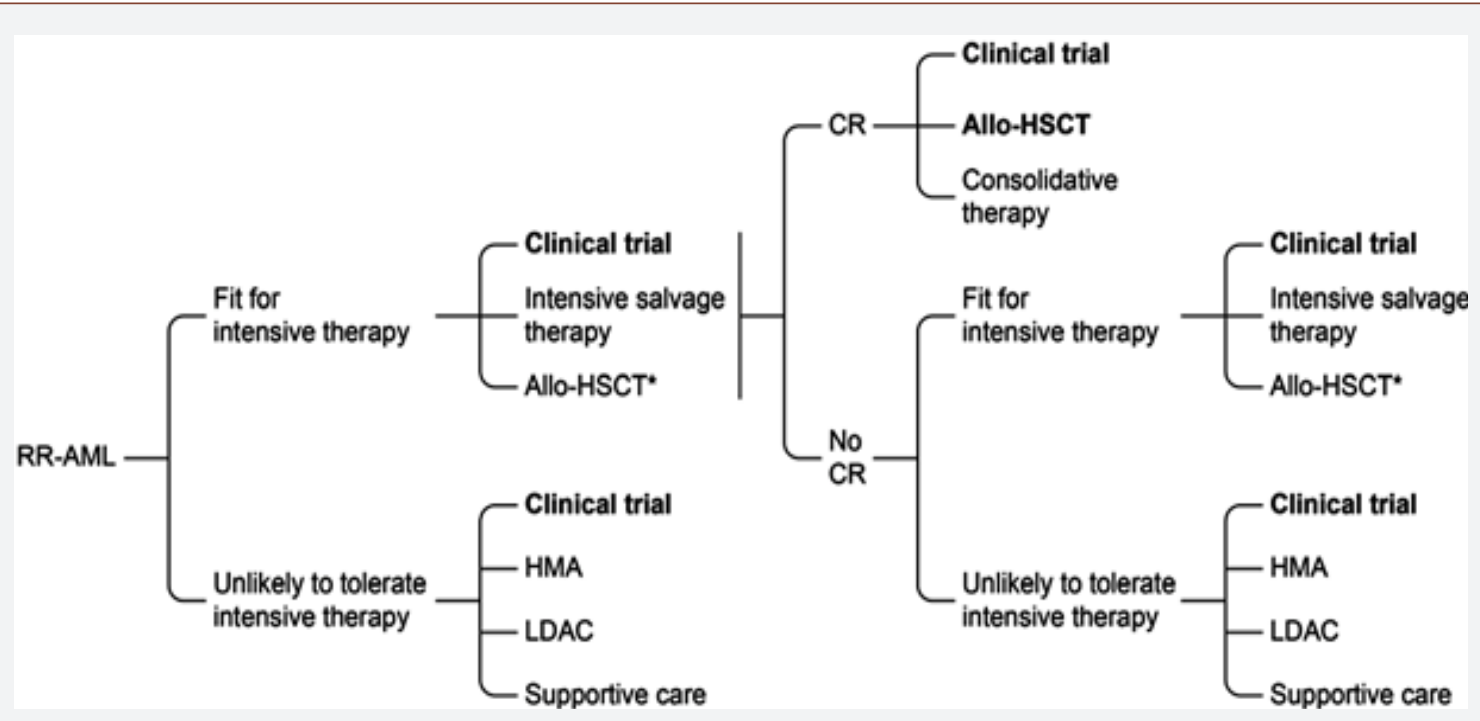

Figure 21: Treatment algorithm for patients with RR-AML [424]. There is no standard of care for the treatment of relapsed or refractory AML. A clinical trial is always the preferred option. The above algorithm is based on current clinical practice and will hopefully change in coming years due to improvements. In particular the targeted and immunotherapeutic agents detailed in this review may ultimately have utility in (1) initial therapy; (2) as a bridge to, or as a temporizing measure before, allo-HSCT; and/or (3) as part of consolidative therapy. * Achievement of a complete remission (CR) prior to undergoing alloHSCT is associated with best survival and is generally preferred. The survival of patients with residual disease undergoing alloHSCT varies considerably however and this therapy may be a reasonable option in selected patients not in CR. HMA: Hypomethylating agent. LDAC: Low-dose cytosine arabinoside. Allo-HSCT: Allogeneic Hematopoietic Stem Cell Transplant.

\section{Breast cancer}

The most common breast cancer type is the invasive ductal carcinoma accounting for $70-80 \%$ of all breast cancers diagnosed [427]. It starts in a milk passage (a duct), breaks through the wall of the duct and invades the tissue of the breast [428]. In US, 232,000 new cases of breast cancer were diagnosed [429] and claimed the lives of 40,290 women [430] in 2015. First-degree relatives of patients with breast cancer have a 2-fold to 3-fold excess risk for development of the disease [431]. BRCA1 and BRCA2 are the 2 most important genes responsible for increased breast cancer susceptibility [432]. Early breast cancer detection programs depend for effectiveness on the participation rate, which is affected by risk factor awareness [433]. Since 1990, between 384,000 and 614,500 breast cancer deaths have been averted due to increased mammography screening and improved treatment [434]. However, more than $25 \%$ breast cancer is projected to be increased by 2020 [435] (Figure 22).

All breast cancers arise in the terminal duct lobular units (the functional unit of the breast) of the collecting duct. The histological and molecular characteristics have important implications for therapy, and several classifications on the basis of molecular and histological characteristics have been developed. The histological subtypes described here (top right) are the most frequent subtypes of breast cancer; ductal carcinoma (now referred to as 'no special type' (NST)) and lobular carcinoma are the invasive lesions; their preinvasive counterparts are ductal carcinoma in situ and lobular carcinoma in situ (or lobular neoplasia), respectively. The intrinsic subtypes are based on a 50-gene expression signature (PAM50). The surrogate intrinsic subtypes are typically used clinically and are based on histology and immunohistochemistry expression of key proteins: estrogen receptor (ER), progesterone receptor (PR), human epidermal growth factor receptor 2 (HER2) and the proliferation marker Ki67. Tumors expressing ER and/or PR are termed 'hormone receptor-positive'; tumors not expressing ER, PR and HER2 are called 'triple-negative'. The relative placement of the boxes aligns with the characteristics (for example, proliferation and grade) in green. -, negative; +, positive. GES, gene expression signature. (a) ESR1 mutations induced by aromatase inhibitor targeted therapy. (b) Artefact; expression of normal breast components due to low tumor cellularity. 


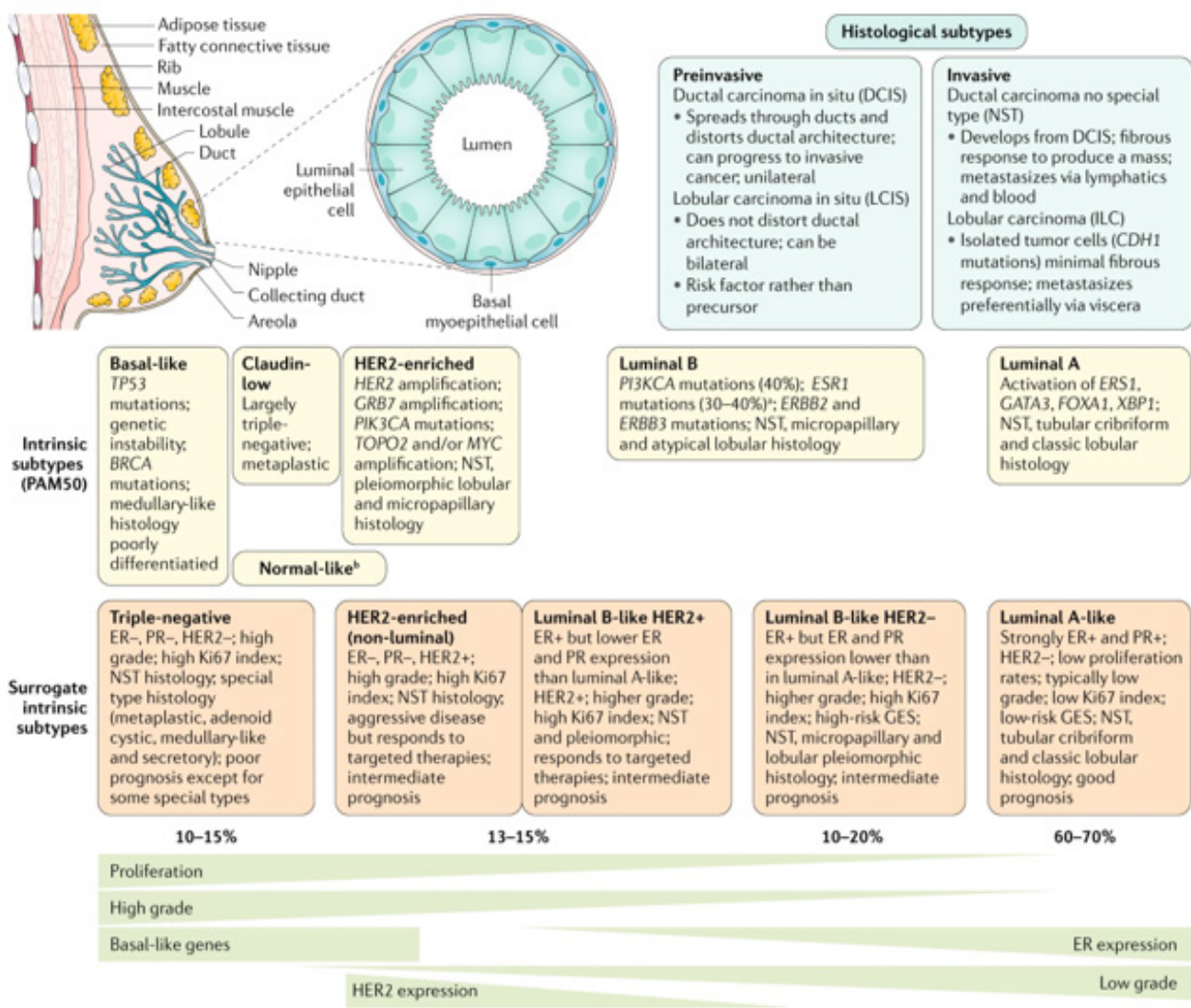

Figure 22: Breast Cancer Features [436]. All breast cancers arise in the terminal duct lobular units (the functional unit of the breast) of the collecting duct. The histological and molecular characteristics have important implications for therapy, and several classifications on the basis of molecular and histological characteristics have been developed. The histological subtypes described here (top right) are the most frequent subtypes of breast cancer; ductal carcinoma (now referred to as 'no special type' (NST)) and lobular carcinoma are the invasive lesions; their preinvasive counterparts are ductal carcinoma in situ and lobular carcinoma in situ (or lobular neoplasia), respectively. The intrinsic subtypes are based on a 50-gene expression signature (PAM50). The surrogate intrinsic subtypes are typically used clinically and are based on histology and immunohistochemistry expression of key proteins: estrogen receptor (ER), progesterone receptor (PR), human epidermal growth factor receptor 2 (HER2) and the proliferation marker Ki67. Tumors expressing ER and/or PR are termed 'hormone receptor-positive'; tumors not expressing ER, PR and HER2 are called 'triple-negative'. The relative placement of the boxes aligns with the characteristics (for example, proliferation and grade) in green. -, negative; +, positive. GES, gene expression signature. (a) ESR1 mutations induced by aromatase inhibitor targeted therapy. (b) Artefact; expression of normal breast components due of low tumor cellularity.

Women with breast cancer had a higher risk of developing new comorbidities than women without cancer [437]. stressful life [438], urban living, mastectomy [439], lower socioeconomic status [435], [440], genetic predisposition, African-American origin, not having children or breastfeeding, early menstruation/ late menopause, obesity, alcohol abuse, HRT after menopause, benign breast conditions or having breast proliferation, using contraceptives and exposure to diethylstilbestrol [441], age between 40-60, late age first pregnancy, smoking [442], abortion history [443] are the associated factors. Distressingly, the 5 -year cumulative mortality remains unacceptably high at $50 \%$, primarily due to a late-stage presentation [316]. Wearing bra is not associated with breast cancer risk [443] but wearing (tight) bras for many hours and having breast implants [442], [445] may have associations. Around $60 \%$ of breast cancer mortality occurs in LMICs [446]. Conflicting data exists about the influence of oral contraceptive pills (OCPs) on the development of breast cancer. There are clear benefits to the use of OCPs, including a reduction in ovarian cancer risk by $40 \%$ and reduction in endometrial cancer risk by $60 \%$. Due to evidence from the Women's Health Initiative, use of hormone replacement therapy is not recommended for patients to prevent the occurrence of breast cancer [447]. Yuan et.al, 2019 reported that medical and surgical abortion and less than 20 years IUD use could increase the risk of breast cancer for post-menopausal women [448]. The prevalence costs of breast cancer care in the US in 2010 was $\$ 16.5$ billion $[449,450]$ and exceeded $\$ 39$ billion before 2017 [451]. Pharmacists can improve chemotherapy breast cancer patients' QOL regarding malaise and nausea by providing personal counseling before the medical examinations. In addition to the attending physician and nurses, pharmacists can also partially alleviate malaise through active intervention that involves patient counseling and guidance [452]. It is worth mentioning that clinical pharmacists are well accepted as patient medication educator and psychological consultant. Wang et.al, 2015 reported reduced fatigue, the symptoms of nausea and vomiting, and pain as they followed clinical pharmacists' advice. Medication education and nonpharmacological intervention (e.g., cognitive behavioral interventions, relaxation interventions, and 
music therapy) by clinical pharmacists could effectively improve the quality of sleep and reduced cancer-related constipation and diarrhea of cancer patients [453]. Clinical pharmacist may observe all patients who receive active therapy and monitors the emergence and management of treatment-related toxicities through patient assessment and evaluation of laboratory results. During discussions with the patient, the clinical pharmacist may reinforce the importance of adhering to therapy as prescribed. This is especially important for patients who receive oral chemotherapy, which is self-administered so patients may have fewer clinic visits than those who receive IV treatment. Depending on the patient's needs, the clinical pharmacist may also work with other staff members, such as financial counselors or social workers, to optimize patient care. Similarly, clinical pharmacists confer with specialty pharmacists to ensure that insurance issues are resolved so that the patient receives timely access to treatment. In some cases, it may be necessary to switch therapies. When this occurs, clinical pharmacists leverage their specialized training to make treatment recommendations based on the patient's breast cancer subtype, extent of disease, treatment history, and performance status [454].

\section{Colorectal cancer}

Colorectal cancer (CRC) is the third most common cancer worldwide and the fourth most common cause of cancer death
[455]. It is the second leading cause of death in US, affecting some 135,000 estimated new patients with more than 50000 deaths every year [456-458]. In 2015, there were 376,000 new cases and 191,000 deaths in China [459]. The overall incidence of CRC is decreasing in many high-income countries, although reported significant increase in Denmark, New Zealand, Australia, UK and Canada, mainly driven by increases in distal (left) tumors of the colon and predominant in [460-467]. Lifestyle determines around $50 \%$ to $60 \%$ incident of CRC irrespective of age [468-471]. Physical activity may prevent approximately $15 \%$ of the colon cancers [472]. Fish, poultry, cheese, fruit, vegetables, tea and coffee were not associated with colorectal-cancer risk [473]. Alcohol consumption, red meat/processed meat, junk food, smoking, diabetes and obesity potentiate the same risk [474-477]. In 2018, the estimated national expenditure was $\$ 16.6$ billion in US, which was $\$ 4.5$ billion to $\$ 9.6$ billion in 2009 and projected to be more than $\$ 20$ in 2020 [478480]. There were over 1.8 million new cases in 2018. Hungary, North Korea, Slovakia, Norway, Denmark, Portugal, Japan are in the topranking positions [481]. 5-year survival for patients with stage IV CRC is less than $10 \%$ [482]. The overall risk of CRC among patients with ulcerative colitis is about ten times higher than that of the general population [483]. CRC patients have unique psychosocial needs (e.g., isolation, embarrassment) related to altered eating and bowel habits and sexual dysfunction that warrant clinical attention [484] (Figure 23).

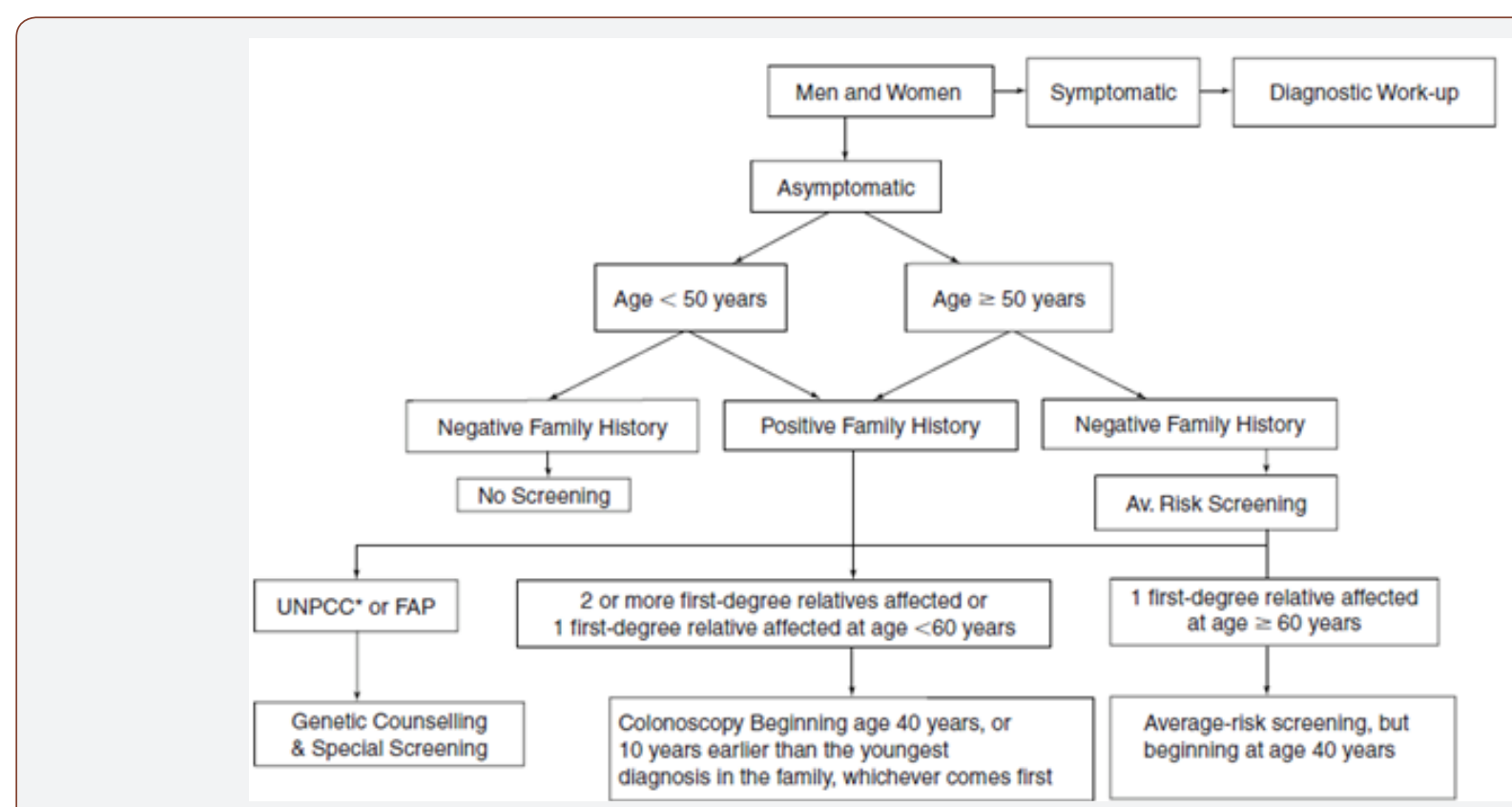

Figure 23: Algorithm for colorectal cancer screening [485]. +, Either colorectal cancer or adenomatous polyp; *, HNPCC = hereditary nonpolyposis colorectal cancer and FAP = familial adenomatous polyposis.

Multiple risk factors are associated with the development of this malignancy, including genetic susceptibility, environmental, and lifestyle. It has been suggested that diets high in fiber are protective against the development of colorectal cancer. Cho et.al, 2019 revealed that age, sex, family history of colorectal cancer, and education and additionally adjusted for the five modifiable risk factors (i.e., prior BMI, physical activity, dietary inflammatory index, smoking, and alcohol consumption) are CRC promoters [486]. The risk of colon cancer may be increased as much as twofold in men who are in the highest quintile of body size. Potential mechanisms to this relationship include the observation that physical activity stimulates bowel peristalsis, resulting in decreased bowel transit time, and the possibility that exercise can alter levels of blood glucose, insulin, and other hormones, which may reduce tumor cell growth. In the Physicians' Health Study, men with C-peptide in the top vs the bottom quintile had a 2.7 -fold significantly higher risk of 
colorectal cancer after control for BMI and exercise [487]. Heavy alcohol consumption increases risk of rectal and colon cancer by as much as two to three times, although some studies have found no significant increase in risk [488]. The strongest evidence-based screening recommendations include offering annual fecal occult blood testing (FOBT) or flexible sigmoidoscopy every 5 years. Each of these screening tests has been associated with reductions in mortality. Patients with a positive specimen should be followed up with colonoscopy. Flexible sigmoidoscopy reduced mortality by two-thirds for lesions within reach of the sigmoidoscope. Hypnosis, music and relaxing video reduced anxiety and pain associated with colonoscopy and need for sedation during colon cancer screening [489-497]. The pharmacist can help provide educational and financial resources and relieve any anxiety related to the screening process. Pharmacists have the ability to recommend colorectal cancer screening tips and tools to reduce risk. Pharmacists can also refer patients to qualified health care providers for follow-up care and act as a prescriber-patient liaison. Pharmacists can also play an essential role by reviewing the proper instructions for any colorectal screening preparation medications [498]. Pharmacists should be aware that there are differences in the guidelines with regards to method and frequency of colorectal cancer screening, but the accepted starting range for screening all adult patients at average risk is 50 years. Mass media campaigns have increased the awareness of the need for colon cancer screening, and counseling by pharmacists is a good way to help reinforce these recommendations. Additionally, pharmacists should be aware of patients displaying any of the colorectal cancer warning signs (eg, bleeding, changes in bowel habits, weight loss, abdominal pain) so that they can be referred to appropriate medical care and diagnostic work-up. Chemotherapy-induced diarrhea can negatively affect the QoL of patients and treatment process. A chemotherapeutic treatment for colon cancer consisting of fluorouracil and capecitabine is associated with $50 \%$, and irinotecan with $80 \%$ occurrence of diarrheal symptoms. Also, the clinical oncology pharmacist has an important role in the identification and resolution of DRPs. Evaluation of symptom-related quality of life is important for the monitoring of patients receiving chemotherapy [499].

\section{Prostate cancer}

Prostate cancer is the second most frequent malignancy (after lung cancer) in men worldwide, counting 1,276,106 new cases and causing 358,989 deaths $(3.8 \%$ of all deaths caused by cancer in men) in 2018. Based on GLOBOCAN 2018 estimates, 1,276,106 new cases of prostate cancer were reported worldwide in 2018, with higher prevalence in the developed countries [500,501]. In Europe, prostate cancer is now the most common cancer in men, accounting for $23 \%$ of all male cancers and $10 \%$ of cancer-related deaths in males in 2012 [502]. In the USA, the total estimated expenditure on prostate cancer was $\$ 9.9$ billion 2006 [503] and expected to be $\$ 39$ billion to more than $\$ 58$ billion in 2020 [504]. The incidence rate of prostate cancer increases dramatically after 55 years of age. Americans have a 5 -year survival approximately $15 \%$ less than whites, perhaps due to the combination of higher levels of testosterone compared to white males and increased androgen receptor activation. Obesity is associated with an increased risk of prostate cancer mortality and recurrence. Low-fat diets and other dietary considerations such as $\beta$-carotene, lycopene, and vitamin $\mathrm{E}$ may be protective, although these are still unproven [502]. Smoking has not been associated with an increased risk of prostate cancer, but smokers with prostate cancer have an increase in mortality $[505,506]$. Alcohol consumption does not appear to be associated with the development of prostate cancer $[507,508]$. Many patients with localized prostate cancer are asymptomatic, while those with more invasive disease develop symptoms of alterations in urinary frequency, hesitancy, and flow, and newonset impotence. There are several prostate cancer cell lines that form primary tumors but will not metastasize to bone [509]. Some nonspecific signs of more advanced disease include anemia and weight loss. The prostate specific antigen (PSA) test involves taking a simple blood sample and detecting the enzyme levels. While it is simple and readily available, it does generate false-positives and false-negatives and cannot be recommended alone as a screening tool. The American Cancer Society recommends digital rectal examination (DRE) and prostate specific antigen (PSA) be offered annually to men beginning at age 50 years with at least a 10year life expectancy, and to younger men (45 years old) who are considered to be at high risk for prostate cancer development (eg, those with a strong family history, African Americans) [510,511]. If both tests are normal, no further diagnostic work-up is required. If either is abnormal, further work-up by transrectal ultrasound is indicated. However, to transition to patient-centered care, pharmacy services should organize around the understanding of patients' needs, preferences, and expectations for the clinical judgment and decision-making processes. Pharmacist-patient communication is an important strategy for humanized practice. This allows the pharmacist to see beyond an individual with health problems to a patient being with particularized needs [512]. The initial management of newly diagnosed prostate cancer should consider the extended natural history of this malignancy and the risk of progression to more aggressive disease. Shared decisionmaking, the patient's life expectancy, and personal preferences play an increasing role in the choice of appropriate treatment options. Pharmacists may play an important role in consulting and educating patients about the screening tests, treatments, and related benefits and harms. Enhanced risk-classification methods and expanded treatment options allow pharmacists to counsel patients regarding therapy based on cancer prognosis and patient preference. Androgen deprivation therapy (ADT) remains the standard of care for newly diagnosed metastatic disease and an important option in the management of higher risk localized cancer. Pharmacists are well-equipped to provide patient counseling and management of complications of ADT [513]. Patel et.al, 2016 demonstrated maximized oral chemotherapy treatment outcomes with the addition of a formalized monitoring program directed by an oncology pharmacist [514]. Also, pharmacist led adherence program facilitated timely dose adjustments and high patient adherence [515]. Pharmacists can play active roles in the 
management of prostate cancer, particularly by assisting in the prevention and management of the side effects of hormone therapy and chemotherapy. Hormone therapy can be associated with various adverse effects, such as osteoporosis and hot flashes. Pharmacists can suggest therapies to manage hot flashes and promote the intake of adequate amounts of calcium and vitamin D to prevent osteoporosis. Common side effects of systemic chemotherapy, such as neutropenia and thrombocytopenia, can lead to dose reductions or treatment delays, if not managed properly. Pharmacists, using a variety of online resources can counsel patients and ensure the maximum cycles of chemotherapy can be administered [516,517] (Figure 24).

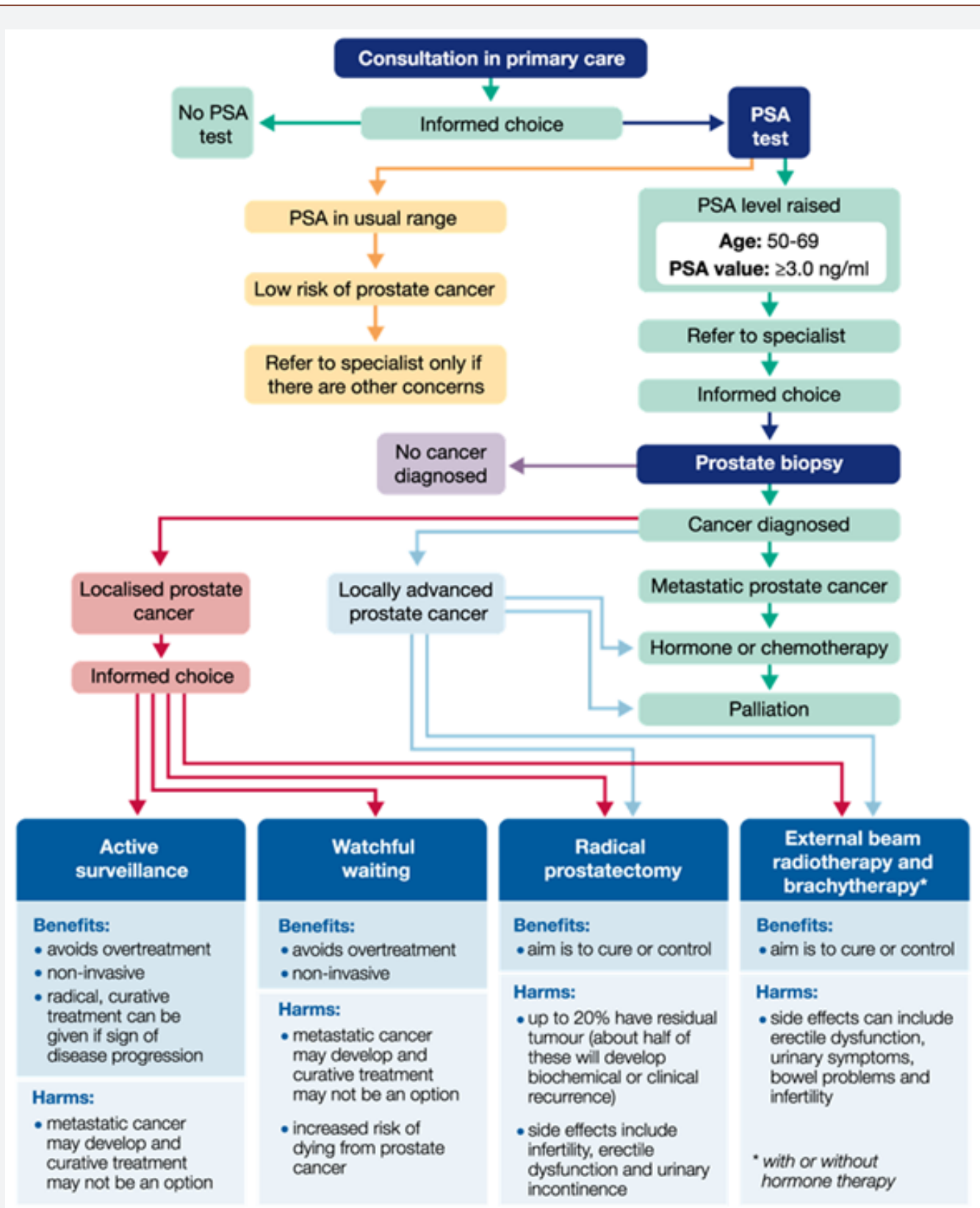

Figure 24: Prostate-specific antigen (PSA) testing and prostate cancer patient pathway [518]. Screening for prostate cancer is a highly debated topic due to limitations in the sensitivity and specificity of the PSA test, and also due to the potential harms of unnecessary investigations. In the UK, there is currently no formal screening program. The Department of Health has developed the Prostate Cancer Risk Management Program (PCRMP) for men aged over 50 years, which includes a pathway shown in this figure. The program aims to help ensure that the GP and the patient make robust, informed decisions regarding investigation for prostate cancer.

\section{Conclusion}

The pharmacist's main responsibility is to maximize positive outcomes of drug therapy and minimize drug misadventures. Patient therapy should result in the achievement of definite outcomes that improve the patient's QoL. To date, numerous studies have found an increased rate of hospital admission rates secondary to medication noncompliance and/or adverse drug reactions. The actual number of DRPs necessitating hospital admission may be higher than reported because of lack of documentation, further underestimating the problem. Initially, collecting and interpreting relevant patient information, identifying patient health-care needs, and formulating a DRP list may be challenging for the pharmacist. Preventive or chronic care is a challenge that should be undertaken by health care providers in all practice settings. Pharmacists should 
"seize the moment" to educate and counsel patients regarding these various topics when the opportunities arise. Clinical pharmacists use population health methods to generate chronic disease management referrals for patients with uncontrolled chronic conditions. Opportunities for pharmacists to help bring about awareness of recommendations and risk factors for the development of disease, and educate patients as to the benefits of prevention, occur daily. It is important for the pharmacists on the "front line" to have a general understanding of current recommendations for screening and disease prevention so that they can provide appropriate counseling and care for their patients. Also, pediatric clinical pharmacists have evolved over the last 2 decades and have proven to be a key player in the multidisciplinary team. Although, there are ample of evidences of positive impact on clinical, humanistic and economic outcomes and the benefits of clinical pharmacists managing chronic conditions have been extensively published, their involvement in the multidisciplinary team providing care to patients with chronic cases, more highquality research is warranted.

\section{Acknowledgement}

I'm thankful to Dr. Christel G. Svingen, Deputy Director of Pharmacy Red Lake Indian Health Service Hospital, Minnesota for his valuable time to audit my paper and for his thoughtful suggestions. I'm also grateful to seminar library of Faculty of Pharmacy, University of Dhaka and BANSDOC Library, Bangladesh for providing me books, journal and newsletters.

\section{Conflict of Interest}

The author declares that he has no competing interests.

\section{References}

1. Miller RR (1981) History of clinical pharmacy and clinical pharmacology. J Clin Pharmacol 21(4): 195-197.

2. Somogyi A, Loke YK, Ferro A, Lewis LD, Cohen AF, et al. (2010) Clinical pharmacology: a declaration of intent. Br J Clin Pharmacol 70(1): 1-2.

3. Calvert RT (1999) Clinical pharmacy-a hospital perspective. Br J Clin Pharmacol 47(3): 231-238.

4. Carter BL (2016) Evolution of Clinical Pharmacy in the USA and Future Directions for Patient Care. Drugs Aging 33(3): 169-77.

5. Dhingra S, Kumria R (2014) A case report on the significance of clinical pharmacy services in India. Clin Case Rep 2(3): 86-87.

6. Lebovitz L, Eddington ND (2019) Trends in the Pharmacist Workforce and Pharmacy Education. Am J Pharm Educ 83(1): 7051.

7. Veggeland T, Dyb S (2008) The contribution of a clinical pharmacist to the improvement of medication at a geriatric hospital unit in Norway. Pharm Pract (Granada) 6(1): 20-24.

8. Horn E, Jacobi J (2006) The critical care clinical pharmacist: evolution of an essential team member. Crit Care Med 34(3 Suppl): S46-51.

9. Hazen ACM, Antoinette A de Bont, Leendertse AJ, Zwart DLM, Niek J de Wit, et al. (2019) How Clinical Integration of Pharmacists in General Practice has Impact on Medication Therapy Management: A Theoryoriented Evaluation. Int J Integr Care 19(1): 1.

10. Islam MA, Talukder RM, Taheri R, Blanchard N (2016) Integration of Basic and Clinical Science Courses in US PharmD Programs. Am J Pharm Educ 80(10): 166.

11. American College of Clinical Pharmacy (2008) The definition of clinical pharmacy. Pharmacotherapy 28(6): 816-817.
12. McCarthy MW (2009) Clinical Pharmacy Skills. In; Michelle McCarthy and Denise Kockler. Oxford American Handbook of Clinical Pharmacy, published by Oxford University Press.

13. Institute of Medicine (US) Roundtable on Evidence-Based Medicine (2009) Leadership Commitments to Improve Value in Healthcare: Finding Common Ground: Workshop Summary. Washington (DC): National Academies Press (US).

14. Knoer SJ, Eck AR, Lucas AJ (2016) A review of American pharmacy: education, training, technology, and practice. J Pharm Health Care Sci 2: 32.

15. Ma CS, Holuby RS, Bucci LL (2010) Physician and pharmacist collaboration: The University of Hawaii at Hilo College of Pharmacy-JABSOM experience. Hawaii Med J 69(6 Suppl 3): 42-44.

16. Svingen CG (2019) Clinical Pharmacist Credentialing and Privileging: A Process for Ensuring High-Quality Patient Care. Fed Pract 36(4): 155157.

17. Ismail S, Osman M, Abulezz R, Alhamdan H, Quadri KHM (2018) Pharmacists as Interprofessional Collaborators and Leaders through Clinical Pathways. Pharmacy (Basel) 6(1): E24.

18. Ascione FJ (2019) Preparing Pharmacists for Collaborative/Integrated Health Settings. Pharmacy (Basel) 7(2): E47.

19. Moreno G, Lonowski S, Fu J, Chon JS, Whitmire N, et al. (2017) Physician experiences with clinical pharmacists in primary care teams. J Am Pharm Assoc (2003) 57(6): 686-691.

20. Al Taani GM, Al Azzam SI, Alzoubi KH, Aldeyab MA (2018) Which drugs cause treatment-related problems? Analysis of 10,672 problems within the outpatient setting. Ther Clin Risk Manag 14: 2273-2281.

21. Mohiuddin AK (2019) Pharmacists in Public Health: Scope in Home and Abroad. SOJ Pharmacy \& Pharmaceutical Sciences 6(1): 1-23.

22. Toklu HZ, Hussain A (2013) The changing face of pharmacy practice and the need for a new model of pharmacy education. J Young Pharm 5(2): 38-40.

23. Sakeena MHF, Bennett AA, McLachlan AJ (2019) The Need to Strengthen the Role of the Pharmacist in Sri Lanka: Perspectives. Pharmacy (Basel) 7(2): E54.

24. Hammad EA, Qudah RA, Akour AA (2017) The impact of clinical pharmacists in improving Jordanian patients' health outcomes. Saudi Med J 38(11): 1077-1089.

25. Dalton K, Byrne S (2017) Role of the pharmacist in reducing healthcare costs: current insights. Integr Pharm Res Pract 6: 37-46.

26. Li J, Li Z (2018) Differences and similarities in clinical pharmacy practice in China and the United States: a narrative review. Eur J Hosp Pharm 25(1): 2-5.

27. Tripathi S, Crabtree HM, Fryer KR, Graner KK, Arteaga GM (2015) Impact of Clinical Pharmacist on the Pediatric Intensive Care Practice: An 11Year Tertiary Center Experience. J Pediatr Pharmacol Ther 20(4): 290298.

28. Mekonnen AB, Yesuf EA, Odegard PS, Wega SS (2013) Implementing ward based clinical pharmacy services in an Ethiopian University Hospital. Pharm Pract (Granada) 11(1): 51-57.

29. Francis J, Abraham S (2014) Clinical pharmacists: Bridging the gap between patients and physicians. Saudi Pharm J 22(6): 600-602.

30. Chalasani SH, Ramesh M, Gurumurthy P (2018) Pharmacist-Initiated Medication Error-Reporting and Monitoring Programme in a Developing Country Scenario. Pharmacy (Basel) 6(4) pii: E133.

31. Ernawati DK, Lee YP, Hughes JD (2014) Nature and frequency of medication errors in a geriatric ward: an Indonesian experience. Ther Clin Risk Manag 10: 413-421.

32. Chamoun NR, Zeenny R, Mansour H (2016) Impact of clinical pharmacy interventions on medication error nodes. Int J Clin Pharm 38(6): 14361444 .

33. Gonzalez D, Rao GG, Bailey SC, Brouwer KLR, Cao Y, et al. (2017) Precision Dosing: Public Health Need, Proposed Framework, and Anticipated Impact. Clin Transl Sci 10(6): 443-454. 
34. Sanii Y, Torkamandi H, Gholami K, Hadavand N, Javadi M (2016) Role of pharmacist counseling in pharmacotherapy quality improvement. J Res Pharm Pract 5(2): 132-137.

35. Ip RNS, Tenney JW, Chu ACK, Chu PLM, Young GWM (2018) Pharmacist Clinical Interventions and Discharge Counseling in Medical Rehabilitation Wards in a Local Hospital: A Prospective Trial. Geriatrics (Basel) 3(3) pii: E53.

36. Seidling HM, Lampert A, Lohmann K, Schiele JT, Send AJ, et al. (2013) Safeguarding the process of drug administration with an emphasis on electronic support tools. Br J Clin Pharmacol 76 Suppl 1: 25-36.

37. Bauer SR, Kane Gill SL (2016) Outcome Assessment of Critical Care Pharmacist Services. Hosp Pharm 51(7): 507-513.

38. Viana SSC, Arantes T, Ribeiro SCDC (2017) Interventions of the clinical pharmacist in an Intermediate Care Unit for elderly patients. Einstein (Sao Paulo) 15(3): 283-288.

39. Sjolander M, Gustafsson M, Gallego G (2017) Doctors' and nurses' perceptions of a ward-based pharmacist in rural northern Sweden. Int J Clin Pharm 39(4): 953-959.

40. Van Oostrom SH, Picavet HS, de Bruin SR, Stirbu I, Korevaar JC, et al. (2014) Multimorbidity of chronic diseases and health care utilization in general practice. BMC Fam Pract 15: 61.

41. Yi JY, Kim Y, Cho YM, Kim H (2018) Self-management of Chronic Conditions Using mHealth Interventions in Korea: A Systematic Review. Healthc Inform Res 24(3): 187-197.

42. Kent K, Johnson JD, Simeon K, Frates EP (2016) Case Series in Lifestyle Medicine: A Team Approach to Behavior Changes. Am J Lifestyle Med 10(6): 388-397.

43. Middleton KR, Anton SD, Perri MG (2013) Long-Term Adherence to Health Behavior Change. Am J Lifestyle Med 7(6): 395-404.

44. Young S (2014) Healthy behavior change in practical settings. Perm J 18(4): 89-92.

45. Newsom JT, Huguet N, McCarthy MJ, Ramage Morin P, Kaplan MS, et al. (2012) Health behavior change following chronic illness in middle and later life. J Gerontol B Psychol Sci Soc Sci 67(3): 279-88.

46. Zhang C, Zhang L, Huang L, Luo R, Wen J (2012) Clinical pharmacists on medical care of pediatric inpatients: a single-center randomized controlled trial. PLoS One 7(1): e30856.

47. Han N, Han SH, Chu H, Kim J, Rhew KY, et al. (2018) Service design oriented multidisciplinary collaborative team care service model development for resolving drug related problems. PLoS One 13(9): e0201705.

48. Tan EC, Stewart K, Elliott RA, George J (2014) Pharmacist services provided in general practice clinics: a systematic review and metaanalysis. Res Social Adm Pharm 10(4): 608-622.

49. Fletcher J, Hogg W, Farrell B, Woodend K, Dahrouge S, et al. (2012) Effect of nurse practitioner and pharmacist counseling on inappropriate medication use in family practice. Can Fam Physician 58(8): 862-868.

50. Greer N, Bolduc J, Geurkink E, Rector T, Olson K, et al. (2016) Pharmacistled Chronic Disease Management: A Systematic Review of Effectiveness and Harms Compared With Usual Care. Ann Intern Med.

51. Litke J, Spoutz L, Ahlstrom D, Perdew C, Llamas W, et al. (2018) Impact of the clinical pharmacy specialist in telehealth primary care. Am J Health Syst Pharm 75(13): 982-986.

52. Meo SA, Sheikh SA, Sattar K, Akram A, Hassan A, et al. (2019) Prevalence of Type 2 Diabetes Mellitus Among Men in the Middle East: A Retrospective Study. Am J Mens Health 13(3): 1557988319848577.

53. Hughes JD, Wibowo Y, Sunderland B, Hoti K (2017) The role of the pharmacist in the management of type 2 diabetes: current insights and future directions. Integr Pharm Res Pract 6: 15-27.

54. Muc R, Saracen A, Grabska Liberek I (2018) Associations of Diabetic Retinopathy with Retinal Neurodegeneration on the Background of Diabetes Mellitus. Overview of Recent Medical Studies with an Assessment of the Impact on Healthcare systems. Open Med (Wars) 13: 130-136.
55. Yang JJ, Yu D, Wen W, Saito E, Rahman S, et al. (2019) Association of Diabetes With All-Cause and Cause-Specific Mortality in Asia: A Pooled Analysis of More Than 1 Million Participants. JAMA network open 2(4): e192696.

56. Raghavan S, Vassy JL, Ho YL, Song RJ, Gagnon DR, et al. (2019) Diabetes Mellitus-Related All-Cause and Cardiovascular Mortality in a National Cohort of Adults. J Am Heart Assoc 8(4): e011295.

57. Einarson TR, Acs A, Ludwig C, Panton UH (2018) Prevalence of cardiovascular disease in type 2 diabetes: a systematic literature review of scientific evidence from across the world in 2007-2017. Cardiovasc Diabetol 17(1): 83.

58. Longo M, Bellastella G, Maiorino MI, Meier JJ, Esposito K, et al. (2019) Diabetes and Aging: From Treatment Goals to Pharmacologic Therapy. Front Endocrinol (Lausanne) 10: 45.

59. Ares J, Valdes S, Botas P, Sanchez Ragnarsson C, Rodriguez Rodero S, et al. (2019) Mortality risk in adults according to categories of impaired glucose metabolism after 18 years of follow-up in the North of Spain: The Asturias Study. PLoS One 14(1): e0211070.

60. Mohiuddin AK (2019) Patient Compliance: Fact or Fiction?. Innovations in pharmacy 10 (1): 1-13.

61. Al Omar LT, Anderson SL, Cizmic AD, Vlasimsky TB (2019) Implementation of a Pharmacist-Led Diabetes Management Protocol. Am Health Drug Benefits 12(1): 14-20.

62. Gardea J, Papadatos J, Cadle R (2018) Evaluating glycemic control for patient-aligned care team clinical pharmacy specialists at a large Veterans Affairs medical center. Pharm Pract (Granada) 16(2): 1164.

63. Shane McWhorter L, McAdam Marx C, Lenert L, Petersen M, Woolsey S, et al. (2015) Pharmacist-provided diabetes management and education via a telemonitoring program. J Am Pharm Assoc (2003) 55(5): 516-526.

64. Davis CS, Ross LAR, Bloodworth LS (2017) The Impact of Clinical Pharmacist Integration on a Collaborative Interdisciplinary Diabetes Management Team. J Pharm Pract 30(3): 286-290.

65. Wallgren S, Berry Caban CS, Bowers L (2012) Impact of clinical pharmacist intervention on diabetes-related outcomes in a military treatment facility. Ann Pharmacother 46(3): 353-357.

66. Ray S, Lokken J, Whyte C, Baumann A, Oldani M (2019) The impact of a pharmacist-driven, collaborative practice on diabetes management in an Urban underserved population: a mixed method assessment. J Interprof Care 5: 1-9.

67. Schmidt K, Caudill JA, Hamilton T (2019) Impact of clinical pharmacy specialists on glycemic control in veterans with type 2 diabetes. Am J Health Syst Pharm 76(Supplement_1): S9-S14.

68. Sharp LK, Tilton JJ, Touchette DR, Xia Y, Mihailescu D, et al. (2018) Community Health Workers Supporting Clinical Pharmacists in Diabetes Management: A Randomized Controlled Trial. Pharmacotherapy 38(1): 58-68.

69. Neves CM, Nascimento MMGD, Silva DAM, Ramalho de Oliveira D (2019) Clinical Results of Comprehensive Medication Management Services in Primary Care in Belo Horizonte. Pharmacy (Basel) 7(2) pii: E58.

70. Jeong S, Lee M, Ji E (2018) Effect of pharmaceutical care interventions on glycemic control in patients with diabetes: a systematic review and meta-analysis. Ther Clin Risk Manag 14: 1813-1829.

71. Wassell K, Sullivan J, Jett BP, Zuber J (2018) Comparison of clinical pharmacy specialists and primary care physicians in treatment of type 2 diabetes mellitus in rural Veterans Affairs facilities. Am J Health Syst Pharm 75(5 Supplement 1): S6-S12.

72. Kharjul M, Braund R, Green J (2018) The influence of pharmacist-led adherence support on glycaemic control in people with type 2 diabetes. Int J Clin Pharm 40(2): 354-359.

73. Alqudah S, Jarab AS, Alefishat EA, Mayyas F, Khdour M, et al. Factors Associated with Poor Hemoglobin A1c Control in Patients with Type 2 Diabetes. Curr Diabetes Rev 15(2): 164-170.

74. Peasah SK, Granitz K, Vu M, Jacob B (2019) Effectiveness of a Student Pharmacist-Led Telephone Follow-Up Intervention to 
Improve Hemoglobin $\mathrm{A}(1 \mathrm{C})$ in Diabetic Patients. J Pharm Pract 25: 897190019857409.

75. Goruntla N, Mallela V, Nayakanti D (2019) Impact of Pharmacist-directed Counseling and Message Reminder Services on Medication Adherence and Clinical Outcomes in Type 2 Diabetes Mellitus. J Pharm Bioallied Sci 11(1): 69-76.

76. Al Haqan AA, Al Taweel DM, Awad A, Wake DJ (2017) Pharmacists' Attitudes and Role in Diabetes Management in Kuwait. Med Princ Pract 26(3): 273-279.

77. Berta E, Lengyel I, Halmi S, Zrinyi M, Erdei A, et al. (2019) Hypertension in Thyroid Disorders. Front Endocrinol (Lausanne). 10: 482.

78. Okubadejo NU, Ozoh OB, Ojo OO, Akinkugbe AO, Odeniyi IA, et al. (2019) Prevalence of hypertension and blood pressure profile amongst urbandwelling adults in Nigeria: a comparative analysis based on recent guideline recommendations. Clin Hypertens 25: 7.

79. Web WHO. Cardiovascular disease. World Heart Day. Scale up prevention of heart attack and stroke.

80. Web WHO. (2017) News/ Fact sheets/Detail/Cardiovascular diseases (CVDs).

81. Ofori SN, Obosi J (2019) Prevalence of hypertension among office workers in a multi-national company in the Niger-Delta with the 2017 American College of Cardiology/American Heart Association Blood Pressure Guidelines. Prev Med Rep 15: 100899.

82. Lanza GA (2019) Diagnostic Approach to Patients with Stable Angina and No Obstructive Coronary Arteries. Eur Cardiol 14(2): 97-102.

83. Yasue H, Mizuno Y, Harada E (2019) Coronary artery spasm - Clinical features, pathogenesis and treatment. Proc Jpn Acad Ser B Phys Biol Sci 95(2): 53-66.

84. Ferdinand KC, Senatore FF, Clayton Jeter H, Cryer DR, Lewin JC, et al. (2017) Improving Medication Adherence in Cardiometabolic Disease: Practical and Regulatory Implications. J Am Coll Cardiol 69(4): 437-451.

85. Hinton W, McGovern A, Coyle R, Han TS, Sharma P, et al. (2018) Incidence and prevalence of cardiovascular disease in English primary care: a cross-sectional and follow-up study of the Royal College of General Practitioners (RCGP) Research and Surveillance Centre (RSC). BMJ Open 8(8): e020282.

86. Mohiuddin Ak (2019) Natural Foods and Indian Herbs of Cardiovascular Interest. Pharmacy \& Pharmacology International Journal 7(2).

87. Gums TH, Uribe L, Vander Weg MW, James P, Coffey C, et al. (2015) Pharmacist intervention for blood pressure control: medication intensification and adherence. J Am Soc Hypertens 9(7): 569-578.

88. Mohiuddin AK (2019) Risks and Reasons Associated with Medication Non-Adherence. Journal of Clinical Pharmacy 1(1): 50-53.

89. Williams B, Mancia G, Spiering W, Agabiti Rosei E, Azizi M, et al. (2018) 2018 ESC/ESH Guidelines for the management of arterial hypertension. Eur Heart J 39(33): 3021-3104.

90. Niriayo YL, Ibrahim S, Kassa TD, Asgedom SW, Atey TM, et al. (2019) Practice and predictors of self-care behaviors among ambulatory patients with hypertension in Ethiopia. PLoS One 14(6): e0218947.

91. National High Blood Pressure Education Program. (2004) The Seventh Report of the Joint National Committee on Prevention, Detection, Evaluation, and Treatment of High Blood Pressure. Bethesda (MD): National Heart, Lung, and Blood Institute (US).

92. Mohiuddin AK (2019) A Brief Review of Traditional Plants as Sources of Pharmacological Interests. Open J Plant Sci 4(1): 1-8.

93. Mohiuddin AK (2019) Traditional System of Medicine and Nutritional Supplementation: Use Vs Regulation. Journal of Clinical Trials, Pathology and Case Studies 4(1): 5-30.

94. Mohiuddin AK (2019) Patient History and Medical Record: Proper Solution from Accurate Problem Identification. Medicine and Medical Sciences 7(7): 82-86.

95. Omboni S, Caserini M (2018) Effectiveness of pharmacist's intervention in the management of cardiovascular diseases. Open Heart 5(1): e000687.

96. Morgado M, Rolo S, Castelo Branco M (2011) Pharmacist intervention program to enhance hypertension control: a randomised controlled trial. Int J Clin Pharm 33(1): 132-140.

97. Bex SD, Boldt AS, Needham SB, Bolf SM, Walston CM, et al. (2011) Effectiveness of a hypertension care management program provided by clinical pharmacists for veterans. Pharmacotherapy 31(1): 31-38.

98. Von Muenster SJ, Carter BL, Weber CA, Ernst ME, Milchak JL, et al. (2008) Description of pharmacist interventions during physician-pharmacist co-management of hypertension. Pharm World Sci 30(1): 128-135.

99. Ramanath K, Balaji D, Nagakishore Ch, Kumar SM, Bhanuprakash M (2012) A study on impact of clinical pharmacist interventions on medication adherence and quality of life in rural hypertensive patients. J Young Pharm 4(2): 95-100.

100. Bhat S, Kroehl M, Yi WM, Jaeger J, Thompson AM, et al. (2019) Factors influencing the acceptance of referrals for clinical pharmacist managed disease states in primary care. J Am Pharm Assoc (2003) 59(3): 336-342.

101. Kane JA, Mehmood T, Munir I, Kamran H, Kariyanna PT, et al. (2019) Cardiovascular Risk Reduction Associated with Pharmacological Weight Loss: A Meta-Analysis. Int J Clin Res Trials 4(1): 131.

102. Hasegawa K, Komiyama M, Takahashi Y (2019) Obesity and Cardiovascular Risk After Quitting Smoking: The Latest Evidence. Eur Cardiol 14(1): 60-61.

103. El Hajj MS, Kheir N, Al Mulla AM, Shami R, Fanous N, et al. (2017) Effectiveness of a pharmacist-delivered smoking cessation program in the State of Qatar: a randomized controlled trial. BMC Public Health 17(1): 215.

104. Dobrinas M, Blanc AL, Rouiller F, Christen G, Coronado M, et al. (2014) Clinical pharmacist's role in implementing a smoking cessation intervention in a Swiss regional hospital: an exploratory study. Int J Clin Pharm 36(3): 526-534.

105. El Hajj MS, Awaisu A, Kheir N, Mohamed MHN, Haddad RS, et al. (2019) Evaluation of an intensive education program on the treatment of tobacco-use disorder for pharmacists: a study protocol for a randomized controlled trial. Trials 20(1): 25.

106. Li VW, Lam J, Heise P, Reid RD, Mullen KA (2018) Implementation of a Pharmacist-Led Inpatient Tobacco Cessation Intervention in a Rehabilitation Hospital: A Before-and-After Pilot Study. Can J Hosp Pharm 71(3): 180-186.

107. Klop B, Elte JW, Cabezas MC (2013) Dyslipidemia in obesity: mechanisms and potential targets. Nutrients 5(4): 1218-1240.

108. Cercato C, Fonseca FA (2019) Cardiovascular risk and obesity. Diabetol Metab Syndr 11: 74.

109. Jordan MA, Harmon J (2015) Pharmacist interventions for obesity: improving treatment adherence and patient outcomes. Integr Pharm Res Pract 4: 79-89.

110. Carbone S, Canada JM, Billingsley HE, Siddiqui MS, Elagizi A, et al. (2019) Obesity paradox in cardiovascular disease: where do we stand? Vasc Health Risk Manag 15: 89-100.

111. Koliaki C, Liatis S, Kokkinos A (2019) Obesity and cardiovascular disease: revisiting an old relationship. Metabolism 98-107.

112. De Lorenzo A, Gratteri S, Gualtieri P, Cammarano A, Bertucci P, et al. Why primary obesity is a disease? J Transl Med 17(1): 169.

113. Nuffer Monika (2019) Integrative Health and Medicine: Dietary Supplements and Modalities for the Treatment of Obesity. Nutrition in the Prevention and Treatment of Abdominal Obesity 393-408.

114. Butryn ML, Webb V, Wadden TA (2011) Behavioral treatment of obesity. Psychiatr Clin North Am 34(4): 841-859.

115. Sanyal D, Raychaudhuri M (2016) Hypothyroidism and obesity: An intriguing link. Indian J Endocrinol Metab 20(4): 554-557. 
116. Fruh SM (2017) Obesity: Risk factors, complications, and strategies for sustainable long-term weight management. J Am Assoc Nurse Pract 29(S1): S3-S14.

117. Tsai Adam Gilden, Daniel H Bessesen (2019) Obesity. Annals of Internal Medicine $170(5)$

118. Tsai AG (2019) Why I Treat Obesity. Perm J 23.

119. Tamez Pérez HE, Proskauer Peña SL, Herníndez Coria MI, Garber AJ (2013) AACE Comprehensive Diabetes Management Algorithm 2013. Endocrine Practice 19(2): 327-336.

120. De Geeter Michelle, Shawn Riser Taylor, Ece Ilkiz Okarlton, Jamie Ellex, Christian Dolder (2018) Results of a Pharmacist Intervention on Weight Parameters and A1c Compared to Standard Patient Care. J Pharm Technol 34(5): 194-198.

121. Zanni GR (2014) Hyperlipidemia: Updated Guidelines Impact Counseling. Pharmacy Times ${ }^{\circledR}$.

122. Hetro A, Rossetto J, Bahlawan N, Ryan M (2003) Clinical pharmacists supporting patients with diabetes and/or hyperlipidemia in a military medical home. J Am Pharm Assoc 55(1): 73-76.

123. Tsuyuki RT, Rosenthal M, Pearson GJ (2016) A randomized trial of a community-based approach to dyslipidemia management: Pharmacist prescribing to achieve cholesterol targets (RxACT Study). Can Pharm J (Ott) 149(5): 283-292.

124. O Riordan M (2016) Pharmacist Management of High Cholesterol Gets More Patients to Goal, Lowers LDL Levels: RxACT. TCTMD News.

125. Joel C Mars (2010) Pharmacy Perspectives in Dyslipidemia Management. US Pharmacist.

126. Cassagnol M, Ezzo D, Patel PN (2013) New Therapeutic Alternatives for the Management of Dyslipidemia." Journal of Pharmacy Practice 26(6): 528-540.

127. Lewis A, Torvinen S, Dekhuijzen PN, Chrystyn H, Watson AT, et al. (2016) The economic burden of asthma and chronic obstructive pulmonary disease and the impact of poor inhalation technique with commonly prescribed dry powder inhalers in three European countries. BMC Health Serv Res 16: 251.

128. Xin C, Xia Z, Jiang C, Lin M, Li G (2016) The impact of pharmacistmanaged clinic on medication adherence and health-related quality of life in patients with COPD: a randomized controlled study. Patient Prefer Adherence 10: 1197-1203.

129. Usmani OS (2019) Choosing the right inhaler for your asthma or COPD patient. Ther Clin Risk Manag 15: 461-472.

130. Mubarak N, Hatah E, Khan TM, Zin CS (2019) A systematic review and meta-analysis of the impact of collaborative practice between community pharmacist and general practitioner on asthma management. J Asthma Allergy 12: 109-153.

131. Duong TN, Zeki AA, Louie S (2017) Medical Management of Hospitalized Patients with Asthma or Chronic Obstructive Pulmonary Disease. Hosp Med Clin 6(4): 437-455.

132. Krishnan JA, Nibber A, Chisholm A, Price D, Bateman ED, et al. (2019) Prevalence and Characteristics of Asthma-Chronic Obstructive Pulmonary Disease Overlap in Routine Primary Care Practices. Ann Am Thorac Soc 16(9):1143-1150.

133. López Campos JL, Quintana Gallego E, Carrasco Hernández L (2019) Status of and strategies for improving adherence to COPD treatment. Int J Chron Obstruct Pulmon Dis 14: 1503-1515.

134. Jardim JR, Nascimento OA (2019) The Importance of Inhaler Adherence to Prevent COPD Exacerbations. Med Sci (Basel) 7(4): E54.

135. Abdulsalim S, Unnikrishnan MK, Manu MK, Alsahali S, Alrasheedy AA et al. (2019) Impact of a Clinical Pharmacist Intervention on Medicine Costs in Patients with Chronic Obstructive Pulmonary Disease in India. Pharmacoecon Open.

136. Mc Gurran MA, Richter LM, Leedahl ND, Leedahl DD (2019) Impact of a Comprehensive COPD Therapeutic Interchange Program on 30-Day Readmission Rates in Hospitalized Patients. P T 44(4): 185-191.
137. Cawley MJ, Warning WJ $2^{\text {nd }}$ (2018) Impact of a Pharmacist-driven Spirometry Clinic Service within a Community Family Health Center: A 5-year Retrospective Review. J Res Pharm Pract 7(2): 88-94.

138. Ottenbros S, Teichert M, de Groot R, Griens F, Sodihardjo F, et al. (2014) Pharmacist-led intervention study to improve drug therapy in asthma and COPD patients. Int J Clin Pharm 36(2): 336-344.

139. Usmani OS, Lavorini F, Marshall J, Dunlop WCN, Heron L, et al. (2018) Critical inhaler errors in asthma and COPD: a systematic review of impact on health outcomes. Respir Res 19(1): 10.

140. Kuipers E, Wensing M, Wong Go E, Daemen BJG, De Smet PAGM, et al. (2019) Adherence to guideline recommendations for asthma care in community pharmacies: actual and needed performance. NPJ Prim Care Respir Med 29(1): 26.

141. Deeks LS, Kosari S, Boom K, Peterson GM, Maina A, et al. (2018) The Role of Pharmacists in General Practice in Asthma Management: A Pilot Study. Pharmacy Basel 6(4): E114.

142. Hunt V, Anderson D, Lowrie R, Montgomery Sardar C, Ballantyne S, et al. (2018) A non-randomised controlled pilot study of clinical pharmacist collaborative intervention for community dwelling patients with COPD. NPJ Prim Care Respir Med 28(1): 38

143. Twigg MJ, Wright DJ (2017) Community pharmacy COPD services: what do researchers and policy makers need to know? Integr Pharm Res Pract 6: 53-59.

144. Greenhalgh T, Macfarlane F, Steed L, Walton R (2016) What works for whom in pharmacist-led smoking cessation support: realist review. BMC Med 14(1): 209.

145. Kadam NS, Chiplonkar SA, Khadilkar AV, Khadilkar VV (2018) Prevalence of Osteoporosis in Apparently Healthy Adults above 40 Years of Age in Pune City, India. Indian J Endocrinol Metab 22(1): 6773.

146. Patel D, Worley JR, Volgas DA, Crist BD (2018) The Effectiveness of Osteoporosis Screening and Treatment in the Midwest. Geriatr Orthop Surg Rehabil 9: 2151459318765844

147. Tu KN, Lie JD, Wan CKV, Cameron M, Austel AG, et al. (2018) Osteoporosis: A Review of Treatment Options. P T 43(2): 92-104.

148. Elias MN, Burden AM, Cadarette SM (2011) The impact of pharmacist interventions on osteoporosis management: a systematic review. Osteoporos Int 22(10): 2587-2596.

149. Jaleel A, Saag KG, Danila MI (2018) Improving drug adherence in osteoporosis: an update on more recent studies. Ther Adv Musculoskelet Dis 10(7): 141-149.

150. Balkhi B, Seoane Vazquez E, Rodriguez Monguio R(2018) Changes in the utilization of osteoporosis drugs after the 2010 FDA bisphosphonate drug safety communication. Saudi Pharm J 26(2): 238-243.

151. Lau E, Papaioannou A, Dolovich L, Adachi J, Sawka AM, (2008) Patients' adherence to osteoporosis therapy: exploring the perceptions of postmenopausal women. Can Fam Physician 54(3): 394-402.

152. McGreevy JL, Kane MP, Busch RS, Bakst G, ElDeiry S (2019) A pharmacist-run anabolic osteoporosis clinic: An abaloparatide descriptive report. J Am Pharm Assoc (2003) 59(4): 593-597.

153. Cho H, Byun JH, Song I, Kim HY, Ha YC, et al. (2018) Effect of improved medication adherence on health care costs in osteoporosis patients. Medicine Baltimore 97(30): e11470.

154. Ivanova S, Vasileva L (2017) Current and Emerging Strategies in Osteoporosis Management. Curr Pharm Des 23(41): 6279-6287.

155. Leslie WD, Morin SN, Martineau P, Bryanton M, Lix LM (2019) Association of Bone Density Monitoring in Routine Clinical Practice with Anti-Osteoporosis Medication Use and Incident Fractures: A Matched Cohort Study. J Bone Miner Res 34(10): 1808-1814.

156. Tit DM, Bungau S, Iovan C, Nistor Cseppento DC, Endres L, et al. (2018) Effects of the Hormone Replacement Therapy and of Soy Isoflavones on Bone Resorption in Postmenopause. J Clin Med 7(10): E297.

157. Fait T (2019) Menopause hormone therapy: latest developments and clinical practice. Drugs Context 8: 212551. 
158. Zuo H, Sun A, Gao L, Xue W, Deng Y, et al. (2019) Effect of Menopausal Hormone Therapy on Bone Mineral Density in Chinese Women: A 2-Year, Prospective, Open-Label, Randomized-Controlled Trial. Med Sci Monit 25: 819-826.

159. Bowers BL, Drew AM, Verry C (2018) Impact of Pharmacist-Physician Collaboration on Osteoporosis Treatment Rates. Ann Pharmacother 52(9): 876-883.

160. Duquet N (2014) Osteoporosis: treatment and pharmaceutical care]. J Pharm Belg (2): 14-24.

161. Uhlig HH (2013) Monogenic diseases associated with intestinal inflammation: implications for the understanding of inflammatory bowel disease. Gut 62(12): 1795-805.

162. Cury DB, Oliveira R, Cury MS (2019) Inflammatory bowel diseases: time of diagnosis, environmental factors, clinical course, and management - a follow-up study in a private inflammatory bowel disease center (2003-2017). J Inflamm Res 12: 127-135.

163. Bon L, Scharl S, Vavricka S, Rogler G, Fournier N, et al. (2019) Association of IBD specific treatment and prevalence of pain in the Swiss IBD cohort study. PLoS One 14(4): e0215738.

164. Aniwan S, Harmsen WS, Tremaine WJ, Loftus EV (2019) Incidence of inflammatory bowel disease by race and ethnicity in a populationbased inception cohort from 1970 through 2010. Therap Adv Gastroenterol 12: 1756284819827692.

165. Ye BD, Travis S (2019) Improving the quality of care for inflammatory bowel disease. Intest Res 17(1): 45-53.

166. Lichtenstein GR, Shahabi A, Seabury SA, Lakdawalla DN, Espinosa OD, et al. (2019) Lifetime Economic Burden of Crohn's Disease and Ulcerative Colitis by Age at Diagnosis. Clin Gastroenterol Hepatol S1542-S3565(19): 30765-30767.

167. Barrett K, Glatter J (2019) New standards for IBD aim to improve patient experience and outcomes. Guidelines in Practice, Gastrointestinal, UK.

168. Sood A, Ahuja V, Kedia S, Midha V, Mahajan R, et al. (2019) Diet and inflammatory bowel disease: The Asian Working Group guidelines. Indian J Gastroenterol 38(3): 220-246.

169. Rizzello F, Spisni E, Giovanardi E, Imbesi V, Salice M, et al. (2019) Implications of the Westernized Diet in the Onset and Progression of IBD. Nutrients 11(5): E1033.

170. Malekzadeh MM, Sima A, Alatab S, Sadeghi A, Daryani NE, et al. Iranian Registry of Crohn's and Colitis: study profile of first nation-wide inflammatory bowel disease registry in Middle East. Intest Res 17(3): 330-339.

171. Choi K, Chun J, Han K, Park S, Soh H, et al. (2019) Risk of Anxiety and Depression in Patients with Inflammatory Bowel Disease: A Nationwide, Population-Based Study. J Clin Med 8(5): E654.

172. Panhwar MS, Mansoor E, Al Kindi SG, Sinh P, Katz J, et al. (2019) Risk of Myocardial Infarction in Inflammatory Bowel Disease: A Populationbased National Study. Inflamm Bowel Dis 25(6): 1080-1087.

173. Kuenzig ME, Bishay K, Leigh R, Kaplan GG, Benchimol EI et al. (2018) Co-occurrence of Asthma and the Inflammatory Bowel Diseases: A Systematic Review and Meta-analysis. Clin Transl Gastroenterol 9(9): 188.

174. Vutcovici M, Brassard P, Bitton A (2016) Inflammatory bowel disease and airway diseases. World J Gastroenterol 22(34): 7735-7741.

175. Kelly OB, Li N, Smith M, Chan J, Inman RD, et al. (2019) The Prevalence and Clinical Associations of Subclinical Sacroiliitis in Inflammatory Bowel Disease. Inflamm Bowel Dis 25(6): 1066-1071.

176. Scharl S, Barthel C, Rossel JB, Biedermann L, Misselwitz B, et al. (2019) Malignancies in Inflammatory Bowel Disease: Frequency, Incidence and Risk Factors-Results from the Swiss IBD Cohort Study. Am J Gastroenterol 114(1): 116-126.

177. Waters BM, Jensen L, Fedorak RN (2005) Effects of formal education for patients with inflammatory bowel disease: a randomized controlled trial. Can J Gastroenterol 19(4): 235-244.
178. Ashok K, Mathew AA, Thomas A, Mohan D, Gopalakrishna R, et al. (2017) Clinical Pharmacist's Interventions on Medication Adherence and Knowledge of Inflammatory Bowel Disease Patients. J Young Pharm 9(3): 381-385

179. Tiao DK, Chan W, Jeganathan J, Chan JT, Perry J, et al. (2017) Inflammatory Bowel Disease Pharmacist Adherence Counseling Improves Medication Adherence in Crohn's Disease and Ulcerative Colitis. Inflamm Bowel Dis 23(8): 1257-1261.

180. McDowell C, Haseeb M (2019) Inflammatory Bowel Disease (IBD). StatPearls, Treasure Island (FL): StatPearls Publishing.

181. Jones ASC (2014) Optimising therapy for inflammatory bowel disease. Clinical Pharmacist.

182. Alan Steel, Helen Morgan, Wei Tan, Vanessa Marvin, Mahmood Wahed (2018) PTU-140 Does a dedicated inflammatory bowel disease (IBD) pharmacist clinic improve patient safety? Gut 67: A265-A266.

183. Bhat S (2015) The Pharmacist's Role in Biologic Management for IBD in a Health System-Integrated Practice Model. Pharmacy Times ${ }^{\circledR}$.

184. Leung AM (2016) Thyroid Emergencies. J Infus Nurs 39(5): 281-286.

185. De Leo S, Lee SY, Braverman LE (2016) Hyperthyroidism. Lancet 388(10047): 906-918.

186. Taylor PN, Albrecht D, Scholz A, Gutierrez Buey G, Lazarus JH, et al. (2018) Global epidemiology of hyperthyroidism and hypothyroidism. Nat Rev Endocrinol 14(5): 301-316.

187. Calsolaro V, Niccolai F, Pasqualetti G, Calabrese AM, Polini A, et al. (2019) Overt and Subclinical Hypothyroidism in the Elderly: When to Treat? Front Endocrinol (Lausanne) 10: 177.

188. Leng O, Razvi S (2019) Hypothyroidism in the older population. Thyroid Res 12: 2 .

189. Talwalkar P, Deshmukh V, Bhole M (2019) Prevalence of hypothyroidism in patients with type 2 diabetes mellitus and hypertension in India: a cross-sectional observational study. Diabetes Metab Syndr Obes 12: 369-376.

190. Thavaraputta S, Dennis JA, Laoveeravat P, Nugent K, Rivas AM (2019) Hypothyroidism and Its Association With Sleep Apnea Among Adults in the United States: NHANES 2007-2008. J Clin Endocrinol Metab 104(11): 4990-4997.

191. Sriphrapradang C, Pinyopodjanard S, Suntornlohanakul O, Nimitphong $\mathrm{H}$, Chirakalwasan $\mathrm{N}$, et al. (2019) Lack of associations between thyroid function and obstructive sleep apnea severity in adults with prediabetes and diabetes mellitus. Sleep Breath 23(3): 963-967.

192. Bruyneel M, Veltri F, Poppe K (2019) Prevalence of newly established thyroid disorders in patients with moderate-to-severe obstructive sleep apnea syndrome. Sleep Breath 23(2): 567-573.

193. Sweed RA, Hassan S, ElWahab NHA, Aref SR, Mahmoud MI (2019) Comorbidities associated with obstructive sleep apnea: a retrospective Egyptian study on 244 patients. Sleep Breath 23(4): 1079-1085.

194. Gabrielson AT, Sartor RA, Hellstrom WJG (2019) The Impact of Thyroid Disease on Sexual Dysfunction in Men and Women. Sex Med Rev 7(1): 57-70.

195. Yuan J, Sun C, Jiang S, Lu Y, Zhang Y, et al. (2019) The Prevalence of Thyroid Disorders in Patients With Vitiligo: A Systematic Review and Meta-Analysis. Front Endocrinol (Lausanne) 9: 803.

196. Biondi B, Cappola AR, Cooper DS (2019) Subclinical Hypothyroidism: A Review. JAMA 322(2): 153-160.

197. Fayyaz B, Upreti S (2018) Autoimmune inner ear disease secondary to Hashimoto's thyroiditis: a case report. J Community Hosp Intern Med Perspect 8(4): 227-229.

198. Chaudhary SC, Ahmad T, Usman K, Sawlani KK, Gupta KK, et al. (2018) Prevalence of thyroid dysfunction in chronic obstructive pulmonary disease patients in a tertiary care center in North India. J Family Med Prim Care 7(3): 584-588.

199. Akpinar EE (2019) An underestimated comorbidity of COPD: Thyroid dysfunction. Tuberk Toraks 67(2): 131-135. 
200. Rugge B, Balshem H, Sehgal R, Rose Relevo, Paul Gorman, et al. (2011) Screening and Treatment of Subclinical Hypothyroidism or Hyperthyroidism. Rockville (MD): Agency for Healthcare Research and Quality, US.

201. Bensenor IM, Olmos RD, Lotufo PA (2012) Hypothyroidism in the elderly: diagnosis and management. Clin Interv Aging 7: 97-111.

202. De Groot LJ (2000) Diagnosis and Treatment of Graves' Disease. In: Feingold KR, Anawalt B, Boyce A (ed.) Endotext, South Dartmouth, USA.

203. Maharjan S, Himal Paudel C (2015) Assessment of Interventions by Pharmacist in Improving Knowledge, Attitude and Practice towards Hypothyroidism among the Patients Attending at an Endocrine Clinic in Nepal. Indian Journal of Pharmacy Practice, 8(2): 67-71.

204. Lloyd J, Yerbury P, Ruszala V (2011) Thyroid disorders management.

205. Mueller L (2018) Changing the Conversation About Mental Health. Chicago Health, USA

206. Harms M, Haas M, Larew J, DeJongh B (2018) Impact of a mental health clinical pharmacist on a primary care mental health integration team. Ment Health Clin pp: 101-105.

207. Rehm J, Shield KD (2019) Global Burden of Disease and the Impact of Mental and Addictive Disorders. Curr Psychiatry Rep 21(2): 1-10.

208. Faquih AE, Memon RI, Hafeez H, Zeshan M, Naveed S (2019) A Review of Novel Antidepressants: A Guide for Clinicians. Cureus 11(3): e4185.

209. Horackova K, Kopecek M, Machů V, Kagstrom A, Aarsland D, Motlova LB, Cermakova P (2019) Prevalence of late-life depression and gap in mental health service use across European regions. Eur Psychiatry: 19-25.

210. Singh OP (2018) Closing treatment gap of mental disorders in India: Opportunity in new competency-based Medical Council of India curriculum. Indian J Psychiatry 60(4): 375-376.

211. Swaminath G, Enara A, Rao R, Kumar KVK, Kumar CN (2019) Mental Healthcare Act, 2017 and homeless persons with mental illness in India. Indian J Psychiatry (Suppl 4): S768-S772.

212. Hayes K, Berry P, Ebi KL (2019) Factors Influencing the Mental Health Consequences of Climate Change in Canada. Int J Environ Res Public Health 16(9) pii: E1583.

213. Cook L (2019) Mental health in Australia: a quick guide. Parliament of Australia

214. Shpigelman CN, HaGani N (2019) The impact of disability type and visibility on self-concept and body image: Implications for mental health nursing. J Psychiatr Ment Health Nurs 26(3-4): 77-86.

215. Yamauchi T, Sasaki T, Yoshikawa T, Matsumoto S, Takahashi M (2018) Incidence of overwork-related mental disorders and suicide in Japan. Occup Med (Lond) 68(6):370-377.

216. Uhlenbusch N, Löwe B, Härter M, Schramm C, Weiler-Normann C (2019) et al. Depression and anxiety in patients with different rare chronic diseases: A cross-sectional study. PLoS One 14(2): e0211343.

217. Rokach A (2019) The Effect of Psychological Conditions on Sexuality: A Review. Psychol Psychother Res Stud 2(2): PPRS.000534.

218. Gibu M, Clark J, Gold J (2018) Mental health pharmacists as interim prescribers. Ment Health Clin 7(3):111-115.

219. Mohiuddin AK (2019) Psychiatric Pharmacy: New Role of Pharmacists in Mental Health. J Psychiatry Mental Disord 4(1): 1010.

220. Matlala M, Maponya ML, Chigome AK, Meyer H-jc (2018) Overview of mental health: A public health priority. S Afr Pharm J 85(6): 46-53.

221. Guillaumie L, Ndayizigiye A, Beaucage C, Moisan J, Grégoire JP et al. (2018) Patient perspectives on the role of community pharmacists for antidepressant treatment: A qualitative study. Can Pharm J (Ott) 151(2):142-148.

222. Srimongkon P, Aslani P, Chen TF (2018) Consumer-related factors influencing antidepressant adherence in unipolar depression: a qualitative study. Patient Prefer Adherence 12:1863-1873.

223. Holvast F, Oude Voshaar RC, Wouters H, Hek K, Schellevis F et al. (2019) Non-adherence to antidepressants among older patients with depression: a longitudinal cohort study in primary care. Fam Pract 36(1): 12-20.
224. American Pharmacists Association (2008) National Association of Chain Drug Stores Foundation. Medication therapy management in pharmacy practice: core elements of an MTM service model (version 2.0). J Am Pharm Assoc (2003) 48(3):341-53.

225. Chavez B, Kosirog E (2019) Impact on an integrated psychiatric pharmacy service in a primary care clinic. Ment Health Clin. 9(4):269-274

226. Bingham J, Axon DR, Scovis N, Taylor AM (2018) Evaluating the Effectiveness of Clinical Pharmacy Consultations on Nutrition, Physical Activity, and Sleep in Improving Patient-Reported Psychiatric Outcomes for Individuals with Mental Illnesses. Pharmacy (Basel) 7(1). pii: E2.

227. Riley TB, Alemagno S (2019) Pharmacist utilization of prescription opioid misuse interventions: Acceptability among pharmacists and patients. Res Social Adm Pharm. 15(8):986-991.

228. Eltorki Y, Abdallah O, Omar N, Zolezzi M (2019) Perceptions and expectations of health care providers towards clinical pharmacy services in a mental health hospital in Qatar. Asian J Psychiatr 42:62-66.

229. El-Den S, Chen TF, Moles RJ, O’Reilly C (2018) Assessing Mental Health First Aid Skills Using Simulated Patients. Am J Pharm Educ 82(2):6222.

230. Choonara YE, Pillay V, du Toit LC, Modi et al. (2009) G Trends in the molecular pathogenesis and clinical therapeutics of common neurodegenerative disorders. Int J Mol Sci 10(6): 2510-57.

231. GBD 2016 Neurology Collaborators (2019) Global, regional, and national burden of neurological disorders, 1990-2016: a systematic analysis for the Global Burden of Disease Study 2016. Lancet Neurology vol. 18,5 (2019): 459-480.

232. Weller J, Budson A (2018) Current understanding of Alzheimer's disease diagnosis and treatment. F1000Res 7. pii: F1000 Faculty Rev-1161.

233. Martinez-Martin P, Macaulay D, Jalundhwala YJ, Mu F et al. (2019) The long-term direct and indirect economic burden among Parkinson's disease caregivers in the United States. Mov Disord 34(2): 236-245.

234. Kowal SL, Dall TM, Chakrabarti R, Storm MV, Jain A (2013) The current and projected economic burden of Parkinson's disease in the United States. Mov Disord 28(3):311-8.

235. Stephens W (2019) Financial Burden of Parkinson Disease Is $\$ 52$ Billion, More Than Double Previous Estimates. AJMC News.

236. Economic Burden and Future Impact of Parkinson's Disease Final Report. LewinGroup (2019).

237. Magyari M, Sorensen PS (2019) The changing course of multiple sclerosis: rising incidence, change in geographic distribution, disease course, and prognosis. Curr Opin Neurol 32(3):320-326.

238. Díaz C, Zarco LA, Rivera DM (2019) Highly active multiple sclerosis: An update. Mult Scler Relat Disord 30:215-224.

239. Rivera VM (2019) Biosimilar Drugs for Multiple Sclerosis: An Unmet International Need or a Regulatory Risk? Neurol Ther 8(2): 177-184.

240. Thijs RD, Surges R, O’Brien TJ, Sander JW (2019) Epilepsy in adults. Lancet 393(10172): 689-701.

241. O'Donohoe TJ, Choudhury A, Callander E (2019) The global macroeconomic burden of epilepsy and the role for neurosurgery: A modelling study based upon the 2016 Global Burden of Disease data. Eur J Neurol.

242. Grossberg GT, Tong G, Burke AD, Tariot PN (2019). Present Algorithms and Future Treatments for Alzheimer's Disease. J Alzheimers Dis 67(4): 1157-1171.

243.Terrie YC (2007) The Pharmacist's Role in the Management of Alzheimer's Disease. Pharmacy Times $®$.

244. Duong S, Patel T, Chang F (2017) Dementia: What pharmacists need to know. Can Pharm J (Ott) 150(2): 118-129.

245. Yllmaz, Nihan Çarçak, et al. (2017) Pharmacist's role in pharmacotherapeutic management of Alzheimer's disease. Istanbul J Pharm vol. 47 , no. 1, pp. $1-4$.

246. Ciulla M, Marinelli L, Cacciatore I, Stefano AD (2019) Role of Dietary Supplements in the Management of Parkinson's Disease. Biomolecules 9(7). pii: E271. 
247. Lyons KE, Pahwa R, Hermanowicz N, Davis T et al. (2019) Changing the treatment paradigm for Parkinson's disease psychosis with pimavanserin. Expert Rev Clin Pharmacol 12(7): 681-691.

248. Raza C, Anjum R, Shakeel NUA (2019) Parkinson's disease: Mechanisms, translational models and management strategies. Life Sci 226: 77-90.

249. Foppa AA, Chemello C, Vargas-Peláez CM, Farias MR (2016) Medication Therapy Management Service for Patients with Parkinson's Disease: A Before-and-After Study. Neurol Ther 5(1): 85-99.

250. Patel T, Chang F, Parkinson Society Canada (2014) Parkinson's disease guidelines for pharmacists. Can Pharm J (Ott147(3): 161-70.

251. Patel T, Chang F (2015) Practice recommendations for Parkinson's disease: Assessment and management by community pharmacists. Can Pharm J (Ott) 148(3): 142-9.

252. Hill AC, Thomson KE, Newell TG, White HS (2019) Correction of medication nonadherence results in better seizure outcomes than dose escalation in a novel preclinical epilepsy model of adherence. Epilepsia $60(3): 475-484$.

253. Kälviäinen R, Reinikainen M (2019) Management of prolonged epileptic seizures and status epilepticus in palliative care patients. Epilepsy Behav pii: S1525-5050(19)30372-5

254. Ernawati I, Islamiyah WR, Sumarno (2018) How to Improve Clinical Outcome of Epileptic Seizure Control Based on Medication Adherence? A Literature Review. Open Access Maced J Med Sci 6(6): 1174-1179.

255. Gutierrez-Colina AM, Smith AW, Mara CA, Modi AC (2018) Adherence barriers in pediatric epilepsy: From toddlers to young adults. Epilepsy Behav 80: 229-234.

256. Gschwind M, Seeck M (2016) Modern management of seizures and epilepsy. Swiss Med Wkly 146: w14310.

257. Koshy S (2012) Role of pharmacists in the management of patients with epilepsy. Int J Pharm Pract 20(1):65-8.

258. dos Reis TM, Campos MSA, Nagai MM, Pereira LRL (2016) Contributions of Pharmacists in the Treatment of Epilepsy: A Systematic Review. Pharmacy Times®.

259. Ha H (2013) Epilepsy: Treatment and Management. US Pharmacists.

260. Chen C, Lee DS, Hie SL (2013) The impact of pharmacist's counseling on pediatric patients' caregiver's knowledge on epilepsy and its treatment in a tertiary hospital. Int J Clin Pharm 35(5):829-34.

261. dos Reis TM, Campos MSA, Nagai MM, Pereira LRL (2016) Contributions of Pharmacists in the Treatment of Epilepsy: A Systematic Review. Am J Pharm Benefits 8(3): e55-e60

262. Cabo-Meseguer A, Cerdá-Olmedo G, Trillo-Mata JL (2017) Fibromyalgia: Prevalence, epidemiologic profiles and economic costs. Med Clin (Barc) 149(10):441-448

263. Muraleetharan D, Fadich A, Stephenson C, Garney W (2018) Understanding the Impact of Fibromyalgia on Men: Findings From a Nationwide Survey. Am J Mens Health 12(4):952-960.

264. AK Mohiuddin (2019) Non-drug pain management: opportunities to explore. BiomedGrid LLC, USA ISBN: 978-1-946628-01-5

265. Pappolla MA, Manchikanti L, Andersen CR, Greig NH (2019) Is insulin resistance the cause of fibromyalgia? A preliminary report. PLoS One 14(5): e0216079.

266. Palstam A, Mannerkorpi K (2017) Work Ability in Fibromyalgia: An Update in the 21st Century. Curr Rheumatol Rev 13(3):180-187.

267. D’Agnelli S, Arendt-Nielsen L, Gerra MC, Zatorri K (2019) Fibromyalgia: Genetics and epigenetics insights may provide the basis for the development of diagnostic biomarkers. Mol Pain 15: 1744806918819944.

268. Sosa-Reina MD, Nunez-Nagy S, Gallego-Izquierdo T, Pecos-Martín D (2017) Effectiveness of Therapeutic Exercise in Fibromyalgia Syndrome: A Systematic Review and Meta-Analysis of Randomized Clinical Trials. Biomed Res Int 2356346.

269. Ghavidel-Parsa B, Bidari A, Amir Maafi A, Ghalebaghi B (2015) The Iceberg Nature of Fibromyalgia Burden: The Clinical and Economic Aspects. Korean J Pain 28(3):169-76.
270. Arout CA, Sofuoglu M, Bastian LA, Rosenheck RA (2018) Gender Differences in the Prevalence of Fibromyalgia and in Concomitant Medical and Psychiatric Disorders: A National Veterans Health Administration Study. J Womens Health (Larchmt) 27(8):1035-1044.

271. Bhargava J, Hurley JA (2019) Fibromyalgia. [Updated 2019 May 1]. In: StatPearls [Internet] (ed.) Treasure Island (FL): StatPearls Publishing.

272. Kaltsas G, Tsiveriotis K. Fibromyalgia. [Updated 2017 Oct 2]. In: Feingold KR, Anawalt B, Boyce A (ed.) Endotext, South Dartmouth USA.

273. Galvez-Sánchez CM, Duschek S, Reyes Del Paso GA (2019) Psychological impact of fibromyalgia: current perspectives. Psychol Res Behav Manag 12: 117-127.

274. Bellato E, Marini E, Castoldi F, Barbasetti N et al. (2012) Fibromyalgia syndrome: etiology, pathogenesis, diagnosis, and treatment. Pain Res Treat 2012: 426130.

275. Mahjoub F, Salari R, Noras MR, Yousefi M (2017) Are Traditional Remedies Useful in Management of Fibromyalgia and Chronic Fatigue Syndrome? A Review Study. J Evid Based Complementary Altern Med 22(4): 1011-1016.

276. Abdul Kader Mohiuddin (2019) Comparison of Drug and Non-Drug Treatment Options of Fibromyalgia Glob J Ortho Res. 1(5): 2019. GJOR. MS.ID.000522.

277. Sawynok J , Lynch ME (2017) Qigong and Fibromyalgia circa 2017. Medicines (Basel) 4(2). pii: E37

278. Wang X, Li P, Pan C, Dai L et al. (2019) The Effect of Mind-Body Therapies on Insomnia: A Systematic Review and Meta-Analysis. Evid Based Complement Alternat Med 2019: 9359807.

279. Silva AR, Bernardo A, Costa J, Cardoso A et al. (2014) Dietary interventions in fibromyalgia: a systematic review. Ann Med 51(sup1): 2-14.

280. Marum AP, Moreira C, Saraiva F, Tomas-Carus P, Sousa-Guerreiro C (2016) A low fermentable oligo-di-mon saccharides and polyols (FODMAP) diet reduced pain and improved daily life in fibromyalgia patients. Scand J Pain 13: 166-172.

281. Marum AP, Moreira C, Tomas-Carus P, Saraiva F, Guerreiro CS (2017) A low fermentable oligo-di-mono-saccharides and polyols (FODMAP) diet is a balanced therapy for fibromyalgia with nutritional and symptomatic benefits. Nutr Hosp 34(3): 667-674.

282. Lattanzio SM, Imbesi F (2018) Fibromyalgia Syndrome: A Case Report on Controlled Remission of Symptoms by a Dietary Strategy. Front Med (Lausanne) 5: 94

283. Zabihiyeganeh M, Vafaee Afshar S, Amini Kadijani A, Jafari D et al. (2019) The effect of cognitive behavioral therapy on the circulating proinflammatory cytokines of fibromyalgia patients: A pilot controlled clinical trial. Gen Hosp Psychiatry 57:23-28.

284. (2018) Cologne, Germany: Institute for Quality and Efficiency in Health Care (IQWiG) 2006-. Fibromyalgia: Multimodal pain management and cognitive behavioral therapy.

285. McCrae CS, Williams J, Roditi D, Anderson R, Mundt JM et al. (2019) Cognitive behavioral treatments for insomnia and pain in adults with comorbid chronic insomnia and fibromyalgia: clinical outcomes from the SPIN randomized controlled trial. Sleep 42(3) pii: zsy234.

286. Aman MM, Jason Yong R, Kaye AD, Urman RD (2018) Evidence-Based Non-Pharmacological Therapies for Fibromyalgia. Curr Pain Headache Rep 22(5): 33.

287. McCrae CS, Mundt JM, Curtis AF, Craggs JG, O'Shea AM (2018) Gray Matter Changes Following Cognitive Behavioral Therapy for Patients With Comorbid Fibromyalgia and Insomnia: A Pilot Study. J Clin Sleep Med 14(9): 1595-1603.

288. Karatay S, Okur SC, Uzkeser H, Yildirim K, Akcay F (2018) Effects of Acupuncture Treatment on Fibromyalgia Symptoms, Serotonin, and Substance P Levels: A Randomized Sham and Placebo-Controlled Clinical Trial. Pain Med 19(3): 615-628.

289. McPherson ML, Lofton JC (2010) Fibromyalgia: An update for pharmacists. Pharmacy Today 16(1)48-59.

290. Northcott MJ, Guymer EK, Littlejohn GO (2017) Pharmacological treatment options for fibromyalgia. Clinical Pharmacist. 
291. Kodner C (2015) Common questions about the diagnosis and management of fibromyalgia. Am Fam Physician 91(7): 472-8.

292. Medina M, Castillo-Pino E (2019) An introduction to the epidemiology and burden of urinary tract infections. Ther Adv Urol 11: 1756287219832172.

293. Al-Badr A, Al-Shaikh G (2013) Recurrent Urinary Tract Infections Management in Women: A review. Sultan Qaboos Univ Med J 13(3): 359-67.

294. Lema VM (2015) Urinary Tract Infection In Young Healthy Women Following Heterosexual Anal Intercourse: Case Reports. Afr J Reprod Health 19(2): 134-9.

295. Harrington RD, Hooton TM (2000) Urinary tract infection risk factors and gender. J Gend Specif Med 3(8): 27-34

296. Oladeinde BH, Omoregie R, Olley M, Anunibe JA (2011) Urinary tract infection in a rural community of Nigeria. N Am J Med Sci 3(2): 75-7.

297. Behzadi P, Behzadi E, Pawlak-Adamska EA (2019) Urinary tract infections (UTIs) or genital tract infections (GTIs)? It's the diagnostics that count. GMS Hyg Infect Control 14: Doc14.

298. Arnold JJ, Hehn LE, Klein DA (2016) Common Questions About Recurrent Urinary Tract Infections in Women. Am Fam Physician 93(7): $560-9$

299. Tan CW, Chlebicki MP (2016) Urinary tract infections in adults. Singapore Med J 57(9): 485-90.

300. Hickling DR, Nitti VW (2013) Management of recurrent urinary tract infections in healthy adult women. Rev Urol 15(2): 41-8.

301. Jhang JF, Kuo HC (2017) Recent advances in recurrent urinary tract infection from pathogenesis and biomarkers to prevention. Ci Ji Yi Xue Za Zhi 29(3): 131-137.

302. Gupta K, Trautner BW (2013) Diagnosis and management of recurrent urinary tract infections in non-pregnant women. BMJ 346: f3140.

303. Li R, Leslie SW (2019) Cystitis. In: StatPearls. Treasure Island (FL): StatPearls Publishing (ed.).

304. Scholes D, Hooton TM, Roberts PL, Stapleton AE et al. (2000) Risk factors for recurrent urinary tract infection in young women. J Infect Dis 182(4): 1177-82.

305. Nseir W, Farah R, Mahamid M, Sayed-Ahmad H et al. (2015) Obesity and recurrent urinary tract infections in premenopausal women: a retrospective study. Int J Infect Dis 41: 32-5.

306. Flores-Mireles AL, Walker JN, Caparon M, Hultgren SJ (2015) Urinary tract infections: epidemiology, mechanisms of infection and treatment options. Nat Rev Microbiol 13(5): 269-84.

307. Gajdács M, Urbán E (2019) Comparative Epidemiology and Resistance Trends of Proteae in Urinary Tract Infections of Inpatients and Outpatients: A 10-Year Retrospective Study. Antibiotics 8(3). pii: E91.

308. Mickymaray S, Al Aboody MS (2019) In Vitro Antioxidant and Bactericidal Efficacy of 15 Common Spices: Novel Therapeutics for Urinary Tract Infections? Medicina (Kaunas) 55(6). pii: E289.

309. Liya SJ, Siddique R (2018) Determination of Antimicrobial Activity of Some Commercial Fruit (Apple, Papaya, Lemon and Strawberry) Against Bacteria Causing Urinary Tract Infection. Eur J Microbiol Immunol (Bp) 8(3): 95-99.

310. Albu S, Voidazan S, Bilca D, Badiu M, Truţă A et al. (2018) Bacteriuria and asymptomatic infection in chronic patients with indwelling urinary catheter: The incidence of ESBL bacteria. Medicine (Baltimore) 97(33): e11796.

311. Frellick M (2017) Drinking More Water Reduces Repeat Urinary Tract Infections. Medscape.

312. Hooton TM, Vecchio M, Iroz A, et al. (2018) Effect of Increased Daily Water Intake in Premenopausal Women With Recurrent Urinary Tract Infections: A Randomized Clinical Trial. JAMA Intern Med 178(11): 15091515.

313. Luo EK (2018) How can you stop a chronic UTI? MedicalNewsToay, Wed.
314. Kennelly M, Thiruchelvam N, Averbeck MA, Konstatinidis C, ChartierKastler E et al. (2019) Adult Neurogenic Lower Urinary Tract Dysfunction and Intermittent Catheterisation in a Community Setting: Risk Factors Model for Urinary Tract Infections. Adv Urol 2019: 2757862.

315. Plüddemann A (2019) Can drinking more water prevent urinary tract infections? The evidence says yes. BMJ Evid Based Med. 24(5): 191-192.

316. Akgül T, Karakan T (2018) The role of probiotics in women with recurrent urinary tract infections. Turk J Urol 44(5): 377-383.

317. Asadi Karam MR, Habibi M, Bouzari S (2019) Urinary tract infection: Pathogenicity, antibiotic resistance and development of effective vaccines against Uropathogenic Escherichia coli. Mol Immunol 108: 56-67.

318. Wnorowska U, Piktel E, Durnaś B, Fiedoruk K, Savage PB et al. (2019) Use of ceragenins as a potential treatment for urinary tract infections. BMC Infect Dis 19(1): 369

319. Abdul Kader Mohiuddin (2019) Alternative Management of Uncomplicated UTIs In Women. J Urol Neph St 2(2)- 2019. JUNS. MS.ID.000133.

320. Abdul Kader Mohiuddin (2019) Lifestyle Issues and Prevention of Recurrent UTIs. Biomed J Sci \& Tech Res 21(3)-2019. BJSTR. MS.ID.003618.

321. Silverman JA, Schreiber HL 4th, Hooton TM, Hultgren SJ (2013) From physiology to pharmacy: developments in the pathogenesis and treatment of recurrent urinary tract infections. Curr Urol Rep 14(5): 448-56.

322. Mohiuddin AK. (2019). Lifestyle Issues and Prevention of Recurrent UTIs. Mathews J Urol Nephrol 3(1): e003.

323. Beahm NP, Nicolle LE, Bursey A, Smyth DJ, Tsuyuki RT (2017) The assessment and management of urinary tract infections in adults: Guidelines for pharmacists. Can Pharm J (Ott) 150(5): 298-305.

324. Beahm NP, Smyth DJ, Tsuyuki RT (2018) Outcomes of Urinary Tract Infection Management by Pharmacists (R(x)OUTMAP): A study of pharmacist prescribing and care in patients with uncomplicated urinary tract infections in the community. Can Pharm J (Ott) 151(5): 305-314.

325. Minejima E, Lee E, Quach S, Santos N, Lou M et al. (2019) Understanding patientperceptions and attitudes toward urinary tract infections andtreatment in a medically underserved population. J Am Coll ClinPharm $1-7$.

326. Crews DC, Bello AK, Saadi G (2019) 2019 World Kidney Day Editorial - burden, access, and disparities in kidney disease. J Bras Nefrol 41(1):1-9.

327. Saran R, Robinson B, Abbott KC, Agodoa LYC, Bragg-Gresham J, et al. (2019) US Renal Data System 2018 Annual Data Report: Epidemiology of Kidney Disease in the United States. American journal of kidney diseases: the official journal of the National Kidney Foundation vol. 73,3S1 (2019): A7-A8.

328. Hu MK, Witham MD, Soiza RL (2019) Oral Bicarbonate Therapy in NonHaemodialysis Dependent Chronic Kidney Disease Patients: A Systematic Review and Meta-Analysis of Randomised Controlled Trials. J Clin Med 8(2) pii: E208.

329. Lv JC, Zhang LX (2019) Prevalence and Disease Burden of Chronic Kidney Disease. Adv Exp Med Biol 1165: 3-15.

330. Motedayen M, Sarokhani D, Ghiasi B, Khatony A, Hasanpour Dehkordi A (2019) Prevalence of Hypertension in Renal Diseases in Iran: Systematic Review and Meta-Analysis. Int J Prev Med 10: 124.

331. Moreno Velásquez I, Tribaldos Causadias M, Valdés R, Gómez B et al. (2019) End-stage renal disease-financial costs and years of life lost in Panama: a cost-analysis study. BMJ Open 9(5): e027229.

332. Bikbov B, Global Burden of Disease Study Genitourinary Disease Expert Group (2019) Letter to the Editor: Chronic Kidney Disease - a Neglected Disease in the Economic Conditions Burden Analysis in Korea. J Korean Med Sci 34(32): e220.

333. Bello AK, Ronksley PE, Tangri N, Kurzawa J, Osman MA et al. (2019) Prevalence and Demographics of CKD in Canadian Primary Care Practices: A Cross-sectional Study. Kidney Int Rep 4(4): 561-570.

334. Home dialysis as the 'first' treatment option for end-stage kidney disease (ESKD). 
335. Stemer G, Lemmens-Gruber R (2011) Clinical pharmacy activities in chronic kidney disease and end-stage renal disease patients: a systematic literature review. BMC Nephrol 12: 35.

336. McKinnon A (2010) Practice spotlight: pharmacist in a chronic kidney disease clinic. Can J Hosp Pharm 63(6): 452-3.

337. Raymond CB, Wazny LD, Sood AR (2013) Standards of clinical practice for renal pharmacists. Can J Hosp Pharm 66(6): 369-74.

338. Cabello-Muriel A, Gascón-Cánovas JJ, Urbieta-Sanz E, Iniesta-Navalón C (2014) Effectiveness of pharmacist intervention in patients with chronic kidney disease. Int J Clin Pharm 36(5): 896-903.

339. Salgado TM, Moles R, Benrimoj SI, Fernandez-Llimos F (2012) Pharmacists' interventions in the management of patients with chronic kidney disease: a systematic review. Nephrol Dial Transplant 27(1): 276-92.

340. Pai AB, Cardone KE, Manley HJ, St Peter WL, Shaffer R et al. (2013) Medication reconciliation and therapy management in dialysis-dependent patients: need for a systematic approach. Clin J Am Soc Nephrol 8(11): 1988-99.

341. Kempton J, Hill A, Levi JA, Heath K, Pozniak A (2019) Most new HIV infections, vertical transmissions and AIDS-related deaths occur in lowerprevalence countries. J Virus Erad 5(2): 92-101.

342. Eilami O, Nazari A, Dousti M, Sayehmiri F, Ghasemi M (2019) Investigation of HIV/AIDS prevalence and associated risk factors among female sex workers from 2010 to 2017: a meta-analysis study. HIV AIDS (Auckl) 11: 105-117.

343. Sulung N, Asyura R (2019) The Analysis of Spirituality of Patients with HIV/AIDS in Taking Lessons and Self-Acceptance. Indian J Palliat Care 25(2): 232-235.

344. Sayyah M, Rahim F, Kayedani GA, Shirbandi K, Saki-Malehi A (2019) Global View of HIV Prevalence in Prisons: A Systematic Review and MetaAnalysis. Iran J Public Health 48(2): 217-226.

345. Zhu Z, Yan H, Wu S, Xu Y, Xu W et al. (2019) Trends in HIV prevalence and risk behaviours among men who have sex with men from 2013 to 2017 in Nanjing, China: a consecutive cross-sectional survey. BMJ Open 9(1): e021955.

346. Silverman JG, Decker MR, Saggurti N, Balaiah D, Raj A (2008) Intimate partner violence and HIV infection among married Indian women. JAMA 300(6): 703-10.

347. Global Burden of Disease Health Financing Collaborator Network (2018) Spending on health and HIV/AIDS: domestic health spending and development assistance in 188 countries, 1995-2015. Lancet 391(10132): 1799-1829.

348. Atta MG, De Seigneux S, Lucas GM (2019) Clinical Pharmacology in HIV Therapy. Clin J Am Soc Nephrol 14(3): 435-444.

349. Tseng A, Foisy M, Hughes CA, Kelly D, Chan S et al. (2012) Role of the Pharmacist in Caring for Patients with HIV/AIDS: Clinical Practice Guidelines. Can J Hosp Pharm 65(2): 125-45.

350. Nevo ON, Lesko CR, Colwell B, Ballard C, Cole SR et al. (2015) Outcomes of pharmacist-assisted management of antiretroviral therapy in patients with HIV infection: A risk-adjusted analysis. Am J Health Syst Pharm 72(17): 1463-70.

351. Molino CGRC, Carnevale RC, Rodrigues AT, Moriel P, Mazzola PG (2017) HIV pharmaceutical care in primary healthcare: Improvement in CD4 count and reduction in drug-related problems. Saudi Pharm J 25(5): 724-733.

352. Molino Cde G, Carnevale RC, Rodrigues AT, Visacri MB, Moriel P et al. (2014) Impact of pharmacist interventions on drug-related problems and laboratory markers in outpatients with human immunodeficiency virus infection. Ther Clin Risk Manag 10: 631-9.

353. Carnevale RC, de Godoi Rezende Costa Molino C, Visacri MB, Mazzola PG, Moriel P (2015) Cost analysis of pharmaceutical care provided to HIVinfected patients: an ambispective controlled study. Daru 23: 13.

354. Ma A, Chen DM, Chau FM, Saberi P (2010) Improving adherence and clinical outcomes through an HIV pharmacist's interventions. AIDS Care 22(10): 1189-94.
355. Murphy P, Cocohoba J, Tang A, Pietrandoni G, Hou J et al. (2012) Impact of HIV-specialized pharmacies on adherence and persistence with antiretroviral therapy. AIDS Patient Care STDS 26(9): 526-31.

356. Grossberg R, Zhang Y, Gross R (2004) A time-to-prescription-refill measure of antiretroviral adherence predicted changes in viral load in HIV. J Clin Epidemiol 57(10): 1107-10.

357. Regal GG, Wong W (2019) The Pharmacist's Role in Maximizing HIV Antiretroviral Therapy. Pharmacy Times®.

358. Holtzman CW, Brady KA, Yehia BR (2015) Retention in care and medication adherence: current challenges to antiretroviral therapy success. Drugs 75(5): 445-54

359. (2018) Pharmacist Intervention and Continued HIV Care: Examining the Connection. Pharmacy Times $®$.

360. Guilamo-Ramos V, Thimm-Kaiser M, Benzekri A, Futterman D (2019) Shifting the Paradigm in HIV Prevention and Treatment Service Delivery Toward Differentiated Care for Youth. National Academy of medicine.

361. Siegel RL, Miller KD, Jemal A (2019) Cancer statistics, 2019. CA Cancer J Clin 69(1): 7-34.

362. Shah SC, Kayamba V, Peek RM Jr, Heimburger D (2019) Cancer Control in Low- and Middle-Income Countries: Is It Time to Consider Screening? J Glob Oncol 5: 1-8.

363. Ferlay J, Colombet M, Soerjomataram I, Mathers C, Parkin DM et al. (2019) Estimating the global cancer incidence and mortality in 2018: GLOBOCAN sources and methods. Int J Cancer 144(8): 1941-1953.

364. Feng RM, Zong YN, Cao SM, Xu RH (2019) Current cancer situation in China: good or bad news from the 2018 Global Cancer Statistics? Cancer Commun (Lond 39(1): 22.

365. WHO (2018) Latest global cancer data: Cancer burden rises to 18.1 million new cases and 9. 6 million cancer deaths in 2018. Presse Release.

366. Schüz J, Espina C, Wild CP (2019) Primary prevention: a need for concerted action. Mol Oncol 13(3): 567-578.

367. WHO (2018) Cancer. Health Topics.

368. World Cancer Day.

369. Miller KD, Nogueira L, Mariotto AB, Rowland JH, Yabroff KR et al. (2019) Cancer treatment and survivorship statistics, 2019. CA Cancer J Clin.

370. DeSantis CE, Miller KD, Goding Sauer A, Jemal A, Siegel RL (2019) Cancer statistics for African Americans, 2019. CA Cancer J Clin 69(3): 211233.

371. Layne TM, Graubard BI, Ma X, Mayne ST, Albanes D (2019) Prostate cancer risk factors in black and white men in the NIH-AARP Diet and Health Study. Prostate Cancer Prostatic Dis 22(1): 91-100.

372. Ghose S, Radhakrishnan V, Bhattacharya S (2019) Ethics of cancer care: beyond biology and medicine. Ecancermedicalscience 13: 911.

373. Allcott N, Dunham L, Levy D, Carr J, Stitzenberg K (2019) Financial burden amongst cancer patients treated with curative intent surgery alone. Am J Surg pii: S0002-9610(18)31611-8.

374. Coumoundouros C, Ould Brahim L, Lambert SD, McCusker J (2019) The direct and indirect financial costs of informal cancer care: A scoping review. Health Soc Care Community.

375. WHO (2018) $\$ 46$ billion in productivity lost to cancer in major emerging economies. Presse Release.

376. World Cancer Day.

377. PDQ Screening and Prevention Editorial Board (2002) Cancer Prevention Overview (PDQ®): Health Professional Version. 2019 Aug 2. In: PDQ Cancer Information Summaries. Bethesda (MD): National Cancer Institute (US).

378. Sung H, Siegel RL, Rosenberg PS, Jemal A (2019) Emerging cancer trends among young adults in the USA: analysis of a population-based cancer registry. Lancet Public Health 4(3): e137-e147. 
379. Park B, You S, Cho WCS, Choi JY, Lee MS (2019) A systematic review of herbal medicines for the treatment of cancer cachexia in animal models. J Zhejiang Univ Sci B 20(1): 9-22.

380. Zhang Q (2015). Traditional and Complementary Medicine in Primary Health Care. In: Medcalf A, Bhattacharya S, Momen H (ed.) Health For All: The Journey of Universal Health Coverage. Hyderabad (IN): Orient Blackswan. Chapter 12 USA.

381. Mawoza, T, Nhachi, C Magwali, (2019) Prevalence of Traditional Medicine Use during Pregnancy, at Labour and for Postpartum Care in a Rural Area in Zimbabwe. Clinics in mother and child health 16(2),pii: 321.

382. Krupa J, Sureshkumar J, Silambarasan R, Priyadarshini K, Ayyanar M (2019) Integration of traditional herbal medicines among the indigenous communities in Thiruvarur District of Tamil Nadu, India. Journal of Ayurveda and integrative medicine, 10(1), 32-37.

383. Wode K, Henriksson R, Sharp L, Stoltenberg A, Hök Nordberg J (2019) Cancer patients' use of complementary and alternative medicine in Sweden: a cross-sectional study. BMC Complement Altern Med 19(1):62.

384. Jermini M, Dubois J, Rodondi PY, Zaman K, Buclin T et al. (2019) Complementary medicine use during cancer treatment and potential herbdrug interactions from a cross-sectional study in an academic centre. Sci Rep 9(1): 5078.

385. Kwon JH, Lee SC, Lee MA, Kim YJ, Kang JH et al. (2019) Behaviors and Attitudes toward the Use of Complementary and Alternative Medicine among Korean Cancer Patients. Cancer Res Treat 51(3): 851-860.

386. Jones E, Nissen L, McCarthy A, Steadman K, Windsor C (2019) Exploring the Use of Complementary and Alternative Medicine in Cancer Patients. Integr Cancer Ther 18: 1534735419854134.

387. Chotipanich A, Sooksrisawat C, Jittiworapan B (2019) Association between complementary and alternative medicine use and prolonged time to conventional treatment among Thai cancer patients in a tertiary-care hospital. PeerJ 7: e7159.

388. Ekor M (2014) The growing use of herbal medicines: issues relating to adverse reactions and challenges in monitoring safety. Front Pharmacol 4: 177 .

389. Haefeli WE, Carls A (2014) Drug interactions with phytotherapeutics in oncology. Expert Opin Drug Metab Toxicol 10(3): 359-77.

390. Kabat G (2018) Why Resorting to Alternative Medicine To Treat Cancer Is A Bad Idea. Forbes.

391. Wong SF, Bounthavong M, Nguyen C, Bechtoldt K, Hernandez E (2014) Implementation and preliminary outcomes of a comprehensive oral chemotherapy management clinic. Am J Health Syst Pharm 71(11): 960-5.

392. McKee M, Frei BL, Garcia A, Fike D, Soefje SA (2011) Impact of clinical pharmacy services on patients in an outpatient chemotherapy academic clinic. J Oncol Pharm Pract 17(4): 387-94.

393. Walter C, Mellor JD, Rice C, Kirsa S, Ball D et al. (2016) Impact of a specialist clinical cancer pharmacist at a multidisciplinary lung cancer clinic. Asia Pac J Clin Oncol 12(3): e367-74.

394. Allison J, Fisher J, Souter C, Bennie M (2019) What patient assessment skills are required by pharmacists prescribing systemic anti-cancer therapy? A consensus study. J Oncol Pharm Pract 25(8): 1933-1944.

395. Morimoto Y, Takei H, Tachibana K, Nakazato Y, Tanaka R et al. (2018) [Role of Pharmacists in Completion of Adjuvant Cisplatin-Vinorelbine Chemotherapy in Japanese Patients with Non-small Cell Lung Cancer]. Yakugaku Zasshi 138(3): 437-442.

396. Abdul Kader Mohiuddin (2019) Cost of Biotech Drug Development and Affordability Issues in LMICs. Arch Biomed Eng \& Biotechnol 2(3): 2019. ABEB.MS.ID.000538.

397. Kim S-K, Kalimuthu S (2014) Chapter 1. Introduction to Anti-cancer Drugs from Marine Origin. In: Se-Kwon Kim. Handbook of Anticancer Drugs from Marine Origin. Publisher: Springer.

398. Jeon SM, Kwon JW, Choi SH, Park HY (2019) Economic burden of lung cancer: A retrospective cohort study in South Korea, 2002-2015. PLoS One 14(2): e0212878.
399. Rezaei S, Akbari Sari A, Woldemichael A, Soofi M, Kazemi A et al. (2016) Estimating the Economic Burden of Lung Cancer in Iran. Asian Pac J Cancer Prev 17(10): 4729-4733.

400. Wood R, Taylor-Stokes G (2019) Cost burden associated with advanced non-small cell lung cancer in Europe and influence of disease stage. BMC Cancer 19(1): 214 .

401. Sun L, Yim WS, Fahey P, Wang S, Zhu X, et al. (2019) Investigation on Advanced Non-Small-Cell Lung Cancer among Elderly Patients Treated with Chinese Herbal Medicine versus Chemotherapy: A Pooled Analysis of Individual Data. Evid Based Complement Alternat Med 2019: 1898345.

402. Abdelaziz HM, Elzoghby AO, Helmy MW, Samaha MW, Fang JY, et al. (2019) Liquid crystalline assembly for potential combinatorial chemoherbal drug delivery to lung cancer cells. Int J Nanomedicine 14: 499-517.

403. Blandin Knight S, Crosbie PA, Balata H, Chudziak J, Hussell T, et al. (2017) Progress and prospects of early detection in lung cancer. Open Biol 7(9): 170070.

404. Seung SJ, Hurry M, Hassan S, Walton RN, Evans WK (2019) Cost-ofillness study for non-small-cell lung cancer using real-world data. Curr Oncol 26(2): 102-107.

405. Zappa C, Mousa SA (2016) Non-small cell lung cancer: current treatment and future advances. Transl Lung Cancer Re 5(3): 288-300.

406. Lin CK, Lin RT, Chen T, Zigler C, Wei Y, et al. (2019) A global perspective on coal-fired power plants and burden of lung cancer. Environ Health 18(1): 9.

407. Alberg AJ, Brock MV, Ford JG, Samet JM, Spivack SD (2013) Epidemiology of lung cancer: Diagnosis and management of lung cancer, $3^{\text {rd }}$ ed: American College of Chest Physicians evidence-based clinical practice guidelines. Chest 143(5 Suppl): e1S-e29S.

408. Cabanero M, Sangha R, Sheffield BS, Sukhai M, Pakkal M, et al. (2017) Management of EGFR-mutated non-small-cell lung cancer: practical implications from a clinical and pathology perspective. Curr Oncol 24(2): $111-119$

409. Abdul Kader Mohiuddin (2019) Alternative Treatments for Cancer Prevention and Cure [Part 1]. Adv Pharmacol ClinTrials 4(4): 000168.

410. Pisters KM, Vallières E, Crowley JJ, Franklin WA, Bunn PA, et al. (2010) Surgery with or without preoperative paclitaxel and carboplatin in early-stage non-small-cell lung cancer: Southwest Oncology Group Trial S9900, an intergroup, randomized, phase III trial. J Clin Oncol 28(11): 18431849.

411 (2007) Pharmacists at the front line in early detection of lung cancer. The Pharmaceutical Journal.

412. (2019) Lung cancer: A patient's perspective. Pharmacy Magazine (UK).

413. Robbins SL, Kumar V, Cotran RS (2010) Robbins and Cotran Pathologic Basis of Disease. Philadelphia, PA: Elsevier.

414. Vakiti A, Mewawalla P. Cancer, Acute Myeloid Leukemia (AML, Erythroid Leukemia, Myelodysplasia-Related Leukemia, BCR-ABL Chronic Leukemia) In: Stat Pearls. Treasure Island (FL): Stat Pearls P.

415. Naik J, Themeli M, de Jong-Korlaar R, Ruiter RWJ, Poddighe PJ, et al. (2019) CD38 as a therapeutic target for adult acute myeloid leukemia and T-cell acute lymphoblastic leukemia. Haematologica 104(3): e100-e103.

416. Bawazir A, Al-Zamel N, Amen A, Akiel MA, Alhawiti NM, et al. (2019) The burden of leukemia in the Kingdom of Saudi Arabia: 15 years period (1999-2013). BMC Cancer 19(1): 703.

417. Dhall A, Zee BM, Yan F, Blanco MA (2019) Intersection of Epigenetic and Metabolic Regulation of Histone Modifications in Acute Myeloid Leukemia. Front Oncol 9: 432.

418. Medeiros BC, Chan SM, Daver NG, Jonas BA, Pollyea DA (2019) Optimizing survival outcomes with post-remission therapy in acute myeloid leukemia. Am J Hematol 94(7): 803-811.

419. Murphy BR, Roth M, Kolb EA, Alonzo T, Gerbing R, et al. (2019) Development of acute lymphoblastic leukemia following treatment for acute myeloid leukemia in children with Down syndrome: A case report and 
retrospective review of Children's Oncology Group acute myeloid leukemia trials. Pediatr Blood Cancer 66(8): e27700.

420. Puckett Y, Chan O (2019) Cancer, Acute Lymphocytic Leukemia. In: Stat Pearls. Treasure Island (FL): Stat Pearls.

421. Branford S, Kim DDH, Apperley JF, Eide CA, Mustjoki S, et al. (2019) International CML Foundation Genomics Alliance. Laying the foundation for genomically-based risk assessment in chronic myeloid leukemia. Leukemia 33(8): 1835-1850

422. Franki R (2018) Report details financial burden of blood cancers. MD edge.

423. Davenport L (2016) Costs of Treating Blood Disorders Explored. Medscape.

424. Ramos NR, Mo CC, Karp JE, Hourigan CS (2015) Current Approaches in the Treatment of Relapsed and Refractory Acute Myeloid Leukemia. J Clin Med 4(4): 665-695.

425. Schlafer D, Panjic EH, Harvey RD (2017) The Evolving Role of the Hematology/Oncology Pharmacist. American Society of Hematology.

426. Lam MS, Cheung N (2016) Impact of oncology pharmacist-managed oral anticancer therapy in patients with chronic myelogenous leukemia. J Oncol Pharm Pract 22(6): 741-748.

427. Erfani N, Nazemosadat Z, Moein M (2015) Cytotoxic activity of ten algae from the Persian Gulf and Oman Sea on human breast cancer cell lines; MDA-MB-231, MCF-7, and T-47D. Pharmacognosy Res 7(2): 133-137.

428. Joseph OA (2016) The prospects of medicinal plants in the treatment of breast cancer. European Pharmaceutical Review.

429. Azubuike So, Muirhead C, Hayes L, McNally R (2018) Rising global burden of breast cancer: the case of sub-Saharan Africa (with emphasis on Nigeria) and implications for regional development: a review. World J Surg Oncol 16(1): 63 .

430. Blumen H, Fitch K, Polkus V (2016) Comparison of Treatment Costs for Breast Cancer, by Tumor Stage and Type of Service. Am Health Drug Benefits 9(1): 23-32.

431. Alkabban FM, Ferguson T (2019) Cancer, Breast. In: Stat Pearls. Treasure Island (FL): Stat Pearls.

432. Mehrgou A, Akouchekian M (2016) The importance of BRCA1 and BRCA2 genes mutations in breast cancer development. Med J Islam Repub Iran 30: 369 .

433. Poehls UG, Hack CC, Wunderle M, Renner SP, Lux MP, et al. (2019) Awareness of breast cancer incidence and risk factors among healthy women in Germany: an update after 10 years. Eur J Cancer Prev.

434. Hendrick RE, Baker JA, Helvie MA (2019) Breast cancer deaths averted over 3 decades. Cancer 125(9): 1482-1488.

435. Vishwakarma G, Ndetan H, Das DN, Gupta G, Suryavanshi M, et al. (2019) Reproductive factors and breast cancer risk: A meta-analysis of casecontrol studies in Indian women. South Asian J Cancer 8(2): 80-84.

436. Harbeck N, Penault-Llorca F, Cortes J, Gnant M, Houssami N, et al. (2019) Breast cancer. Nat Rev Dis Primers 5(1): 66.

437. Ng HS, Vitry A, Koczwara B, Roder D, McBride ML (2019) Patterns of comorbidities in women with breast cancer: a Canadian population-based study. Cancer Causes Control 30(9): 931-941.

438. Bahri N, Fathi Najafi T, Homaei Shandiz F, Tohidinik HR, Khajavi A (2019) The relation between stressful life events and breast cancer: a systematic review and meta-analysis of cohort studies. Breast Cancer Res Treat 176(1): 53-61.

439. Ho-Huynh A, Tran A, Bray G, Abbot S, Elston T, et al. (2019) Factors influencing breast cancer outcomes in Australia: A systematic review. Eur J Cancer Care (Engl) 28(4): e13038.

440. Feng Y, Spezia M, Huang S, Yuan C, Zeng Z, et al. (2018) Breast cancer development and progression: Risk factors, cancer stem cells, signaling pathways, genomics, and molecular pathogenesis. Genes Dis 5(2): 77-106.

441. Sun YS, Zhao Z, Yang ZN, Xu F, Lu HJ, et al. (2017) Risk Factors and Preventions of Breast Cancer. Int J Biol Sci 13(11): 1387-1397.
442. (2017) InformedHealth.org. Cologne, Germany: Institute for Quality and Efficiency in Health Care (IQWiG); 2006-. Risk factors for breast cancer.

443. Alexander A, Kaluve R, Prabhu JS, Korlimarla A, Srinath BS, et al. (2019) The Impact of Breast Cancer on the Patient and the Family in Indian Perspective. Indian J Palliat Care 25(1): 66-72.

444. Chen L, Malone KE, Li CI (2014) Bra wearing not associated with breast cancer risk: a population-based case-control study. Cancer Epidemiol Biomarkers Prev 23(10): 2181-2185.

445. Rios SSD, Chen ACR, Chen JR, et al. (2016) Wearing a Tight Bra for many hours a day is associated with increased risk of breast cancer. Adv Oncol Res Treat 1:1-5.

446. Virani S, Chindaprasirt J, Wirasorn K, Sookprasert A, Somintara O, et al. (2018) Breast Cancer Incidence Trends and Projections in Northeastern Thailand. J Epidemiol 28(7): 323-330.

447. Institute of Medicine (US) Committee on the Relationship Between Oral Contraceptives and Breast Cancer. Oral Contraceptives \& Breast Cancer. Washington (DC): National Academies Press (US); 1991. A, Oral Contraceptives and Breast Cancer: A Review of the Epidemiological Evidence with an Emphasis on Younger Women.

448. Yuan X, Yi F, Hou C, Lee H, Zhong X, et al. (2019) Induced Abortion, Birth Control Methods, and Breast Cancer Risk: A Case-Control Study in China. J Epidemiol 29(5): 173-179.

449. Yabroff KR, Lund J, Kepka D, Mariotto A (2011) Economic burden of cancer in the United States: estimates, projections, and future research. Cancer Epidemiol Biomarkers. Prev Oct 20(10): 2006-2014.

450. Mariotto AB, Yabroff KR, Shao Y, Feuer EJ, Brown ML (2011) Projections of the cost of cancer care in the United States: 2010-2020. J Natl Cancer Inst 103(2): 117-128.

451. Iadeluca L, Mardekian J, Chander P, Hopps M, Makinson GT (2017) The burden of selected cancers in the US: health behaviors and health care resource utilization. Cancer Manag Res 9: 721-730.

452. Tanaka K, Hori A, Tachi T, Osawa T, Nagaya K, et al. (2018) Impact of pharmacist counseling on reducing instances of adverse events that can affect the quality of life of chemotherapy outpatients with breast Cancer. J Pharm Health Care Sci. 4: 9.

453. Wang Y, Wu H, Xu F (2015) Impact of Clinical Pharmacy Services on KAP and QOL in Cancer Patients: A Single-Center Experience. Biomed Res Int 2015: 502431.

454. Val R, Allison R (2017) Treatment of Advanced Breast Cancer: A Clinical Pharmacy Perspective. American Health and Drug Benefits.

455. Araghi M, Soerjomataram I, Jenkins M, Brierley J, Morris E, (2019) Global trends in colorectal cancer mortality: projections to the year 2035. Int J Cancer 144(12): 2992-3000.

456. Recio-Boiles A, Waheed A, Cagir B (2019) Cancer, Colon In: Stat Pearls Treasure Island (FL): Stat Pearls.

457. Virk GS, Jafri M, Ashley C (2019) Colonoscopy and colorectal cancer rates among octogenarians and nonagenarians: nationwide study of US veterans. Clin Interv Aging 14: 609-614.

458. (2002) PDQ Screening and Prevention Editorial Board. Colorectal Cancer Prevention (PDQ ${ }^{\circledast}$ ): Health Professional Version. 2019 Apr 16. In: PDQ Cancer Information Summaries. Bethesda (MD): National Cancer Institute (US).

459. Chen W, Zheng R, Baade PD, Zhang S, Zeng H, et al. (2016) Cancer statistics in China, 2015. CA Cancer J Clin 66(2): 115-132.

460. Araghi M, Soerjomataram I, Bardot A, Ferlay J, Cabasag CJ, et al. (2019) Changes in colorectal cancer incidence in seven high-income countries: a population-based study. Lancet Gastroenterol Hepatol 4(7): 511-518.

461. Wray AJD, Minaker LM (2019) Is cancer prevention influenced by the built environment? A multidisciplinary scoping review. Cancer. 125(19): 3299-3311.

462. Poirier AE, Ruan Y, Walter SD, Franco EL, Villeneuve PJ, et al. (2019) The future burden of cancer in Canada: Long-term cancer incidence projections 2013-2042. Cancer Epidemiol 59: 199-207. 
463. Poirier AE, Ruan Y, Hebert LA, Grevers X, Walter SD, et al. (2019) Estimates of the current and future burden of cancer attributable to low fruit and vegetable consumption in Canada. Prev Med 122: 20-30.

464. Feletto E, Yu XQ, Lew JB, St John DJB, Jenkins MA, et al. (2019) Trends in Colon and Rectal Cancer Incidence in Australia from 1982 to 2014: Analysis of Data on Over 375,000 Cases. Cancer Epidemiol Biomarkers Prev 28(1): 83-90.

465. Jenkins MA, Ait Ouakrim D, Boussioutas A, Hopper JL, Ee HC, et al. (2018) Revised Australian national guidelines for colorectal cancer screening: family history. Med J Aust 209(10): 455-460.

466. Glover M, Mansoor E, Panhwar M, Parasa S, Cooper GS (2019) Epidemiology of Colorectal Cancer in Average Risk Adults 20-39 Years of Age: A Population-Based National Study. Dig Dis Sci.

467. Siegel RL, Medhanie GA, Fedewa SA, Jemal A (2019) State variation in early-onset colorectal cancer in the United States, 1995-2015. J Natl Cancer Inst 111(10):1104-1106.

468. Mannucci A, Zuppardo RA, Rosati R, Leo MD, Perea J, et al. (2019) Colorectal cancer screening from 45 years of age: Thesis, antithesis and synthesis. World J Gastroenterol 25(21): 2565-2580.

469. Erdrich J, Zhang X, Giovannucci E, Willett W (2015) Proportion of colon cancer attributable to lifestyle in a cohort of US women. Cancer Causes Control 26(9): 1271-1279.

470. Aleksandrova K, Pischon T, Jenab M, Bueno-de-Mesquita HB, Fedirko $\mathrm{V}$, et al. (2014) Combined impact of healthy lifestyle factors on colorectal cancer: a large European cohort study. BMC Med 12: 168.

471. Jeon J, Du M, Schoen RE, Hoffmeister M, Newcomb PA, et al. (2018) Colorectal Transdisciplinary Study and Genetics and Epidemiology of Colorectal Cancer Consortium. Determining Risk of Colorectal Cancer and Starting Age of Screening Based on Lifestyle, Environmental, and Genetic Factors. Gastroenterology 154(8): 2152-2164.e19.

472. Oruç Z, Kaplan MA (2019) Effect of exercise on colorectal cancer prevention and treatment. World J Gastrointest Oncol 11(5): 348-366.

473. Bradbury KE, Murphy N, Key TJ (2019) Diet and colorectal cancer in UK Biobank: a prospective study. Int J Epidemiol

474. Fedirko V, Tramacere I, Bagnardi V, Rota M, Scotti L, et al. (2011) Alcohol drinking and colorectal cancer risk: an overall and dose-response meta-analysis of published studies. Ann Oncol 22(9): 1958-1972.

475. Vieira AR, Abar L, Chan DSM, Vingeliene S, Polemiti E, et al. (2017) Foods and beverages and colorectal cancer risk: a systematic review and meta-analysis of cohort studies, an update of the evidence of the WCRFAICR Continuous Update Project. Ann Oncol 28(8): 1788-1802.

476. Pericleous M, Mandair D, Caplin ME (2013) Diet and supplements and their impact on colorectal cancer. J Gastrointest Oncol 4(4): 409-423.

477. Chen Z, Wang PP, Woodrow J, Zhu Y, Roebothan B, et al. (2015) Dietary patterns and colorectal cancer: results from a Canadian population-based study. Nutr J 14: 8.

478. National Cancer Institute. Financial Burden of Cancer Care.

479. American Cancer Society. Colorectal Cancer Facts \& Figures 2017 2019.

480. Gellad ZF, Provenzale D (2010) Colorectal cancer: national and international perspective on the burden of disease and public health impact. Gastroenterology 138(6): 2177-2190.

481. World Cancer Research Fund International. Colorectal cancer statistics.

482. Rodriguez-Bigas MA, Lin EH, Crane CH (2003) Stage IV Colorectal Cancer. In: Kufe DW, Pollock RE, Weichselbaum RR (ed.) Holland-Frei Cancer Medicine. $6^{\text {th }}$ edition. Hamilton (ON): BC Decker

483. Lee SD, Choe JW, Lee BJ, Kang MH, Joo MK, et al. (2015) Butein effects in colitis and interleukin-6/signal transducer and activator of transcription 3 expression. World J Gastroenterol 21(2): 465-474.

484. James S, Aparna JS, Paul AM, Lankadasari MB, Mohammed S, et al. (2017) Cardamonin inhibits colonic neoplasia through modulation of MicroRNA expression. Sci Rep 7(1): 13945.
485. Shapiro NL (2006) Chapter 126. Preventive Care. In: David B. Troy, Paul Beringer (eds.) Remington: The Science and Practice of Pharmacy, Contributor: Joseph Price Remington, Publisher: Lippincott Williams \& Wilkins.

486. Cho YA, Lee J, Oh JH, Chang HJ, Sohn DK, et al. (2019) Genetic Risk Score, Combined Lifestyle Factors and Risk of Colorectal Cancer. Cancer Res Treat 51(3): 1033-1040.

487. Pais R, Silaghi H, Silaghi AC, Rusu ML, Dumitrascu DL (2009) Metabolic syndrome and risk of subsequent colorectal cancer. World J Gastroenterol 15(41): 5141-5148.

488. Rossi M, Jahanzaib Anwar M, Usman A, Keshavarzian A, et al. (2018) Colorectal Cancer and Alcohol Consumption-Populations to Molecules. Cancers (Basel). 10(2): E38.

489. Elkins G, White J, Patel P, Marcus J, Perfect MM, Montgomery GH. (2006) Hypnosis to manage anxiety and pain associated with colonoscopy for colorectal cancer screening: Case studies and possible benefits. Int J Clin Exp Hypn 54(4): 416-431.

490. Cossu G, Saba L, Minerba L, Mascalchi M (2018) Colorectal Cancer Screening: The Role of Psychological, Social and Background Factors in Decision-making Process. Clin Pract Epidemiol Ment Health14: 63-69.

491. Montgomery GH, Schnur JB, Kravits K (2013) Hypnosis for cancer care: over 200 years young. CA Cancer J Clin 63(1): 31-44.

492. Miller SJ, Schnur JB, Montgomery GH, Jandorf L (2011) African Americans' and Latinos' perceptions of using hypnosis to alleviate distress before a colonoscopy. Contemp Hypn Integr Ther 28(3):196-203.

493. Umezawa S, Higurashi T, Uchiyama S, Sakai E, Ohkubo H, et al. (2015) Visual distraction alone for the improvement of colonoscopy-related pain and satisfaction. World J Gastroenterol 21(15): 4707-4714.

494. Lee DW, Chan AC, Wong SK, Fung TM, Li AC, et al. (2004) Can visual distraction decrease the dose of patient-controlled sedation required during colonoscopy? A prospective randomized controlled trial. Endoscopy 36(3): 197-201.

495. Xiaolian J, Xiaolin L, Lan ZH (2015) Effects of visual and audiovisual distraction on pain and anxiety among patients undergoing colonoscopy. Gastroenterol Nurs 38(1): 55-61.

496. Leung FW (2008) Methods of reducing discomfort during colonoscopy. Dig Dis Sci 53(6): 1462-1467.

497. De Silva AP, Niriella MA, Nandamuni Y, Nanayakkara SD, Perera KR, et al. (2016) Effect of audio and visual distraction on patients undergoing colonoscopy: a randomized controlled study. Endosc Int Open 4(11): E1211-E1214.

498. Drury J (2013) Colorectal Cancer Risks and the Community Pharmacist's Role. Pharmacy Times ${ }^{\circledR}$.

499. Tezcan S, Izzettin FV, Sancar M, Turhal NS, Yumuk PF (2018) Role of clinical oncology pharmacist in determination of pharmaceutical care needs in patients with colorectal cancer. Eur J Hosp Pharm. 25(e1): e17-e20.

500. Bray F, Ferlay J, Soerjomataram I, Siegel RL, Torre LA, et al. (2018) Global cancer statistics 2018: GLOBOCAN estimates of incidence and mortality worldwide for 36 cancers in 185 countries. CA Cancer J Clin 68(6): 394-424.

501. Rawla P (2019) Epidemiology of Prostate Cancer. World J Oncol 10(2): 63-89.

502. Smith-Palmer J, Takizawa C, Valentine W (2019) Literature review of the burden of prostate cancer in Germany, France, the United Kingdom and Canada. BMC Urol 19(1): 19.

503. Roehrborn CG, Black LK (2011) The economic burden of prostate cancer. BJU Int108(6): 806-813.

504. (2008) Economic Cost of Cancer Mortality Is High in U.S., Regardless of How Cost Is Measured, JNCI: Journal of the National Cancer Institute 100(24): 1741

505. Pernar CH, Ebot EM, Wilson KM, Mucci LA The Epidemiology of Prostate Cancer. Cold Spring Harb Perspect Med 8(12): a030361.

506. Wilson KM, Markt SC, Fang F, Nordenvall C, Rider JR, et al. (2016) Snus use, smoking and survival among prostate cancer patients. Int J Cancer 139(12): 2753-2759. 
507. Zuccolo L, Lewis SJ, Donovan JL, Hamdy FC, Neal DE, et al. (2013) Alcohol consumption and PSA-detected prostate cancer risk--a case-control nested in the Protect study Int J Cancer 132(9): 2176-2185.

508. Zhao J, Stockwell T, Roemer A, Chikritzhs T (2016) Is alcohol consumption a risk factor for prostate cancer? A systematic review and meta-analysis. BMC Cancer 16(1): 845.

509. Thobe MN, Clark RJ, Bainer RO, Prasad SM, Rinker-Schaeffer CW (2011) From prostate to bone: key players in prostate cancer bone metastasis. Cancers (Basel) 3(1): 478-493.

510. Wallner L, Frencher S, Hsu JW, Loo R, Huang J, et al. (2012) Prostate cancer screening trends in a large, integrated health care system. Perm J 16(3): 4-9.

511. Allard CB, Dason S, Lusis J, Kapoor A (2012) Prostate cancer screening: Attitudes and practices of family physicians in Ontario. Can Urol Assoc J 6(3): 188-1893.

512. Scarabelin A, Santana Dosea A, Aguiar PM, Storpirtis S (2019) Pharmacist-Patient Communication in Prostate Cancer as a Strategy to Humanize Health Care: A Qualitative Study. J Patient Exp 6(2): 150-156.
513. Kachur E (2018) Prostate Cancer Review. US Pharm 43(8): HS-7-HS-12.

514. Patel JM, Holle LM, Clement JM, Bunz T, Niemann C, et al. (2016) Impact of a pharmacist-led oral chemotherapy-monitoring program in patients with metastatic castrate-resistant prostate cancer. J Oncol Pharm Pract 22(6): 777-783.

515. McNatty A, Dow E, Bryce AH Impact of pharmacist-led monitoring of olaparib (0) for metastatic castrate resistant prostate cancer (mCRPC). Journal of Clinical Oncology 35(6suppl): e569-e569.

516. Rivera-Ruiz KM Role of The Pharmacist in Prostate Cancer Prevention and Management.

517. Kletas V, De Lemos ML (2012) Prostate Cancer: Pharmacist's Role in Prevention \& Management. Canadian Healthcare Network.ca (Pharmacy Practice).

518. Cunliffe A, Harker N, Nicola S (2017) Top tips: prostate cancer. Guidelines in Practice. 